\title{
Cross-Section of Equity Returns: Stock Market Volatility and Priced Factors
}

\author{
Bumjean Sohn
}

A dissertation submitted to the faculty of the University of North Carolina at Chapel Hill in partial fulfillment of the requirements for the degree of Doctor of Philosophy in the Kenan-Flagler Business School (Finance).

Chapel Hill

2009

Approved by:

Eric Ghysels

Jennifer Conrad

Gregory Brown

Christian Lundblad

Riccardo Colacito 
(C) 2009

Bumjean Sohn

ALL RIGHTS RESERVED 


\section{ABSTRACT \\ BUMJEAN SOHN: Cross-Section of Equity Returns: Stock Market Volatility and Priced Factors. (Under the direction of Eric Ghysels.)}

We discuss the nature of risk valid factors should represent. The Campbell's (1993) ICAPM extended with heteroskedastic asset returns guides us to identify the risk; we show that many of empirically well-established factors contain information about the future changes in the investment opportunity set and that is why these factors are strongly priced across assets. Specifically, we show that size, momentum, liquidity (trading strategy based factors), industrial production growth, and inflation (macroeconomic factors) factors as well as both short- and long-run market volatility factors are significantly priced because they all have information about the changes in the future market volatility which characterizes the future investment opportunity set in our model. The time-series studies show that the above-mentioned factors do predict the market volatility and the cross-sectional studies show that these factors are priced due to their predictability on the future market volatility. Both studies are consistent and strongly support the relationship between the stock market volatility and the priced factors. By revealing the nature of risk the empirically well-established factors represent, we provide an explanation why we observe so many empirically strong factors in the literature. 


\section{ACKNOWLEDGMENTS}

I would like to thank my advisor, Eric Ghysels for his continued guidance and support throughout my years in the PhD program at the Kenan-Flagler Business School, the University of North Carolina at Chapel Hill. I am also indebted to Jennifer Conrad and Greg Brown for their thoughful advice and guidance and to Chris Lundblad and Riccardo Colacito for their comments and suggestions.

I am also very much grateful to my parents, Younsoo Sohn and Yukyoung Chang, my wife, Joonhee Kim, and my two little lovely daughters, Hannah and Emma. Without their love and support, I could not have come this far. 


\section{TABLE OF CONTENTS}

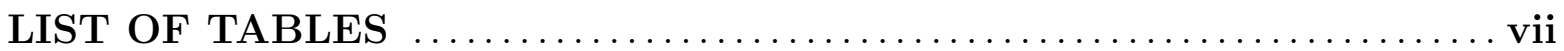

LIST OF FIGURES $\ldots \ldots \ldots \ldots \ldots \ldots \ldots \ldots \ldots \ldots \ldots \ldots \ldots \ldots \ldots$ viii

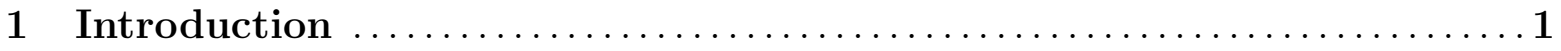

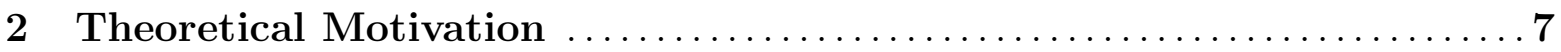

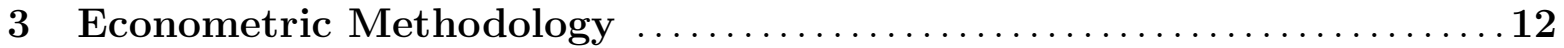

3.1 GARCH-MIDAS Class of Models $\ldots \ldots \ldots \ldots \ldots \ldots \ldots \ldots \ldots \ldots \ldots \ldots \ldots \ldots \ldots \ldots$

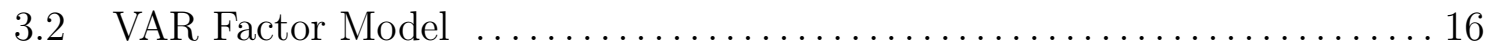

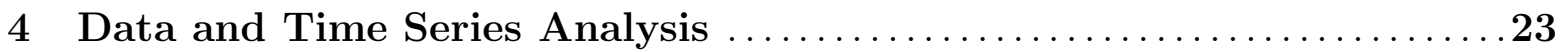

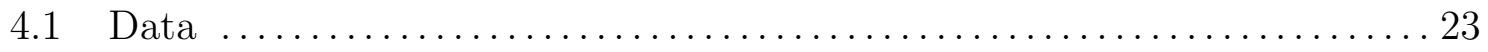

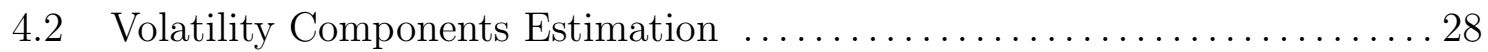

4.3 Long-Lag Predictability (GARCH-MIDAS Results) ................. 29

4.4 Short-Lag Predictability and Base Factor

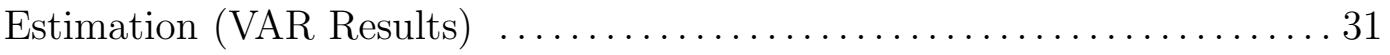

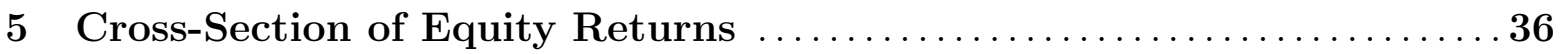

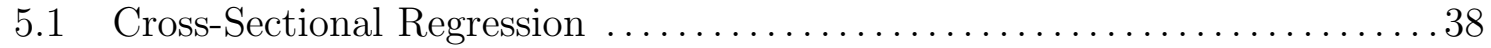

5.2 Explaining Profits of Trading Strategy Based Factors ................ 54

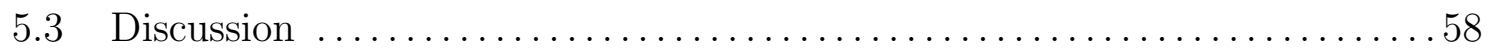

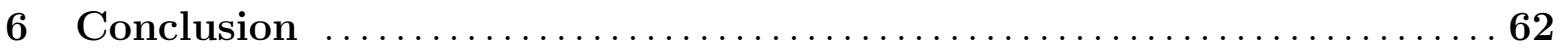


Appendix A: Simple Extension of Campbell (1993)

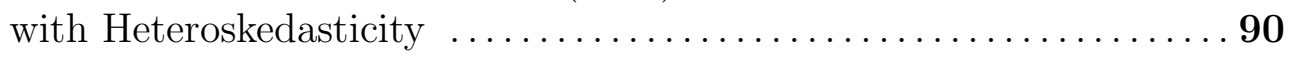

Appendix B: Conditioning Down the Asset Pricing Equation $\ldots \ldots \ldots \ldots \ldots . \ldots 9$

Appendix C: Cross-Sectional Regression with Portfolio Returns

in Excess of Risk Free Rate .......................... 95

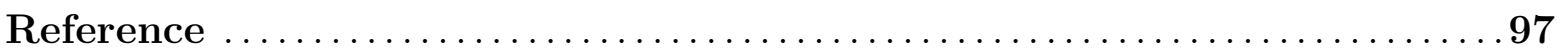




\section{LIST OF TABLES}

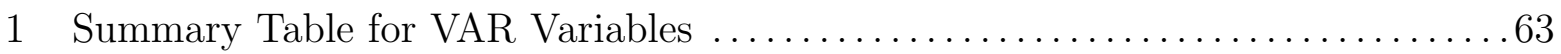

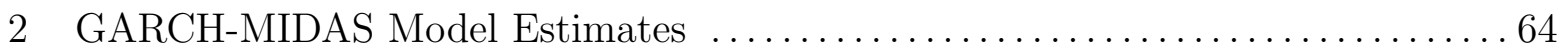

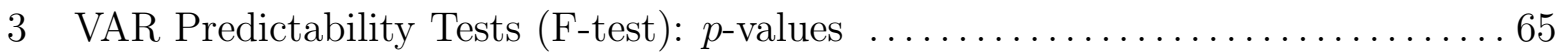

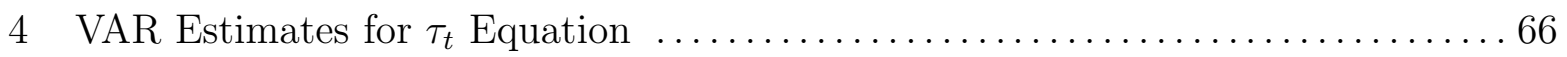

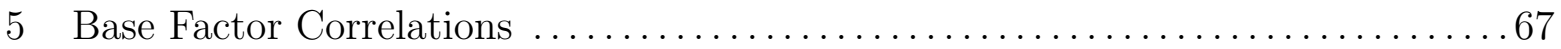

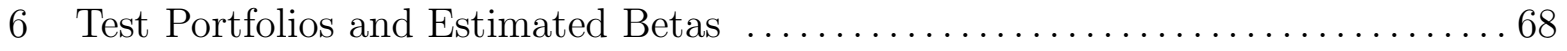

7 Cross-Sectional Regression with Volatility Factors $\ldots \ldots \ldots \ldots \ldots \ldots \ldots \ldots \ldots \ldots$

8 Separate Cross-Sectional Regression on Each Decile Portfolios . . . . . . . . . . . . 72

9 Cross-Sectional Regression with Trading-Strategy Based Factors . . . . . . . . 73

10 Average Factor Loadings for Each Decile Portfolios $\ldots \ldots \ldots \ldots \ldots \ldots \ldots \ldots \ldots 74$

11 Cross-Sectional Regression with Macroeconomic Factors $\ldots \ldots \ldots \ldots \ldots \ldots \ldots 76$

12 Cross-Sectional Regression: Volatility Factors vs.

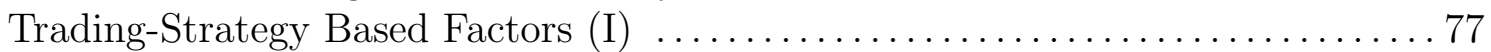

13 Cross-Sectional Regression: Volatility Factors vs.

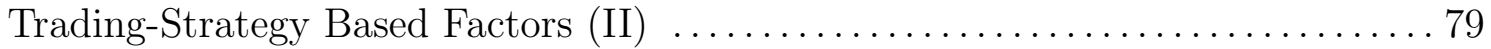

14 Cross-Sectional Regression: Volatility Factors vs.

Macroeconomic Factors . . . . . . . . . . . . . . . . . . . . . . . . . . 81

15 Expected vs. Observed Profits from Various Trading Strategies . ............82 


\section{LIST OF FIGURES}

1 GARCH-MIDAS with Rolling Window RV $\ldots \ldots \ldots \ldots \ldots \ldots \ldots \ldots \ldots \ldots \ldots$

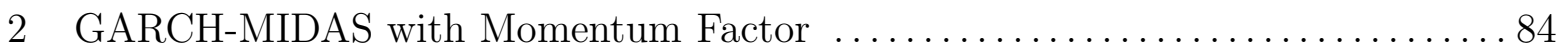

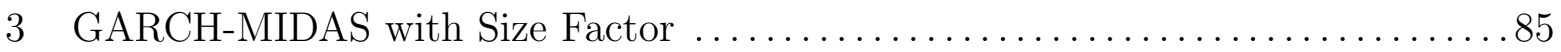

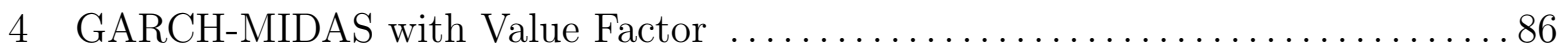

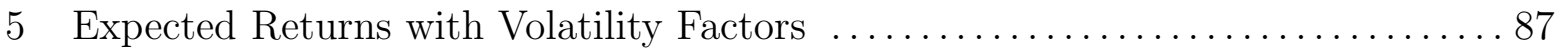

6 Expected Returns with Volatility Factors:

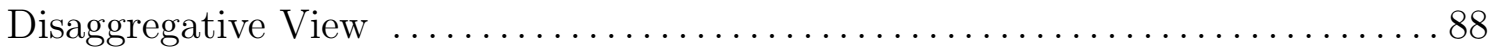

7 Expected Returns with Single Long-Run Volatility

Component Factor: Disaggregative View $\ldots \ldots \ldots \ldots \ldots \ldots \ldots \ldots \ldots \ldots \ldots$ 


\section{Introduction}

We discuss and show the nature of risk empirically well-established factors represent. Specifically, we show that size, momentum, liquidity (trading strategy based factors), industrial production growth, inflation (macroeconomic factors) factors as well as both short- and long-run aggregate market volatility factors represent the same systematic risk. ${ }^{1}$ Within a theoretical framework of intertemporal CAPM, we identify the risk these factors should represent; these factors are priced because they predict either future market return or future market volatility. It is very well known that future market returns, especially over a short horizon like a month, are very hard to predict and is indeed true for our data. Hence, our main research interest in the paper is to examine the relations between stock market volatility and the priced factors. We first show, in our time-series studies, that the factors mentioned contain information about future market volatility. Then, we show, in our cross-sectional studies, that these factors are priced across assets due to their predictability on future market volatility, thereby showing that these factors are not inherently different from one another when it comes to pricing assets. Consequently, we provide an explanation why asset pricing literature has reported to find so many seemingly-unrelated but empirically valid factors. It's hard to believe all these different factors are valid factors; we will show that they are not different.

To develop a theoretical framework to characterize the nature of risk the factors represent, we extend Campbell (1993) to accommodate heteroskedasticity in asset returns and consumption growth. The extension introduces an additional hedge-

\footnotetext{
${ }^{1}$ For papers proposing aggregate market volatility risk as a systematic risk factor, see Ang, Hodrick, Xing, and Zhang (2006) and Adrian and Rosenberg (2008). This view is different from the traditional risk-return tradeoff between stock return and volatility in time-series sense.
} 
demand-driven risk premium involving stock market volatility to those in Campbell (1993). This discrete-time analogue of Merton's (1973) intertemporal CAPM suggests that the variables that forecast either future stock market return or future stock market volatility should show up as valid factors. As was mentioned earlier, the key relation in this framework is the one between stock market volatility and the variables/factors of interests, and it also characterizes the relations among the empirically well-established factors; e.g. momentum factor and industrial production growth seem fairly unrelated, but we show that they both contain information about the future market volatility for which they are priced across assets. This key relation sheds new light on a branch of finance literature that attempts to provide risk-based explanations to trading strategy based factors; e.g. Liu and Zhang (2008) show that industrial production growth is the underlying risk of momentum profits, but we argue that their empirical finding is due to our finding that both of these factors represent the same systematic risk rather than industrial production growth being a true underlying risk for the momentum profits.

Despite their empirical success in explaining the cross-section of equity returns, most of trading strategy based factors lack theoretical foundations leaving us puzzled as to what systematic risk they represent. In response, incuding Liu and Zhang (2008), a group of papers has sought to offer risk-based explanations to these traded factors by linking the traded factors to more intuitive macroeconomic risks. ${ }^{2}$ However, most papers in this group also lack theoretical foundations. They don't show, theoretically and empirically, how the traded factors or even macroeconomic factors are linked to a pricing kernel. They just assume that key macroeconomic variables should be able represent states of an economy. Hence, their arguments are vulnerable to the so-called "fishing license" critique of Fama (1991). ${ }^{3}$ With regard to this matter, Cochrane (2001) points

\footnotetext{
${ }^{2}$ See He and Ng (1994), Liew and Vassalou (2000), Vassalou (2003), Hahn and Lee (2006), Kelly (2003), Griffin, Ji, and Martin (2003), Vassalou and Xing (2004), Petkova (2006), Aretz, Bartram, and Pope (2007), and Liu and Zhang (2008).

${ }^{3}$ Although the ICAPM does not tell us the identity of the state variables, many authors use the
} 
out that one could do a lot to show the chosen state variables actually do comply with theoretical requirements. One of his suggestions is to check that investment-opportunityset state variables actually do forecast something, and it is exactly what we're doing in our time-series studies; using the extended Campbell (1993) model, we explicitly show how conventional factors relate to a preference-based asset pricing equation, and examine the theoretical restriction on valid factors. Within this context, we examine the relations between stock market volatility and empirically successful factors lacking riskbased explanations, and this is the main theme of this paper. We consider size (SMB), value (HML), momentum (WML), and liquidity (LIQ) factors for trading strategy based factors, and industrial production growth (MP), producer price index inflation (PPI), term spread (UTS), and default premium (UPR) for macroeconomic factors. ${ }^{4}$ We try to understand these factors within the framework of intertemporal CAPM.

For empirical implementation, we first estimate stock market volatility. We adopt the GARCH-MIDAS framework proposed by Engle, Ghysels, and Sohn (2008) for this purpose. The GARCH-MIDAS model provides a decomposition of stock market volatility into two parts; one (short-run $g$-component) relates to short-lived factors and the other (long-run $\tau$-component) relates to state of economy. Our motivation for taking the two-component volaility model of the GARCH-MIDAS framework is threefold. First, many have proposed two-component volatilty models and shown that these models benefit from their two-component structure. ${ }^{5}$ Especially, Chernov, Gallant, Ghysels, and Tauchen (2003) examine an exhaustive set of diffusion models for the stock price dynamics and conclude quite convincingly that at least two components are necessary

ICAPM as an obligatory citation to theory on the way to justify their inclusion of any factor of their choice. This practice leads Fama (1991) to characterize the ICAPM as a fishing license. See also Cochrane (2001) for details.

\footnotetext{
${ }^{4}$ We use 'trading strategy based factors' and 'traded factors' interchangeably within this paper.

${ }^{5}$ See Engle and Lee (1999), Ding and Granger (1996), Gallant, Hsu, and Tauchen (1999), Alizadeh, Brandt, and Diebold (2002) and Chernov, Gallant, Ghysels, and Tauchen (2003), among many others.
} 
to adequately capture the dynamics of volatility. Second, we expect to have a clearer picture of the relationship between stock market volatility and the variables/factors of interest when we focus on the long-run component of volatility free of short-lived factors. Our variables of interest in this paper are the empirically well-established factors in the asset pricing literature; they are low-frequency (monthly) variables and supposed to represent the state of an economy. Third, one of the advantages of the GARCH-MIDAS model is that we can directly link the variables of our interest to the long-run volatility component. Hence, by using the GARCH-MIDAS framework, we can investigate predictability relations between long-run volatility component and other variables.

We include both short- and long-run volatility component estimates as well as market return in the VAR factor model of Campbell (1993). Under the assumption of heteroskedastic stock returns, inclusion of volatility components in the VAR system enables us to make the same Campbell's (1993) argument, with regard to the relation between future market returns and priced factors, as to the relation between future market volatility and priced factors. In other words, innovations to the VAR variables that predict future long-run volatility component should be priced across assets; these innovation factors are valid factors in a standard linear factor model. Our predictability analyses using the GARCH-MIDAS and a VAR framework indicate that the momentum factor, as well as short- and long-run components, strongly forecasts the future long-run volatility component. This empirical finding relates to Guo and Savickas (2006) and Guo (2006). Both Guo and Savickas (2006) and Guo (2006) use a rough measure of stock market variance: quarterly realized variance. Using simple regressions, they find the momentum strategy is closely related to the dynamics of stock market variance. However, they find stock market variance predicts the momentum factor while we find the reverse relationship to be strongly significant using a VAR model with the long-run volatility component as a market volatility measure. In addition to these variables, we 
find $\mathrm{SMB}_{t}, \mathrm{LIQ}_{t}, \mathrm{MP}_{t}$, and $\mathrm{PPI}_{t}$ contain good amounts of information about future stock market volatility. Then, the extended Campbell (1993) model suggests that innovations to the size, momentum, and liquidity factors among the traded factors, industrial production growth and inflation among macroeconomic factors, and both short- and long-run volatility components should be significantly priced across assets due to their common predictability on future market volatility.

Due to the persistent feature of stock market volatility, the best predictor of the long-run volatility component is naturally the lags of its own series. Being the best predictor of future market volatility, the long-run volatility component $\tau_{t}$ is supposed to generate innovations that are most relevant to the pricing of assets. The predictability analyses in the time-series studies and the extended Campbell (1993) model imply the following: If these market-volatility-predicting factors $\left(\mathrm{SMB}_{t}, \mathrm{WML}_{t}, \mathrm{LIQ}_{t}, \mathrm{MP}_{t}\right.$, and $\left.\mathrm{PPI}_{t}\right)$ are priced due to their predictability on the future market volatility, the pricing information of these factors should be well summarized by the $\tau_{t}$ innovation factor. Within this context, we expect the $\tau_{t}$ innovation factor would contain the pricing information of $\mathrm{SMB}_{t}, \mathrm{WML}_{t}, \mathrm{LIQ}_{t}, \mathrm{MP}_{t}$, and $\mathrm{PPI}_{t}$, and examine the information content of $\tau_{t}$ innovation factor by running cross-sectional regressions of various specifications. These cross-sectional studies will verify the idea that the information about the future market volatility contained in these factors is the source of their pricing abilities for assets.

We are interested in the pricing of three groups of factors: volatility component factors, trading strategy based factors, and macroeconomic factors. We follow Fama and MacBeth (1973) procedure to test the pricing of these factors on 40 test portfolios consisting of four different decile portfolios sorted by size, book-to-market ratio, momentum, and liquidity measure. ${ }^{6}$ To examine the information content of the $\tau_{t}$

\footnotetext{
${ }^{6}$ The momentum and liquidity decile portfolios are the ones used in Liu and Zhang (2008) and Pástor and Stambaugh (2003), respectively.
} 
innovation factor as well as others, we look into cross-sectional regressions of these factors in three different ways. First, we run Fama and MacBeth (1973) regressions of three sets of factors separately. Our choice of test assets allows us to decompose pricing errors, in terms of sum of squared errors, into four parts that belong to each of the decile portfolios. By looking at the pricing error decomposition of a set of factors or a certain factor, we can evaluate what pricing information such factors contain. Second, we run a horse race of factors among the three groups of factors. By running a horse race, we can directly compare the explanatory power of these factors over cross-sectional variation of mean asset returns and therefore examine the information content of the factors. Third, we extend Griffin, Ji, and Martin (2003) and Liu and Zhang (2008) to see how much of the profits from various trading strategies a set of factors can explain. All these results from three different approaches consistently verify the implications of the results in the predictability analyses. The $\tau_{t}$ innovation factor does contain the pricing information of $\mathrm{SMB}_{t}, \mathrm{WML}_{t}, \mathrm{LIQ}_{t}, \mathrm{MP}_{t}$, and $\mathrm{PPI}_{t}$. In fact, a single factor model of the $\tau_{t}$ innovation factor explains $35 \%$ of cross-sectional variation of mean returns of 40 test assets. The overall performance of this single factor model is on par with four traded factor models that consist of any combination of three traded factors and the market factor. Also, the single factor model of the $\tau_{t}$ innovation explains $73 \%, 65 \%$, and $46 \%$ of size, liquidity, and momentum profits, respectively.

The rest of this paper is organized as follows. In Section 2, we develope a simple extension of Campbell (1993) to explicitly show how stock market volatility and priced factors are related. Section 3 explains the empirical methodologies used to generate relevant factors in this paper. Section 4 discusses our test portfolios as well as other dataset. We also present results from GARCH-MIDAS and VAR models; predictability analyses and statistical properties of estimated factors. Section 5 covers all the crosssectional regression results. Finally, Section 6 concludes. 


\section{Theoretical Motivation}

Campbell (1993) presents a discrete-time analogue of Merton's (1973) ICAPM. A VAR factor model was proposed to implement the theoretical ideas into empirical work. An interesting result of Campbell (1993) is that he shows the asset pricing equation, which is derived from Epstein and Zin (1991) utility function, of the discre-time ICAPM can be represented as a standard linear factor pricing model via the VAR factor model. The linkage between utility-based asset pricing equation and the linear factor model puts theoretical restrictions on the priced factors:

... the intertemporal model suggests that priced factors should be found not by running a factor analysis on the covariance matrix of returns (e.g Roll and Ross 1980), nor by selecting important macroeconomic variables (e.g Chen, Roll, and Ross 1986). Instead, variables that have been shown to forecast stock-market returns should be used in cross-sectional asset pricing studies.

In the context of "fishing license" critique of Fama (1991), this theoretical restriction on valid priced factors can potentially guard us against such claims. Cochrane (2001) also points out that one could do a lot to show the chosen state variables actually do comply with theoretical requirements while few papers have actually done the validity check. One of his suggestions is to check that investment-opportunity-set state variables actually do forecast something. Campbell (1993) suggests that we should check if these state variables forecast market returns. The problem is that, as is well known in the literature, market returns over the short horizon like a month is hard to predict while we have a rich set of factors empirically shown to have significant explanatory power for cross-sectional variation of mean asset returns. Moreover, even if some variables, say term spread, show significant prediction power over market returns, the incremental $R^{2}$ 
for market return is very slim when such a variable is added to a VAR system.

Chen (2003) shows that allowing heteroskedastic asset returns in Campbell (1993) introduces a new hedge-demand-driven risk premium involving stock market volatility, by which he suggests variables that predict either future stock market returns or future stock market volatility should be priced across assets. For empirical implementation, he estimates the return process using a VAR model to describe the conditional means and a multivariate GARCH (MGARCH) model to describe the conditional variances. The VAR-MGARCH methodology allows Chen (2003) to investigate his full specification model in a unified and consistent way. ${ }^{7}$ However, in the VAR-MGARCH framework, stock market volatility needs to be left out of the VAR system, and this feature of the empirical methodology does not allow Chen (2003) to examine predictability relations between stock market volatility and the variables in the VAR model. The variables in the VAR system in Chen (2003) are supposed to forecast future stock market return, but these variables have little to do with dynamics of stock market volatility captured by the MGARCH. Rather, the volatilities of these variables should be able to predict stock market volatility since MGARCH framework jointly models conditional variances of the variables in the VAR. Hence, we cannot make the same Campbell's (1993) argument, with regard to the relations between future stock market returns and the priced VAR variables, to those between future market volatility and the priced VAR variables. Moreover, Chen (2003) focuses only on book-to-market effect. ${ }^{8}$

We are interested in the left-out link in Chen (2003) and focus on the relationship between stock market volatility and already-well-established priced factors such as

\footnotetext{
${ }^{7}$ The full specification model of Chen (2003) includes a term which is tricky to estimate and also hard to interpret.

${ }^{8}$ The estimates of his model indicate that the book-to-market effect cannot be explained as a factor that conveys information about future market returns. However, the analytical derivation of $V_{i \nu, t}$ estimate under VAR-MGARCH framework in Chen (2003) contains an error at (B.12) in his paper and the robustness of his empirical results to this error is unknown.
} 
aggregate volatility factor, trading strategy based factors, and macroeconomic factors. ${ }^{9}$ To examine these relations, we let the theoretical framework of Campbell (1993) to allow heteroskedasticity of asset returns and consumption growth. However, we do not take any ad hoc assumptions to substitute out consumption process from the implied asset pricing equation. Chen (2003) put restrictions on the higher moments of stock market returns to substitute out consumption process from the asset pricing equation in the heteroskedastic environment. ${ }^{10}$ Although the ad hoc assumption is successful in driving out the consumption from the equity premium equation, it introduces a term hard to interpret. With no additional assumptions to those made in Campbell (1993), we can derive the following asset pricing equation: ${ }^{11}$

$$
E_{t}\left[r_{i, t+1}-r_{f, t+1}\right]=-\frac{V_{i i, t}}{2}+\gamma V_{i m, t}+(\gamma-1) V_{i h, t}-\frac{(\gamma-1)^{2}}{2(\sigma-1)^{2}} V_{i \eta, t}
$$

where $\gamma, \sigma, r_{i, t+1}$ and $r_{f, t+1}$ are the coefficient of relative risk aversion, the elasticity of intertemporal substitution, log return of asset $i$ and risk-free asset, respectively. And, $V_{i i, t}=\operatorname{Var}_{t}\left(r_{i, t+1}\right), V_{i m, t}=\operatorname{Cov}_{t}\left(r_{i, t+1}, r_{m, t+1}\right)$, in particular,

$$
V_{i h, t}=\operatorname{Cov}_{t}\left(r_{i, t+1}, r_{h, t+1}\right)=\operatorname{Cov}_{t}\left(r_{i, t+1},\left(E_{t+1}-E_{t}\right) \sum_{j=1}^{\infty} \rho^{j} r_{m, t+1+j}\right)
$$

and

$$
\begin{aligned}
V_{i \eta, t} & =\operatorname{Cov}_{t}\left(r_{i, t+1}, r_{\eta, t+1}\right) \\
& =\operatorname{Cov}_{t}\left(r_{i, t+1},\left[E_{t+1}-E_{t}\right] \sum_{j=1}^{\infty} \rho^{j} \operatorname{Var}_{t+j}\left[\Delta c_{t+j+1}-\sigma r_{m, t+j+1}\right]\right)
\end{aligned}
$$

\footnotetext{
${ }^{9}$ For empirical studies of market volatility risk, see Ang, Hodrick, Xing, and Zhang (2006) and Adrian and Rosenberg (2008).

${ }^{10}$ Chen (2003) assumes the covariance between shocks to aggregate wealth portfolio return, $r_{m, t+1}$ (and powers of these shocks) and the changes in the forecasts of future variances, $\left(E_{t+1}-\right.$ $\left.E_{t}\right) \operatorname{Var}_{t+s+1}\left(r_{m, t+s+1}\right)$, are constants for all $s$.
}

${ }^{11}$ See Appendix A for brief summary of derivation. 
where $\rho$ is a constant that comes from log-linearization of the budget constraint. The first term on the right hand side of equation (1) is from a Jensen's inequality effect in taking expectation of log-normal returns, the second relates to CAPM, and the third is the covariance of asset $i$ 's return with good news about future returns on the market (i.e. upward revisions in expected future returns). Upto the third term, the risk premium equation is identical to that in Campbell (1993) except that $V_{i i, t}$ is a constant in Campbell (1993) due to the assumption in homoskedastic asset returns. Also, Campbell (1993) and Campbell (1996) point out that the equation (1) without the fourth term still holds in heteroskedastic environment when the elasticity of intertemporal substitution $\sigma$ equals one. It is when we allow heteroskedasticity in asset returns and consumption and $\sigma \neq 1$ that the fourth term involving second moments of market return and consumption growth is introduced to risk premium equation (1). ${ }^{12}$ It is interesting to see that the elasticity of intertemporal substitution $\sigma$ plays a role in risk premium determination. In Campbell (1993) and Chen (2003) in which consumption is completely substituted out, $\sigma$ does not enter into the asset pricing equation.

Expanding the conditional variance term in $V_{i \eta, t}$, we can represent $V_{i \eta, t}$ as a sum of three covariance terms. The first is the covariance between return on asset $i$ and the revision in future consumption growth volatility. However, majority of macroeconomic literature reports that the evidence of heteroskedasticity in consumption growth is very weak, and hence we can quite strongly argue that the first covariance term is zero. The second covariance term invloves covariance between consumption growth and stock market return. Duffee (2005) provides evidence that the conditional covariance between stock market return and consumption growth varies substantially over time. He also

\footnotetext{
${ }^{12}$ The macroeconomic evidence on the value of $\sigma$ for the U.S. is conflicting. Calibrated dynamic models require a value close to one of the EIS to match the data. In contrast, direct estimates of the EIS from the first order conditions for the solution of the consumer's intertemporal optimization problem deliver much lower values: Hall (1988) argues that the EIS is very close to zero and subsequent literature has provided further supports to this evidence. (e.g. Campbell and Mankiw (1989) and Yogo (2004))
} 
reports that both the conditional covariance and correlation are high when stock market wealth is high relative to consumption. However, the impact of this covariance term on cross-section of asset returns will be further studied in Sohn (2008) since our current focus is on the relation between stock market volatility and asset returns. Hence, we ignore first two terms in $V_{i \eta, t}$ and we assume

$$
\begin{aligned}
V_{i \eta, t} & \approx V_{i \tilde{\eta}, t}=\operatorname{Cov}_{t}\left(r_{i, t+1}, r_{\tilde{\eta}, t+1}\right) \\
& \approx \sigma^{2} \operatorname{Cov}_{t}\left(r_{i, t+1},\left[E_{t+1}-E_{t}\right] \sum_{j=1}^{\infty} \rho^{j} \operatorname{Var}_{t+j}\left[r_{m, t+j+1}\right]\right) \\
& \approx \sigma^{2} \operatorname{Cov}_{t}\left(r_{i, t+1},\left[E_{t+1}-E_{t}\right] \sum_{j=1}^{\infty} \rho^{j} \hat{h}_{t+j+1}\right)
\end{aligned}
$$

where $\hat{h}_{t}$ is stock market volatility estimates. Chen (2003) uses a MGARCH model to capture dynamics of second order moments of VAR variables and estimate the corresponding covariance terms in the risk premium equation. On the contrary, we will estimate stock market volatility beforehand and treat it as an observable variable. This makes $V_{i \tilde{\eta}, t}$ in the same format as $V_{i h, t}$, or $r_{\tilde{\eta}, t+1}$ in the same format as $r_{h, t+1}$. Hence, including both stock market return and stock market volatility estimates in the VAR system, we can use the VAR factor model of Campbell (1993) to estimate both $r_{\tilde{\eta}, t+1}$ and $r_{h, t+1}$, and rewrite the asset pricing equation (1) in linear factor pricing model of VAR innovations. Both terms involving $V_{i h, t}$ and $V_{i \eta, t}$ represent hedge-demand-driven risk premia and they imply that the variables that predict either stock market return or stock market volatility should show up as priced factors. 


\section{Econometric Methodology}

We introduce econometric methodologies that will be used in our time-series analyses: the GARCH-MIDAS class of models proposed by Engle, Ghysels, and Sohn (2008) and the VAR factor model adapted to accommodate the extension in Campbell (1993). Both the GARCH-MIDAS model and the VAR factor model allow us to examine the predictability of stock market volatility. We use the GARCH-MIDAS model to estimate two volatility components. Including these volatility components, we construct a VAR factor model. The VAR factor model generates the factors that will be used in our cross-sectional studies.

\subsection{GARCH-MIDAS Class of Models}

Different news events may have different impacts on financial markets, depending on whether they have consequences over short or long horizons. A conventional framework to analyze this is the familiar log linearization of Campbell (1991) and Campbell and Shiller (1988) which states that:

$$
r_{m, \delta / t}-E_{\delta-1 / t}\left[r_{m, \delta / t}\right]=\left[E_{\delta / t}-E_{\delta-1 / t}\right] \sum_{j=0}^{\infty} \varrho^{j} \Delta d_{\delta / t+j}-\left[E_{\delta / t}-E_{\delta-1 / t}\right] \sum_{j=1}^{\infty} \varrho^{j} r_{m, \delta / t+j}
$$

where we deliberately write returns in terms of days of the month, namely $r_{m, \delta / t}$ is the $\log$ market return on day $\delta$ during month $t, d_{\delta / t}$ the log dividend on that same day and $E_{\delta / t}[]$ the conditional expectation given information at the same time. Following Engle and Rangel (2008), the left hand side of equation (5), or unexpected returns, can be 
rewritten as follows:

$$
r_{m, \delta / t}-E_{\delta-1 / t}\left[r_{m, \delta / t}\right]=\sqrt{\tau_{\delta / t} \cdot g_{\delta / t}} \zeta_{\delta / t}
$$

where volatility has at least two components, namely $g_{\delta / t}$ which accounts for daily fluctuations that are assumed short-lived, and a secular component $\tau_{\delta / t}$. The main idea of equation (6), is that the same news, say better than expected dividends, may have a different effect depending on the state of the economy. For example, unexpected poor earnings, should have an impact during expansion different from that during recessions. The component $g_{\delta / t}$ is assumed to relate to the day-to-day liquidity concerns and possibly other short-lived factors (see e.g. recent work by Chordia, Roll, and Subrahmanyam (2002) documents quite extensively the impact of liquidity on market fluctuations). In contrast, the component $\tau_{\delta / t}$ relates, first and foremost, to the future expected cash flows and future discount rates, and macro economic variables are assumed to tell us something about this source of stock market volatility.

With this motivation in the background, Engle, Ghysels, and Sohn (2008) introduced the GARCH-MIDAS class of models with many variants. The name comes from the features that it uses a mean reverting unit daily GARCH process, similar to Engle and Rangel (2008), and a MIDAS filter as in Ghysels, Santa-Clara, and Valkanov (2005). The distinct feature of the new class is that the mixed data sampling allows us to link volatility directly to economic activity (i.e. data that is typically sampled at the different frequency than daily returns). We start with introducing the GARCH-MIDAS with rolling window RV. We assume that daily conditional expectation of market return is constant, namely

$$
r_{m, \delta / t}=\mu+\sqrt{\tau_{\delta / t} \cdot g_{\delta / t}} \zeta_{\delta / t}
$$

where $\zeta_{\delta / t} \mid \Phi_{\delta-1 / t} \sim N(0,1)$ with $\Phi_{\delta-1 / t}$ is the information set up to day $(\delta-1)$ of period $t$. Following Engle and Rangel (2008), we assume the volatility dynamics of the 
component $g_{\delta / t}$ is a (daily) unit $\operatorname{GARCH}(1,1)$ process, namely:

$$
g_{\delta / t}=(1-\alpha-\beta)+\alpha \frac{\left(r_{m, \delta-1 / t}-\mu\right)^{2}}{\tau_{\delta-1 / t}}+\beta g_{\delta-1 / t}
$$

To capture dynamics of long-run volatility component, we adopt MIDAS filter or MIDAS regression framework. ${ }^{13}$ The first natural candidate to be placed in the filter is realized variance since this conforms with long tradition from Schwert (1989). One can choose to plug monthly (fixed window) RV or monthly rolling window RV into the MIDAS filter. ${ }^{14}$ Depending on the choice of RV, we call it GARCH-MIDAS with (fixed span/rolling window) RV. Engle, Ghysels, and Sohn (2008) report that, for the monthly horizon forecasts, the GARCH-MIDAS with rolling window RV outperforms that with fixed span RV in almost every measure and, hence, we introduce the GARCH-MIDAS with rolling window RV here: ${ }^{15}$

$$
\tau_{\delta / t}=m+\theta \sum_{j=1}^{J} \varphi_{j}\left(\omega_{1}, \omega_{2}\right) R V_{\delta / t-j}
$$

where

$$
R V_{\delta / t}=\sum_{n^{\prime}=1}^{N^{\prime}} r_{m, \delta / t-n^{\prime}}^{2}
$$

When $N^{\prime}=22$, we call it monthly rolling window RV, while $N^{\prime}=65$ and $N^{\prime}=125$, amount to respectively, quarterly rolling and biannual rolling window RV. The weighting

\footnotetext{
${ }^{13}$ For theoretical background of MIDAS regression, see Ghysels, Santa-Clara, and Valkanov (2002), Ghysels, Sinko, and Valkanov (2007). Also, see Ghysels, Santa-Clara, and Valkanov (2005) and Ghysels, Santa-Clara, and Valkanov (2006) among many others for empirical applications.

${ }^{14}$ Adrian and Rosenberg (2008) report that their long-run volatility component is closely related with the trend component of Hodrick and Prescott (1997) filtered daily squared returns. Although not verified empirically, our long-run volatility component would highly correlate with that of Adrian and Rosenberg (2008) since ours is also modeled by passing squared returns into low-frequency filter of MIDAS.
}

${ }^{15}$ See Engle, Ghysels, and Sohn (2008) for empirical comparison on these models. 
function is defined as

$$
\varphi_{j}(\omega)=\frac{(j / J)^{\omega_{1}-1}(1-j / J)^{\omega_{2}-1}}{\sum_{i=1}^{J}(i / J)^{\omega_{1}-1}(1-i / J)^{\omega_{2}-1}}
$$

where the weights in the above equation sum up to one. The weighting function or smoothing function in equation (11) is the "Beta" lag structure discussed further in Ghysels, Sinko, and Valkanov (2007). The Beta lag, based on the beta function, is very flexible to accommodate various lag structures. It can represent monotonically increasing or decreasing weighting scheme. It can also represent a hump-shaped weighting scheme although it is limited to unimodal shapes. ${ }^{16}$ Due to the small number of parameters and structural flexibility of the weighting function, we can handle large number lags with only a handful of parameters. The GARCH-MIDAS model with RV has parameter space of $\Theta=\left\{\mu, \alpha, \beta, \theta, \omega_{1}, \omega_{2}, m\right\}$ and the number of parameters is fixed regardless of the choice of $J$ and $N^{\prime}$.

We introduce another GARCH-MIDAS class of models to accommodate a wider choice of variables for modelling the long-run volatility component. One of attractive features that GARCH-MIDAS class of models offer is that we can directly link various variables to long-run volatility component $\tau$, and examine whether the chosen variable help predicting long-run volatility component. If a variable does not contain any information about future market volatility, estimation procedure shuts down $\tau$ process by setting $\theta \approx 0$ and making $\tau_{\delta / t} \approx m$. Then, $\tau$ only works as a scaling factor for unit $\operatorname{GARCH}(1,1)$ process $g_{\delta / t}$ to fit unconditional mean of conditional variance $\tau \cdot g$.

Since we are interested in wide variety of variables, the model should be able to accommodate variables that have negative relations with stock market volatility. To make it easy to implement these variables, we consider modeling $\log \tau$ instead of $\tau$ as in

\footnotetext{
${ }^{16}$ See Ghysels, Sinko, and Valkanov (2007) for further details regarding the various patterns one can obtain with Beta lags.
} 
the GARCH-MIDAS model with RV: ${ }^{17}$

$$
\log \tau_{\delta / t}=m+\theta \sum_{j=1}^{J^{\prime}} \varphi_{j}\left(\omega_{1}, \omega_{2}\right) X_{t-j}
$$

where $X_{t}$ is the monthly variable of our interests. Although $\tau$ still has daily time subscript, $\delta, \tau$ is a constant during each calendar months since the regressor $X_{t}$ is of monthly frequency.

For both of our time-series and cross-sectional studies that follow, we work with monthly frequency data and hence we time aggregate $\tau_{\delta / t}$ and $g_{\delta / t}$. For time aggregation, we add up daily $\tau_{\delta / t}$ 's and $g_{\delta / t}$ 's within a month to construct a monthly $\tau$ and $g$. Then, we take averages of the $\tau$ and $g$ volatility components within each month and multiply by the average number of trading days within months over the whole sample period. This procedure ensures that market risk is not affected by the variation in the number of trading days per months. The resulting monthly $\tau$ and $g$ components are denoted with $\tau_{t}$ and $g_{t}$ without daily time subscript $\delta$.

\subsection{VAR Factor Model}

We adopt a VAR factor model of Campbell (1993) and Campbell (1996) to link hedge-demand-driven risk premia in the asset pricing equation (1) to those in the standard linear factor pricing model. It also allows us to implement the theoretical ideas developed in Section 2. Unlike Chen (2003), we first estimate the stock market volatility components by the GARCH-MIDAS model with rolling window RV, and then include these components in the vector for the VAR factor model. The VAR model allows us to construct the innovation series of the variables in the VAR system, which are the base factors for our cross-sectional studies. In addition to this, the VAR factor

\footnotetext{
${ }^{17}$ Note that the estimation process should impose positivity condition on equation (9). However, if we model $\log \tau$, such condition need not be imposed.
} 
model offers two more advantages. One is that we can use the Granger causality tests (F-tests) of the VAR model to investigate predictability relations between stock market volatility and other well-established factors such as trading strategy based factors (SMB, HML, WML, LIQ) and macroeconomic factors (MP, PPI, UTS, UPR). This issue is particularly relevant to Section 2. We expect to find the evidence that these factors contain information about the future stock market volatility.

As was previously discussed in Section 3.1, the predictability relations can also be investigated with the GARCH-MIDAS framework. However, the predictability relations that would be revealed by the GARCH-MIDAS framework and the VAR analysis are different. The strength of the GARCH-MIDAS model is that it can handle many lags of an independent variable with a handful of parameters. This feature allows us to look at the predictability relations that requires many lags of an independent variable. This comes at a cost of restricting the coefficients of regressors. One particular restriction is that the signs of coefficients of regressors cannot differ across the lags; the signs of the coefficients are all determined by $\theta$. On the other hand, a VAR approach has different strengths and weaknesses. A VAR framework, as is often called a "black box," has great flexibility in parameters, but cannot handle large number of lags due to the curse of dimensionality. In sum, the GARCH-MIDAS framework will help us reveal simple bivariate predictability relations that involve long lags of a predictor while a VAR framework will allow us to look at predictability relations with other control variables and great flexibility in parameters but with small number of lags.

The other advantage of adopting a VAR model relates to Campbell (1996). Campbell (1996) argues that it is hard to interpret estimation results for a VAR factor model unless the factors are orthogonalized and scaled in some way. In his paper the innovations to the state variables are orthogonal to both the excess market return and labor income. Following Campbell (1996) and Sims (1980), we can triangularize the VAR system in a similar way. We can also scale all the innovations to have the same variance 
as that of the innovations to the market return. We provide the results of our crosssectional studies with scaled and orthogonalized factors as well as those with conventional innovation factors. Petkova (2006) also adopts this methodology in investigating the relations between the Fama-French factors (HML and SMB) and a set of variables that describes investment opportunities.

We are interested in the relations among the aggregate volatility factors, the trading strategy based factors, and the macroeconomic factors. The theoretical framework introduced in Section 2 suggests that these factors are priced because they predict either stock market return or stock market volatility. Hence, in addition to stock market return and stock market volatility estimates, we will include these factors to examine the predictability relations. We choose two sets of variables for two separate VAR systems to examine these relations. ${ }^{18}$ Let

$$
\mathbf{y}_{t}^{[1]}=\left[\begin{array}{c}
r_{m, t} \\
\tau_{t} \\
g_{t} \\
S M B_{t} \\
H M L_{t} \\
W M L_{t} \\
L I Q_{t}
\end{array}\right] \quad \mathbf{y}_{t}^{[2]}=\left[\begin{array}{c}
r_{m, t} \\
\tau_{t} \\
g_{t} \\
M P_{t} \\
P P I_{t} \\
U T S_{t} \\
U P R_{t}
\end{array}\right]
$$

With these two sets of variables, we estimate the following VAR system separately:

$$
\mathbf{y}_{t+1}^{[\bullet]}=B_{[\bullet]} \mathbf{y}_{t}^{[\bullet]}+\epsilon_{t}^{[\bullet]}
$$

where $[\bullet]$ can be either 1 or 2 . The first-order VAR representation is not restrictive

\footnotetext{
${ }^{18}$ It would be interesting to have all the volatility components, traded factors, and macroeconomic variables in one VAR system, but this will seriously exacerbate the curse of dimensionality problem. Hence, we keep maximum of seven variables in each VAR system.
} 
since a higer-order VAR can always be stacked into first-order (companion) form in the manner discussed by Campbell and Shiller (1988). The matrix $B$ is known as the companion matrix of the VAR. Following Campbell (1993), it is straight forward to show that the VAR factor model of (13) can be used to estimate two terms involving hedge-demand-driven risk premia as in (2) and (4):

$$
\begin{aligned}
\left(E_{t+1}-E_{t}\right) \sum_{j=1}^{\infty} \rho^{j} r_{m, t+1+j} & =\mathbf{e}_{1}^{\prime} \rho B(I-\rho B)^{-1} \boldsymbol{\epsilon}_{t+1} \\
& =\boldsymbol{\lambda}^{\prime} \boldsymbol{\epsilon}_{t+1} \\
\left(E_{t+1}-E_{t}\right) \sum_{j=1}^{\infty} \rho^{j} \hat{h}_{t+1+j} & =\mathbf{e}_{2}^{\prime} \rho B(I-\rho B)^{-1} \boldsymbol{\epsilon}_{t+1} \\
& =\boldsymbol{\xi}^{\prime} \boldsymbol{\epsilon}_{t+1}
\end{aligned}
$$

where $\mathbf{e}_{1}$ is a vector whose first element is one and whose other elements are all zero. And, $\mathbf{e}_{2}$ is defined similarly. As was already pointed out in Section 3.1, $\tau_{t}$ relates to the state of an economy while $g_{t}$ relates to short-lived factors. Hence, we assume $\hat{h}_{t}=\hat{\tau}_{t}$ in the equation (15). ${ }^{19}$ Using these results, we can rewrite equation (1) as follows

$$
E_{t}\left[r_{i, t+1}-r_{f, t+1}\right]=-\frac{V_{i i, t}}{2}+\gamma V_{i m, t}+\sum_{n=1}^{N}\left[(\gamma-1) \lambda_{n}-\frac{(\gamma-1)^{2}}{2(\sigma-1)^{2}} \xi_{n}\right] V_{i n, t}
$$

where $\lambda_{n}$ and $\xi_{n}$ are the $n$th element of $\boldsymbol{\lambda}$ and $\boldsymbol{\xi}$, respectively, and $V_{i n, t}=$ $\operatorname{Cov}_{t}\left(r_{i, t+1}, \epsilon_{n, t+1}\right)$ where $\epsilon_{n, t+1}$ is the $n$th element of the residual vector $\boldsymbol{\epsilon}_{t+1}$ in the VAR system. The equation (16) shows that variables that have been known to forecast either stock market return or stock market volatility should be used in cross-sectional asset pricing studies. The elements of the vector $\boldsymbol{\lambda}$ and $\boldsymbol{\xi}$ measure the importance of each variable in VAR system in forecasting future market returns and future market

\footnotetext{
${ }^{19}$ The predictability analyses in Section 4 show that no trading strategy based factor nor macroeconomic factors contain information about the future $g_{t}$. Also, our cross-sectional studies in Section 5 show that innovations to $g_{t}$ is not priced when the common component with $\tau_{t}$ innovation is eliminated.
} 
volatilities. If a particular element $\lambda_{n}\left(\xi_{n}\right)$ is large and positive (negative), then a shock to $n$th variable in $\mathbf{y}_{t}^{[\bullet]}$ is an important piece of good news about future investment opportunities.

Besides the time-series studies, we will also look into the cross-section of stock returns to examine the information content of the factors investigated. For the purpose of this cross-sectional study, it is convenient to have unconditional version of the asset pricing equation $(16):^{20}$

$$
\begin{aligned}
E\left[R_{i, t+1}-R_{f, t+1}\right] & =\gamma \sigma_{\check{r}, m}^{2} \beta_{i \check{m}}+\sum_{n=1}^{N}\left[(\gamma-1) \lambda_{n}-\frac{(\gamma-1)^{2}}{2(\sigma-1)^{2}} \xi_{n}\right] \sigma_{\epsilon, n}^{2} \beta_{i n} \\
& =\Lambda_{\check{m}} \beta_{i \check{m}}+\sum_{n=1}^{N} \Lambda_{n} \beta_{i n}
\end{aligned}
$$

where $\beta_{i \check{m}}=\operatorname{Cov}\left(R_{i, t+1}, \check{R}_{m, t+1}\right) / \sigma_{\check{r}, m}^{2}, \beta_{i n}=\operatorname{Cov}\left(R_{i, t+1}, \epsilon_{n, t+1}\right) / \sigma_{\epsilon, n}^{2}, \sigma_{\check{r}, m}^{2}=\operatorname{Var}\left(\check{R}_{m, t+1}\right)$, $\sigma_{\epsilon, n}^{2}=\operatorname{Var}\left(\epsilon_{n, t+1}\right)$, and $\check{R}_{m, t+1}=R_{m, t+1}-E_{t}\left[R_{m, t+1}\right]$. For our cross-sectional studies, we consider two different ways to construct factors. One is to construct conventional innovation factors from the estimated residuals in the VAR model. The other is to follow Campbell (1996); orthogonalize and rescale these innovation series. We let

$$
\begin{aligned}
& f_{t}^{\tau[\bullet]}=\mathbf{e}_{2}^{\prime} \boldsymbol{\epsilon}_{t}^{[\bullet]} \\
& f_{t}^{g[\bullet]}=\mathbf{e}_{3}^{\prime} \boldsymbol{\epsilon}_{t}^{[\bullet]}
\end{aligned}
$$

$f_{t}^{\tau}$ is an innovation series of $\tau_{t}$ and $f_{t}^{g}$ is an innovation series of $g_{t}$. Similarly, we define $f_{t}^{M P}=\mathbf{e}_{4}^{\prime} \boldsymbol{\epsilon}_{t}^{[2]}, f_{t}^{P P I}=\mathbf{e}_{5}^{\prime} \boldsymbol{\epsilon}_{t}^{[2]}, f_{t}^{U T S}=\mathbf{e}_{6}^{\prime} \boldsymbol{\epsilon}_{t}^{[2]}, f_{t}^{U P R}=\mathbf{e}_{7}^{\prime} \boldsymbol{\epsilon}_{t}^{[2]}$. On the other hand, for the trading strategy based factors, we define $f_{t}^{S M B}=S M B_{t}, f_{t}^{H M L}=H M L_{t}, f_{t}^{W M L}=W M L_{t}$, and $f_{t}^{L I Q}=L I Q_{t}$. We collect the following set of factors, $\left\{R_{m, t}^{e}, f_{t}^{\tau}, f_{t}^{g}, f_{t}^{S M B}, f_{t}^{H M L}\right.$, $\left.f_{t}^{W M L}, f_{t}^{L I Q}, f_{t}^{M P}, f_{t}^{P P I}, f_{t}^{U T S}, f_{t}^{U P R}\right\}$, and call them 'base factors' to be differentiated from 'orthogonalized factors' which will be introduced a bit later.

\footnotetext{
${ }^{20}$ See Appendix B for brief outline of derivation.
} 
It should be pointed out that traded factor themselves are taken as base factors whereas innovations to macroeconomic variables are taken as base factors. Moreover, the original factors from Chen, Roll, and Ross (1986) include unanticipated inflation $\left(\mathrm{UI}_{t}\right)$ and the change in expected inflation $\left(\mathrm{DEI}_{t}\right)$ instead of producer price index $\left(\mathrm{PPI}_{t}\right)$. Chen, Roll, and Ross (1986) argue that their original factors are noisy enough to be treated as innovations and hence they used these log growth rates or rate differences as their factors. However, as shall be revealed by our VAR analysis, some of these series are highly persistent and predictable. Hence, we take innovations to the relevant macroeconomic variables from the VAR model as our base factors. In doing so, it is hard to interpret the innovations to $\mathrm{UI}_{t}$ and $\mathrm{DEI}_{t}$ because they already take expectations in them and that's why we replace these with $\mathrm{PPI}_{t}$. In addition, macroeconomic innovation factors with $\mathrm{PPI}_{t}$ perform far better than the original model specification of Chen, Roll, and Ross (1986) with $\mathrm{UI}_{t}$ and $\mathrm{DEI}_{t}$. On the contrary, as will be shown in our VAR results, trading strategy based factors are hardly persistent and predictable, which is consistent with the fact that innovation/residual series of these factors from VAR estimation highly correlate (at least $95 \%$ of correlation) with their original factors. The traded factors themselves are good proxies for the innovations associated with these variables.

Once we have estimated the $\hat{\boldsymbol{\epsilon}}_{t}$ series, we can estimate covariance matrix and orthogonalize the shock, $\hat{\boldsymbol{\epsilon}}_{t}$. As a result, we can compute 'orthogonalized factors.' To differentiate it from the base factors $\left(f_{t}^{X}\right)$ we denote the orthogonalized factors with $u_{t}^{X}$ where $X$ refers to the original variable from which the factor is derived $(e . g . X$ can be $\mathrm{SMB}, \mathrm{MP}$, etc.). It is very important to recognize that ordering of variables matters in orthogonalized factors. Note that the ordering of variables in $\mathbf{y}_{t}$ does not make any differences in estimates of $\boldsymbol{\epsilon}_{t}$. However, Sims (1980) orthogonalization makes ordering of variables in $\mathbf{y}_{t}$ have great impact on estimated $u_{t}$. If the variables in $\mathbf{y}_{t}^{[1]}$ are ordered as they are shown, we have $u_{m, t}=\mathbf{e}_{1}^{\prime} u_{t}^{[1]}=\mathbf{e}_{1}^{\prime} \boldsymbol{\epsilon}_{t}^{[1]}$; the innovation to the market return is unaffected. However, the orthogonalized innovation in $\tau_{t}\left(u_{t}^{\tau[1]}\right)$ is the component of the 
original $\tau_{t}$ innovation, $\boldsymbol{\epsilon}_{t}^{\tau[1]}=\mathbf{e}_{2}^{\prime} \boldsymbol{\epsilon}_{t}^{[1]}$, orthogonal to the market return, and so on. The orthogonalized innovation to $\tau_{t}$ is a change in the $\tau_{t}$ component with no change in the excess market return; therefore it can be interpreted as a shock to the $\tau_{t}$. Similarly, the orthogonalized innovation to $g_{t}^{[1]}\left(u_{t}^{g[1]}\right)$ is the component of the original $g_{t}^{[1]}$ innovation orthogonal to both market return and $\tau_{t}$. Following Campbell (1996), we also scale all the orthogonalized innovations to have the same variance as the market return. 


\section{Data and Time Series Analysis}

This section describes the data used in the empirical studies. In particular, we describe the statistical properties of test assets used in the cross-sectional studies, and discuss the advantages from our choice of test portfolios. Also, it presents empirical results of our time-series studies; the predictability relations between stock market volatility and the variables of our interest are examined using the GARCH-MIDAS model and a VAR model.

\subsection{Data}

In order to estimate the GARCH-MIDAS model with rolling window RV, we use daily value-weighted cum-dividend stock market return (NYSE/AMEX/NASDAQ) data from CRSP. Once we construct monthly-aggregated volatility components, $\tau_{t}$ and $g_{t}$, we use VAR framework to estimate innovation factor series. In the process, we have a chance to look at the predictability relations among stock market return and stock market volaility, and other variables of our choice. Our choice of variables include trading strategy based factors (SMB, HML, WML, LIQ) and macroeconomic factors (MP, PPI, UTS, UPR). We include these factors in the VAR model to investigate the theoretical implications of the extended Campbell (1993), i.e some of these empiricallywell-established factors are priced due to their prediction power on the future stock market volatility.

The monthly returns on market portfolio, risk-free rate, SMB, and HML are from Prof. Kenneth French's website. LIQ is the original value-weighted traded liquidity 
factor used in Pástor and Stambaugh (2003) and available at 'Fama French, Momentum, Liquidity' dataset in WRDS. ${ }^{21}$ WML is the momentum factor used in Liu and Zhang (2008) and available at Prof. Xiaolei Liu's website. Note that these are all 'traded' factors and this common feature allows us to examine the link between these factors and others by looking at how much of the profits of these trading strategies can be explained by other factors. This issue is covered in Section 5.2 in detail.

In addition to the traded factors, we are also interested in macroeconomic factors as in Chen, Roll, and Ross (1986) and their link with stock market volatility. We follow their definitions on macroeconomic factors. $\mathrm{MP}_{t}$ is the monthly log growth rate of industrial production, $\mathrm{MP}_{t}=\log \mathrm{IP}(t)-\log \mathrm{IP}(t-1)$, where $\mathrm{IP}_{t}$ is the index of industry production in month $t$ from Federal Reserve Economic Data (henceforth FRED). Similarly, PPI is defined as log growth rate of producer price index also avaiable at FRED. ${ }^{22} \mathrm{UTS}_{t}$ is the term premium defined as the yield spread between the long-term and the one-year Treasury bonds from the Ibbotson database. Lastly, $\mathrm{UPR}_{t}$ is the default premium, the yield spread between Moody's Baa and Aaa corporate bonds from FRED.

Table 1 shows summary statistics for the variables included in the VAR system. As was previously mentioned in Section 3.2, traded factors themselves are base factors and hence they are denoted with $f_{t}^{\bullet}$. Autocorrelations marked with an asterisk are beyond two standard deviations from zero. Table 1 shows that there is a drastic difference in autocorrelation structure between traded factors and macroeconomic factors. Traded factors show very low autocorrelation while macroeconomic factors show large and persistent autocorrelations. This evidently shows that one of assumptions made in Chen, Roll, and Ross (1986) is not correct; they assume that the macroeconomic factors are

\footnotetext{
${ }^{21}$ The LIQ here is the one denoted with $\mathrm{LIQ}^{v}$ in Pástor and Stambaugh (2003) and it is the payoff on the 10-1 spread constructed using value-weighted decile portfolios sorted on predicted liquidity beta. This should be distinguished from the innovation in aggregate liquidity, $\mathcal{L}_{t}$.

${ }^{22}$ Chen, Roll, and Ross (1986) use unanticipated inflation $\left(\mathrm{UI}_{t}\right)$ and changes in expected inflation $\left(\mathrm{DEI}_{t}\right)$ instead of $\mathrm{PPI}_{t}$. However, we chose $\mathrm{PPI}_{t}$ for the reasons given in Section 3.2.
} 
noisy enough to be treated as innovations. Thus, we choose to take traded factors themselves as base factors whereas VAR innovations of macroeconomic factors are taken as base factors. Table 1 also shows mean returns of traded factors; $0.15 \%$ for SMB, $0.31 \%$ for HML, $0.84 \%$ for WML, and $0.33 \%$ for LIQ. These are monthly rates. The WML trading strategy generates the biggest profits in our sample from July, 1966 to December, 1999. However, return on WML strategy also shows high kurtosis and standard deviations.

We run cross-sectional regressions with the base/orthogonalized factors constructed from the variables in Table 1 using a VAR factor model. Our test assets used in the cross-sectional studies in Section 5 consist of 40 portfolios. We use four singlesorted decile portfolios; size-, BM-, momentum-, and liquidity-sorted decile portfolios. Size and BM decile portfolios are from Prof. Kenneth French's website. Momentum portfolios are from Liu and Zhang (2008) and also available at Prof. Xiaolei Liu's website. ${ }^{23}$ Liu and Zhang (2008) follow Jegadeesh and Titman (1993) and sort all stocks (NYSE/AMEX/NASDAQ) at the beginning of every month on the basis of their past six-month returns and hold the resulting ten portfolios for the subsequent six months. All stocks are equal-weighted within each portfolio. To avoid potential microstructure biases, they skip one month between the end of the ranking period and the beginning of the holding period. Pástor and Stambaugh (2003) sort stocks on the basis of their predicted values of sensitivity of the corresponding stocks' returns to the innovation in aggregate liquidity measure and form 10 portfolios. The postformation returns on these portfolios during the next 12 months are linked across years to form a single return series

\footnotetext{
${ }^{23}$ Momentum factor and momentum portfolios are also avaiable at Prof. Kenneth French's website. However, Liu and Zhang (2008) follows Jegadeesh and Titman (1993) more closely in forming portfolios and the factor in the sense that they allow overlapping holding periods. Also, the first and the last momentum portfolios from Prof. Kenneth French's website show signs of outliers. The mean returns of these portfolios are so far distanced from that of the next (\#2 and \#9) portfolios. For our sample from 1966 to 1999, the spread of these two end portfolios generates monthly 1.68\%. In fact, we do have stronger results with our volatility factors on test assets with momentum portfolios and factor from Prof. Kenneth French's website.
} 
for each decile portfolios. These are our liquidity portfolios. ${ }^{24}$

In our cross-sectional studies, we expect to benefit from using these four one-way sorted decile portfolios in many ways. It has been a sort of norm in this field to use, as test assets, 25 Fama French portfolios two-way sorted by size and book-to-market ratio. $^{25}$ However, in addition to SMB and HML, we are also interested in WML and LIQ and their relations to market volatility. Thus, we might as well include momentumand liquidity-sorted decile portfolios. Alternatively, we can consider portfolios four-way sorted by size, book-to-market ratio, momentum, and liquidity, but this will drastically increase the number of test assets while drastically decrease the number of firms included in each portfolio, which will exacerbate error-in-variable problem for which the portfolio formation for test assets was devised in the first place. Say, forming quintile portfolios for each criteria will result in 625 test portfolios. By using 4 one-way sorted decile portfolios, we are able to keep many firms in a portfolio, which will help reducing idiosyncratic shocks for a given test asset. More importantly, our choice of test assets allows us to decompose pricing errors, in terms of sum of squared pricing errors (henceforth SSPE), into parts that belong to each decile portfolios since this measure of pricing errors is additive. Although it is not a formal test, we can get a sense of what pricing information a certain set of factors contain by looking at the pricing error decomposition; e.g. most of pricing errors on the forty test assets for the Fama-French three factor model are expected to come from momentum and liquidity decile portfolios. ${ }^{26}$ Besides these

\footnotetext{
${ }^{24}$ We are very much grateful to Prof. Ľuboš Pástor for providing us with the decile portfolios data.

${ }^{25}$ Since its introduction in Fama and French (1993), these 25 portfolios have been a challenge for many asset pricing models. However, it is also true that many have claimed that they have succeeded in explaining size and $\mathrm{B} / \mathrm{M}$ effects; the recent list includes, but restricted to Campbell and Vuolteenaho (2004), Brennan, Wang, and Xia (2004), Petkova (2006), Jagannathan and Wang (1996), Bansal, Dittmar, and Lundblad (2005), Parker and Julliard (2005), Hansen, Heaton, and Li (2008), Lettau and Ludvigson (2001), etc. In fact, nowdays it is almost deemed to be very easy fit 25 Fama French portfolios. Our volatility factors are also strongly priced in this set of test assets and achieve very high $R^{2}$. By using 40 test assets, we are putting our models in a bigger challenge.

${ }^{26}$ All of these traded factors take form of spread between two end portfolios although this spread might not be from the decile portfolios.
} 
advantages over the conventional 25 Fama French portfolios, the increased number of test assets alone will be more challenging to any asset pricing models. Bansal, Dittmar, and Lundblad (2005) and Liu and Zhang (2008) also use one-way sorted decile portfolios for their cross-sectional asset pricing studies although they do without liquidity-sorted decile portfolios.

Table 6 shows the average returns of our test portfolios. For each set of decile portfolios, we sorted portfolios in order of their average returns over our sample from 1966 to 1999. Their original portfolio numbers are also listed. If a certain sorting criteria is relevant in cross-sectional dispersion of average returns, the portfolio numbers should be monotonically increasing or decreasing from left to right in Table 6. Momentum portfolios show perfect match between their original portfolio numbers and the order of their average returns. Also, BM- and liquidity-sorted portfolios show pretty good match. For these decile portfolios, the order ranked by their average returns doesn't exactly match with the portfolio numbers. However, the portfolios with number 1-5 at least stay at the first half group and the rest at the latter half group. Lastly, size-sorted decile portfolios show particulary many displacements. Moreover, size-sorted portfolios show the smallest spread between the maximum and minimum average returns: $0.21 \%$ for size-, $0.43 \%$ for BM-, $0.84 \%$ for momentum-, and $0.36 \%$ for liquidity-sorted portfolios.

Since Banz (1981) reported size effect on mean asset returns, many have provided empirical evidence and several potential explanations. ${ }^{27}$ However, in recent studies, many have also reported the disappearance of the size effect. Dichev (1998) and Horowitz, Loughran, and Savin (2000) find no evidence of a size effect in the 1981-1995 and 1979-1995 periods, respectively. Also, Hirshleifer (2001) suggests 1984 as the year in which the disappearance of the size effect first materialized. Our test asset data as shown in Table 6 and results in the cross-sectional studies seem to support these results. However, Hou and Van Dijk (2007) argue that the conclusion that the size effect has

\footnotetext{
${ }^{27}$ See Van Dijk (2006) for a survey of the literature to date.
} 
gone away is premature by showing the reduction in the observed size premium can be attributed to profitability shocks to small and large firms.

\subsection{Volatility Components Estimation}

We estimate daily volatility components, $\tau_{\delta / t}$ and $g_{\delta / t}$, using daily stock market returns from January 3, 1966 to December 31, 1999. The GARCH-MIDAS model with rolling window RV consists of equations (7)-(11) introduced in Section 3.1 and it is fitted to daily stock market return series using QMLE. For the empirical implementation, we also need to choose $J$, the number of RV lags in our MIDAS filter, and $N^{\prime}$, spanning period for rolling window RV. Our choices are $J=125$ and $N^{\prime}=22$. This choice ensures efficient use of RV information and high log-likelihood value among other choices. Note that $J=252$ doesn't mean that $\tau$ process is necessarily a function of all 252 lags of rolling window RV. Typical optimal weighting function for the GARCH-MIDAS with RV has monotonically decreasing structure (i.e. $\omega_{2}=1$ ) and might not put any weights beyond a certain number of lags.

The first row of Table 2 shows the parameter estimates of the GARCH-MIDAS with rolling window RV. Optimal weights $\varphi_{j}\left(\omega_{1}, \omega_{2}\right)$ for the GARCH-MIDAS with RV are monotonically decreasing over the lags so we fixed $\omega_{2}=1$ for these models and left blank at the Table. Note that $\alpha+\beta$ measures persistence of $g_{\delta / t}$ process and the estimates are 0.9216, which is far lower than the standard GARCH model. This finding is also consistent with Engle, Ghysels, and Sohn (2008) and Engle and Rangel (2008). The resulting conditional market volatility and its long-run component are shown in Figure 1. The dashed line in the first panel represents annualized conditional

volatility $\left(\sqrt{252 \tau_{\delta / t} g_{\delta / t}}\right)$ and the solid line annualized long-run component $\left(\sqrt{252 \tau_{\delta / t}}\right)$. The $\tau_{\delta / t}$ component in the figure appears to capture very well the long-run persistent component, free of short-lived shocks, of conditional volatility dynamics. To compare 
with a nonparametric measure of stock market volatility, we aggregate these components to make them quarterly estimates and show them with quarterly RV in the second panel. When aggregated over a quarter, short-lived shocks $g_{\delta / t}$ averages out to one, and we can confirm this in the second panel of Figure $1 ; \tau_{q} \cdot g_{q}$ and $\tau_{q}$ share almost the same dynamics. ${ }^{28}$ Both of them also fit well with quarterly RV.

For both of our VAR analyses and cross-sectional regressions, we time aggregate our daily volatility components $\left(\tau_{\delta / t}, g_{\delta, t}\right)$ to monthly components $\left(\tau_{t}, g_{t}\right)$. The summary statistics of these time aggregated components are shown in Table 1. The autocorrelation structure of $\tau_{t}$ process shows that $\tau_{t}$ is quite persistent, but autocorrelations are substantially reduced by 6th lag and dies out beyond 9th lag. On the other hand, the autocorrelation of $g_{t}$ at the first lag is 0.30 and that is the only significant one. Note that $E\left[g_{\delta / t}\right]=1$ and the way we time aggregate $g_{\delta / t}$ makes the average of monthly $g_{t}$ very close to the average number of trading days (21 days) in a month for our sample.

\subsection{Long-Lag Predictability (GARCH-MIDAS Results)}

The GARCH-MIDAS model allows us to directly link wide choice of variables to long-run component $\tau_{\delta / t}$. All the variables that we are going to consider in this section are monthly, which means that $\tau_{\delta / t}$ is fixed at given month $t$. To accommodate a variety of variables, we adopt equation (12) for modeling $\tau_{\delta / t}$ process instead of equation (9). Using our GARCH-MIDAS framework, we investigate whether conventional factors such as trading strategy based factors (SMB, HML, WML, LIQ) and macroeconomic factors (MP, PPI, UTS, UPR) contain information about future stock market volatility.

In the context of Section 2, we examine the predictability of stock market volatility. Section 2 adopts a VAR framework to link predictability of stock market volatility and priced factors. If we are able to estimate a VAR model of any order with high precision,

\footnotetext{
${ }^{28}$ Since $g_{\delta / t}$ is a unit $\operatorname{GARCH}(1,1)$ process, unconditional expectation of $g_{\delta / t}$ is one, i.e. $E\left[g_{\delta / t}\right]=1$.
} 
a VAR approach might be the best way to analyze the relevant predictability relations. However, as we specify the VAR variables in Section 3.2 , we have 7 variables for both $\mathbf{y}_{t}^{[1]}$ and $\mathbf{y}_{t}^{[2]}$ and the number of parameters to be estimated will increase in the order of 49 as we increase the VAR order. The predictability relations in a VAR model depend on a choice of variables in the system. On the other hand, the GARCH-MIDAS framework looks at bivariate relations between long-run component $\tau$ and a chosen independent variable, and is able to handle a large number of independent variable lags with a small number of parameters. In fact, the number of parameters doesn't depend on the number of lags used to model the long-run component. However, it comes with the cost of a restrictive structure in coefficients of independent variable lags. Beta function based weighting scheme is quite flexible to accommodate various structures, but it should be pointed out that the sign of all the coefficients to the lags are governed by $\theta$ and therefore they have all the same signs. These restrictions call for caution when interpreting the impact of the independent variable on the stock market volatility. In a way the MIDAS filter can be looked upon as a low-frequency filter and, in this sense, the predictablity relations revealed by the GARCH-MIDAS might match better with those by VAR with low-frequency data, say quarterly or biannual data. For an empirical implementation, $J^{\prime}=36$ (months) is chosen, but actual number of lags used in $\tau$ modeling will be determined by the optimal weighting function.

Table 2 shows the results. First of all, $\theta$ 's of the GARCH-MIDAS with SMB, WML, LIQ, MP, and PPI turned out to be significant, which implies that these variables do predict the long-run component of stock market volatility. Among these, WML stands out as a best predictor in terms of log-likelihood value (henceforth LLF). ${ }^{29}$ The GARCHMIDAS $\left(\mathrm{WML}_{t}\right)$ achieves $L L F=29760.64$, which is far higher than that achieved by other models. This can also be verified in Figure 2. It shows that WML captures the

\footnotetext{
${ }^{29}$ Note that LLF's of these models cannot be directly compared with that of GARCH-MIDAS with rolling window RV since we do have different specification for $\tau$.
} 
long-run component of stock market volatility amazingly well. Among the variables that don't contain significant information about the future stock market volatility, HML offers the worst fit by $L L F=29735.59$. Figure 4 also confirms this. $\tau(H M L)$ in Figure 4 is flat when compared with $\tau(W M L)$ in Figure 2. If a candidate predictor in the MIDAS filter does not contain much information about the future market volatility, the estimation procedure sets $\theta, \omega_{1}$, and $\omega_{2}$ such that $\tau$ process becomes essentially a constant and works only as a scale factor to the $g$ process, a unit $\operatorname{GARCH}(1,1)$.

To measure how much $\tau$ of a certain variable explains the variation of conditional variance estimates $(\tau \cdot g)$, we compute the ratio: $\operatorname{Var}\left(\log \left[\tau_{\delta / t}(\bullet)\right]\right) / \operatorname{Var}\left(\log \left[\tau_{\delta / t}(\bullet) g_{\delta / t}\right]\right)$ where $\bullet$ refers to a specific variable. We call it a variance ratio and these numbers are also reported in Table 2. It is not suprising to find out that $\tau(R V)$ explains $43 \%$ of market volatility variation. $\tau(W M L)$ and $\tau(L I Q)$ also perform quite well with $31 \%$ and $22 \%$ of variance ratios. The other variables shown to predict market volatility achieve mere $15-16 \%$. Figure 3 also confirms this finding. An interesting observation is that $\tau(S M B)$ seems to capture dynamics of long-run component of market volatility pretty well up until 1984, but it decouples from conditional volatility in 1985. Variance ratio also supports the observation: var ratio $=0.2187$ (1966-1984) and 0.0495 (1985-1999). Although not reported here, $\tau(M P)$ and $\tau(P P I)$ show similar behavior. Regrading SMB, this might have something to do with the argument of Hirshleifer (2001) who suggests 1984 as the year in which the disappearance of the size effect first materialized.

\subsection{Short-Lag Predictability and Base Factor Estimation (VAR Results)}

Now that we have monthly volatility component series, $\tau_{t}$ and $g_{t}$, we can conduct

the VAR analyses discussed in Section 3.2. For a given set of variables in either $\mathbf{y}_{t}^{[1]}$ or $\mathbf{y}_{t}^{[2]}$ in Section 3.2, we estimate the VAR model. The order of the VAR was determined 
on the basis of the likelihood and the Schwarz's information criterion (SIC). The optimal order for the VAR with $\mathbf{y}_{t}^{[1]}$ is 3 and that with $\mathbf{y}_{t}^{[2]}$ is 4 .

Table 3 and Table 4 show the VAR estimation results. For both of the tables, Panel A shows the VAR results with $\mathbf{y}_{t}^{[1]}$ and Panel $\mathrm{B}$ with $\mathbf{y}_{t}^{[2]}$. Table 3 shows $p$ values for the F-tests on each variable. The F-tests reflect the incremental ability of the column variable to predict the respective row variables, given the other variables in the model. ${ }^{30}$ The asset pricing equation (17) suggests that variables that forecast either $r_{m, t}$ or $\tau_{t}$ should be priced. The results in Panel A shows that lags of $\tau, g, f^{W M L}$ strongly predict the long-run market volatility component and the factors generated from these variables are expected have strong explanatory power on cross-sectional variations of mean asset returns. Although not significant at $5 \%$ level, $f^{L I Q}$ weakly predicts $\tau$. Also, $f^{S M B}$ weakly predicts $r_{m}$. As was discussed previously, the predictability relations in a VAR model are affected by the choice of variables in the system. However, the forecasting ability of $\tau, g$, and $f^{W M L}$ on the long-run stock market volatility component are robust to various choices of VAR variables and various VAR orders. For some choices of VAR variables and VAR orders, $f^{S M B}$ and $f^{L I Q}$ predict $\tau$ quite strongly. However, for the current specification, $f^{S M B}$ weakly predicts $r_{m}$ and strongly predicts $f^{W M L}$ which strongly predicts $\tau$ while $f^{S M B}$ does not predict $\tau$ directly. The far right column shows $R^{2}$ of each equation. $R^{2}$ 's of the equations for $f^{S M B}, f^{H M L}, f^{W M L}$, and $f^{L I Q}$ are very low suggesting that the correlations between these and corresponding $\epsilon^{S M B}, \epsilon^{H M L}$, $\epsilon^{W M L}$, and $\epsilon^{L I Q}$ should be very high; at least $95 \%$.

Panel B of Table 3 shows the VAR F-test results with macroeconomic variables. As in the case with traded factors, $\tau$ and $g$ are strong predictors of future $\tau$. In addition to these variables, $M P$ and $P P I$ weakly predicts future stock market volatility.

\footnotetext{
${ }^{30}$ In a part, these F-tests investigate which variable predicts stock market volatility. These results partly answer the main research question that Schwert (1989) answered about two decades ago. However, Schwert (1989) looks at predictability relations between $\sqrt{R V}$ and macroeconomic variables while Table 3 shows the results between $\tau_{t}$ and other variables. Note that $\tau_{t} \cdot g_{t}$ is a forecasts of $R V_{t}$ and not of $\sqrt{R V_{t}}$.
} 
These predictability relations are also consistent with those revealed by the GARCHMIDAS model in Table 2. Many have reported that term spread UTS predicts market return and our results also support this finding. We expect MP, PPI, and UTS to be priced across assets. One notable differences in Panel $\mathrm{A}$ and Panel $\mathrm{B}$ are that $R^{2}$ 's of equations for the last four variables are higher in Panel B and naturally there are many significant predictors for these variables. Especially, consistent with autocorrelations shown in Table 1, variations of term spread UTS and default premium UPR are explained 92-95\%. These results suggest that MP, PPI, UTS, and UPR cannot be deemed as innovations as asserted by Chen, Roll, and Ross (1986). On the contrary, traded factors themselves seem to be good proxies for innovations. Hence, these results support our decision that traded factors themselves are taken as base factors while innovations $\left(\epsilon^{\bullet}\right)$ of macroeconomic variables are taken as base factors.

One concern with regard to the generated factors from the VAR model is that the VAR system may not, in fact is highly unlikely to contain the full information set used by investors. Also, since the VAR system with $\mathbf{y}_{t}^{[1]}$ and one with $\mathbf{y}_{t}^{[2]}$ contain different set of variables, $\tau_{t}$ and $g_{t}$ innovation factors from these two different VAR systems might differ much. First of all, the correlation between $\epsilon_{t}^{\tau[1]}=f_{t}^{\tau[1]}$ from the VAR model with $\mathbf{y}_{t}^{[1]}$ and $\epsilon_{t}^{\tau[2]}=f_{t}^{\tau[2]}$ from that with $\mathbf{y}_{t}^{[2]}$ is 0.90 and correlation between similarly defined $f_{t}^{g[1]}$ and $f_{t}^{g[2]}$ is 0.98 ; the innovation factors from two different systems are strongly correlated. Secondly, we check if macroeconomic variables in $\mathbf{y}_{t}^{[2]}$ should be added to $\mathbf{y}_{t}^{[1]}$; we add macroeconomic variables to $\mathbf{y}_{t}^{[1]}$ one by one to see if the added variable becomes a significant predictor of any variables in $\mathbf{y}_{t}^{[1]}$. We do the same for the $\mathbf{y}_{t}^{[2]}$. For both robustness checks, in some cases, added variable turns out to be significant in predicting either the added variable itself or market return. However, the increase in $R^{2}$ of market return equation is marginal. Hence, we conclude that the benefit of adding $\mathbf{y}^{[2]}$ (or $\mathbf{y}^{[1]}$ ) variables to $\mathbf{y}^{[1]}$ (or $\mathbf{y}^{[2]}$ ) is very limited while innovations to volatility components from two different VAR specifications are essentially the same. 
Table 4 shows parameter estimates for $\tau_{t}$ equation for both VAR models with $\mathbf{y}_{t}^{[1]}$ and $\mathbf{y}_{t}^{[2]}$. For both specifications, most of $\tau$ and $g$ lags are significant. Note that the variables (HML, UTS, and UPR) that are not significant in the GARCH-MIDAS results in Table 2 don't have any significant lags in Table 4, either. For those significant at Table 2, the sign of $\theta$ coincide with the sign of coefficient to the significant lag of the corresponding variable in Table 4 except for $f^{L I Q} .31$ One might think these seemingly consistent positive/negative relations between stock market volatility and variables of our interest would determine the sign of price of risk of the variable. However, it is not that simple. The asset pricing equation (17) guides us on how prices of risk should be determined. The price of risk of a certain base factor, say $f_{t}^{g[1]}=\mathbf{e}_{3}^{\prime} \epsilon_{t}^{[1]}$, is determined by two part; one that relates to forecasting future market returns and the other future market volatility. Also, since $\lambda_{n}$ and $\xi_{n}$ are determined as in equation (14)-(15), it is not only the coefficient of one significant lag, but all the parameters in the VAR model that affect the determination of the price of risk of the factor. Lastly, the structural parameters such as $\gamma$ and $\sigma$ should be known beforehand or jointly estimated to determine the price of risk. It is not our interest in this study to recover these structural parameters. Moreover, cross-sectional regressions give us only the price of risk as a whole (i.e. $\Lambda_{n}$ as in equation (18)), but not a break down of future market return part and future market volatility part. Hence, it is beyond the scope of this paper to examine the theoretical values of prices of risk.

We estimate both VAR specifications and collect the base factors. Table 5 shows the correlation structure of the base factors. It shows the contemporaneous relations among innovations (base factors) to the VAR variables whereas we've been so far looking at the time-series relations of VAR variables themselves. Within each group of volatility-based factors, traded factors, and macroeconomic factors, some factors are highly correlated. However, most of factors across the groups show fairly low correlations. Low correlations

\footnotetext{
${ }^{31}$ For SMB, there is no significant lag, but the sign of $\theta$ in GARCH-MIDAS(SMB) coincides with that of the first SMB lag which has the largest $t$-stat among three lags.
} 
do not necessarily mean that two factors are irrelevant in the cross-sectional studies. In principle, the fact that two factors are strongly correlated does not mean these two factors have similar correlation strucutres with various assets. In other words, even if a factor A explains the cross-section of various mean asset returns and another factor B is strongly correlated with the factor A, we cannot argue for sure that the factor B would do the same unless we look at the joint distribution of factor A, B and all the assets. Also, Lewellen, Nagel, and Shanken (2006) show that it is not the correlations between two sets of factors (say F and P), but zero correlations of residuals of time-series regression of one set of factors $(\mathrm{F})$ on the asset returns and the other factors $(\mathrm{P})$ that matters in cross-sectional regressions. 


\section{Cross-Section of Equity Returns}

The asset pricing equation (17) is an extension of the theoretical framework in Campbell (1993). However, unlike its empirical work in Campbell (1996) where the GMM is adopted, we use the Fama and MacBeth (1973) procedure for testing the crosssectional explanatory power of factors. The idea of equation (17) is that the innovations of the variables that forecast either market return or market volatility should be priced. In other words, the variables that forecast either of these two very well should also generate factors that are strongly priced across assets. This approach is somewhat different from conventional asset pricing models where a true model is assumed. To test such a conventional model, we conduct specification tests by adding other factors to the true model and see if the added factor turns out to be significant. Although it may seem the same empirically, we run a horse race of various factors discussed so far; volatility-based factors, trading strategy based factors, and macroeconomic factors. However, our perspective on this horse race is not a specification test because we don't have a true model. The idea behind the horse race is the prediction of our model in (17); the more strongly a variable predicts either market return or market volatility, the better explanatory power over cross-section of equity returns the factor generated from the variable will have.

Adopting the Fama-MacBeth procedure gives us some disadvantages and some advantages. First of all, the Fama-MacBeth procedure allows us to estimate $\Lambda$ 's in equation (18), but it does not allow us to recover structural parameters such as $\gamma$ and $\sigma$ or breakdown of $\lambda_{n}$ 's and $\xi_{n}$ 's. Also, by taking a two-step approach of first generating the factors by the VAR estimation and secondly running the Fama-MacBeth regressions, 
we run into a generated-regressors problem in standard errors. On the other hand, if one-step estimation using the GMM as in Campbell (1996) is used, the standard errors for the parameters are adjusted to reflect the fact that factors are generated from the VAR model. Although we make corrections to the standard errors using a method proposed by Jagannathan and Wang (1998), this does not take care of generated-factor problem in the time-series regression. However, as pointed out by Pagan (1984), the OLS estimates of the parameters' standard errors will still be correct if the generated regressor represents the unanticipated part of a certain variable. On the other hand, if the factors are only noisy proxies for the true surprises in the state variables, then the estimates of the factor loadings in the regression will be biased downward, which in turn would bias the results against finding a relation between the innovations and asset returns.

The GMM comes with its own problems. The GMM with estimated optimal weighting matrix suffers from the small-sample problem especially when there is a large number of test assets; we use 40 test portfolios. When cross-sectional sample size is large and time-series sample size is relatively small, the optimal GMM weighting matrix of Hansen (1982) are likely to be poorly estimated. In this case, Cochrane (2001) recommends using the GMM with the identity weighting matrix as a robustness check. Also, Altonji and Segal (1996) show that the first-stage GMM estimates using the identity matrix are far more robust to small-sample problems than the GMM estimates in which the criterion function has been weighted with an estimated matrix. And, it turns out that, as Cochrane (2001) pointed out, the Fama-MacBeth methodology is practically the same as the first-stage GMM, where the identity weighting matrix is used. In this sense, the Fama-MacBeth methodology is more robust than the second-stage GMM.

We use four decile portfolios, each of which is sorted by size, book-to-market ratio, momentum, and liquidity. These were chosen carefully to represent economically interesting characteristics. However, when an estimated weighting matrix is used in the 
GMM estimation, test portfolios become linear combinations of the original portfolios, which can be difficult to interpret economically and can even imply implausible long and short positions in the original assets. ${ }^{32}$ The Fama-MacBeth methodology or the firststage GMM with the identity weighting matrix allows us to focus asset pricing tests on the original test portfolios constructed carefully based on economically interesting characteristics.

\subsection{Cross-Sectional Regression}

There are three groups of factors that we are interested in; volatility based factors, trading strategy based factors, and macroeconomic factors. For traded factors, we consider SMB, HML, WML, and LIQ. The volatility factors are motivated by Chen (2003). Ang, Hodrick, Xing, and Zhang (2006) and Adrian and Rosenberg (2008) empirically show that the aggregate volatility risk is strongly priced across assets. We use two component volatility model, the GARCH-MIDAS model with rolling window RV, to estimate short- and long-run volatility components. From the innovations to these series, we construct short- and long-run volatility factors.

Chen, Roll, and Ross (1986) proposed a linear factor model of macroeconomic variables. The macroeconomic variables investigated as factors are of MP, UI, DEI, UTS, and UPR. ${ }^{33}$ They argue that these macroeconomic variables as they are defined in the paper are noisy enough to be treated as innovations. However, our VAR analysis show that these variables are quite predictable, and hence we take innovations to these variables from the VAR model as our base factors rather than the variables themselves. Shanken and Weinstein (2006) revisit the model and raise concerns about the lack of

\footnotetext{
${ }^{32}$ See Cochrane (2001) for more detail arguments.

${ }^{33}$ Chen, Roll, and Ross (1986) argue that, since $\mathrm{IP}_{t}$ is the flow of industrial production during month $t, \mathrm{MP}_{t}$ measures the change in industrial production lagged by at least a partial month. To make this variable contemporaneous with other series, their statistical work lead it by 1 month and we folllow this convention.
} 
robustness of the results in Chen, Roll, and Ross (1986). Chen, Roll, and Ross (1986) use 20 size-sorted portfolios as their test assets, but Shanken and Weinstein (2006) find that their results are surprisingly sensitive to the specific way in which the portfolio returns are generated and $\beta$ 's are estimated. Also, Shanken and Weinstein (2006) obtain strong evidence of pricing only for MP and market factor. Our results confirm their concerns and results.

The predictability analyses in Section 4.3 and 4.4 imply that $f^{\tau}, f^{g}, f^{W M L}$, and $f^{U T S}$ should be strongly priced among all the factors since the variables that generated first three are very strong predictors of stock market volatility and UTS predicts future market return very strongly. SMB, LIQ, MP, and PPI seem to contain fair amount of information about future market volatility and SMB future market return. However, HML and UPR seem to have no link to either future market returns or future market volatility. The implications from these predictability analyses will be thoroughly investigated in the following horse race of the factors. However, before we get into the horse race, we would like to check how each of these three factor groups performs on our 40 test assets in the first place.

To test the explanatory power of factors chosen, we use the Fama and MacBeth (1973) cross-sectional regression. Our test assets are four different decile portfolios sorted by size, book-to-market ratio, momentum, and liquidity. The monthly returns on these portfolios from July, 1966 to December 1999 are used for the cross-sectional studies. Section 4.1 discusses these portfolios as test assets in detail.

First, we specify a time-series regression that provides estimates of the assets' loadings:

$$
R_{i, t}=a_{i}+\sum_{s=1}^{S} \beta_{i, s} F_{t}^{s}+e_{i, t} \quad \forall i \in\{1, \ldots, I\}
$$

where $R_{i, t}$ is the simple return of asset $i$ at the end of month $t$, and $\left\{F^{s}\right\}_{s=1, \ldots, S}$ is a group of factors chosen from base factors or orthogonalized factors. We obtain full- 
sample $\beta$ 's by running the above time-series regression for the full sample. The second step of the Fama-MacBeth procedure is to run a cross-sectional regression with estimated full-sample $\beta$ 's:

$$
R_{i, t}^{e}=\sum_{s=1}^{S} \Lambda_{s} \hat{\beta}_{i, s}+\alpha_{i, t} \forall t \in\{1, \ldots, T\}
$$

where $R_{i, t}^{e}$ is the return on asset $i$ in excess of the risk-free rate at the end of month $t$ and $\Lambda_{s}$ 's are the prices of risk for the factor $s$. A couple of things should be noted. One is that we impose the null that average pricing error is zero by not including a constant in equation (21). The other is that we are running time-series regressions with simple returns on assets while cross-sectional regressions with excess returns on assets. Since risk-free rates are predetermined ahead of time (and that's why they are risk-free rate), $\beta$ 's of returns on the risk-free asset should be all zero. However, if we run timeseries regression with asset returns in exess of risk-free rate, the estimated $\beta$ 's will be contaminated from the spurious non-zero $\beta_{i, f}{ }^{\prime}$ s. ${ }^{34}$

\subsubsection{Volatility Component Factors}

We start with a set of market and volatility factors, $\left\{R_{m, t}^{e}, f_{t}^{\tau}, f_{t}^{g}\right\}$. Table 6 and Table 7 show these results. The volatility factors can be generated from the VAR models; one with $\mathbf{y}_{t}^{[1]}$ and the other $\mathbf{y}_{t}^{[2]}$. The results of the former is presented at Table $7(i)$, and those of the latter at Table $7(i i)$. For a both variable choices, the estimated prices of risk show huge differences across factors in magnitude. ${ }^{35}$ This can be understood

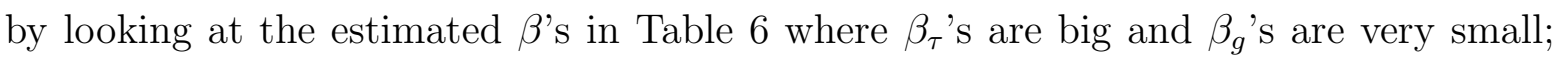
the volatility risk premiums calculated as $\beta \cdot \Lambda$ will be in comparable magnitude with those from market risk. All the prices of risk estimated are turned out to be significant in terms of $t$-stats computed with Jagannathan and Wang (1998) corrected standard

\footnotetext{
${ }^{34}$ For detailed arguments, see Appendix C.

${ }^{35}$ Prices of risk are expressed as percentage of month.
} 
errors. ${ }^{36}$ To obtain asymptotic covariance matrix of Jagannathan and Wang (1998), we also used Newey and West (1987) adjustment for autocorrelation.

For overall performance measures for a given choice of factors, we provide three statistics; cross-sectional $R^{2}$, root mean squared pricing error (henceforth RMSPE), and pricing error decomposition. When full-sample $\beta$ 's are used in the Fama-MacBeth crosssectional regression, the estimated prices of risk are identical to those obtained from cross-sectional OLS regression where mean asset returns are regressed on $\beta$ 's. Hence, we report cross-sectional $R^{2}$ as defined in a cross-sectional OLS regression since it is an informative summary statistic which reflects how well the model fits the data. Although it is a very intuitive measure, it should be interpreted with caution. Jagannathan and Wang (1996) point out that a low $R^{2}$ does not necessarily indicate that a particular specification is bad in any absolute sense. Also, Lewellen, Nagel, and Shanken (2006) warn that the high $R^{2}$ 's reported in the literature aren't nearly as impressive as they might appear. With simulated artificial factors, Lewellen, Nagel, and Shanken (2006) show that the power of the test is extremely small for three or five factors; the sampling distribution of the adjusted $R^{2}$ is almost the same when the true $R^{2}$ is zero and when it is as high as $70 \%$ or $80 \%$.

RMSPE is defined as $\sqrt{\sum_{i}\left(\hat{\alpha}^{i}\right)^{2} / I}$ where $\hat{\alpha}^{i}=\sum_{t} \hat{\alpha}_{i, t}$ and $\hat{\alpha}_{i, t}$ is the fitted error from cross-sectional regression in (21). It measures how big the average pricing errors are. The advantage of using this measure of pricing errors and four different decile portfolios as test assets is that we can compute the pricing error decomposition (henceforth PED) as shown in Table 7. The numbers shown as pricing error decomposition are the ratios of sum of squared pricing errors (henceforth SSPE, $\left.\sum_{i}\left(\hat{\alpha}^{i}\right)^{2}\right)$ that belong to a certain decile portfolios to the total SSPE. Hence, the numbers in pricing error decomposition always

\footnotetext{
${ }^{36}$ Shanken (1992) shows how to take into account the sampling errors in the $\beta$ 's obtained in the first stage under the assumption that, given the realization of factors, asset returns show conditional homoskedasticity. Jagannathan and Wang (1998) extend Shanken (1992) and derive asymptotic distribution of the estimators without assuming conditional homoskedasticity.
} 
sum up to one. Hence, we can recover SSPE for any decile portfolios. Say, SSPE(size)= $\mathrm{RMSPE}^{2} \times I \times \operatorname{PED}($ size $)$.

Back to Panel A of Table 7, all the measures for the performance of two volatility factor models are very close showing that $f_{t}^{\tau[1]}$ and $f_{t}^{g[1]}$ are essentially the same as $f_{t}^{\tau[2]}$ and $f_{t}^{g[2]}$. Note that prices of risk for $f^{\tau}$ and $f^{g}$ are both significant and both negative, supporting the empirical results of Adrian and Rosenberg (2008). The estimated $\beta$ 's from model $(i i)$ of Table 7 are listed in Table 6 and $\beta_{\tau}$ 's are especially well-aligned with average asset returns of momentum- and liquidity-sorted decile portfolios. In case of momentum portfolios, $\beta_{\tau}$ 's are monotonically decreasing except for the \#9 and \#10 portfolios. Except for \#5, \#7, and \#8 portfolios, $\beta_{\tau}$ 's are also well lined up with liquidity portfolios.

Figure 5 and 6 plot expected returns fitted by volatility factor model as specified in (ii) of Table 7 against their realized average returns. Figure 5 and 6 present the same thing. However, since we use four different one-way sorted decile portfolios, we can plot fitted expected returns against realized average returns on each decile portfolios separately as in Figure 6 and we call it a 'disaggregative view.' These figures also show fitted pricing errors, $\hat{\alpha}^{i}$, in very intuitive way; for each portfolio plotted, the vertical distance to the 45 degree line is the average pricing error. Pricing error decomposition in Table 7 and Figure 6 give us very intuitive ideas about how the given factor model performs over a certain decile portfolios sorted by economically interesting characteristics. The pricing error decomposition shows that our volatility factor model performs poor on a decile portfolios sorted by book-to-market ratio because almost the half $(46 \%)$ of total SSPE comes from these portfolios. Figure 6 confirms this. The pricing error decomposition also suggests that the volatility factor model performs fairly poor on momentum portfolios. However, Figure 6 tells us a different story. It turns out that most of the pricing errors come from extreme portfolios on the right $(\# 10)$. The squared pricing errors of \#10 momentum portfolio $\left(\left(\hat{\alpha}^{10}\right)^{2}\right)$ is more than the double the 
sum of the squared pricing errors of all the rest (\#1-\#9). In fact, the volatility model prices momentum portfolios very well except for the portfolio \#10.

Various specifications in Panel B of Table 7 are to compare $f_{t}^{\tau}$ and $f_{t}^{g}{ }^{37}$ Although both factors are significantly priced in Panel A, Panel B shows interesting results. $t$-stat for $f_{t}^{g}$ in model $(i v)$ of Table 7 is fairly strong, but $R^{2}$ is near zero and RMSPE soars up to 0.00164 . On the contrary, one factor model of $f_{t}^{\tau}$ in $(v)$ shows very impressive performance. In every measure, the one factor model performs very close to three factor model in $(i)$ and $(i i)$. Figure 7 presents this result. Figure 7 and Figure 6 are essentially the same showing that even pricing errors are similarly distributed.

The Orthogonalized factor specifications in Panel $\mathrm{C}$ in Table 7 show many of observations in Panel A and B more clearly. As was discussed in Section 3.2, the order of variables in the VAR model do matter in the construction of orthogonalized factors, and hence we report the order as well in the table. For model (vi) and (vii), the first three variables in $\mathbf{y}_{t}^{[2]}$ are ordered as they are shown in Panel $\mathrm{C}$ of Table 7 whereas the rest are ordered in the same way as $\mathbf{y}_{t}^{[2]}$ in Section 3.2. Then, we follow Campbell (1996) and Sims (1980) and triangularize the VAR system so that innovations are orthogonal to one another. In the model (vii) of Table 7, the orthogonalization doesn't affect the market factor in the sense that $u_{m, t}$ is still identical to the first element of $\epsilon_{t}^{[2]}$. However, $u_{t}^{\tau[2]}$ is the corresponding component of the $\epsilon_{t}^{[2]}$ without the common component with $u_{m, t}=\mathbf{e}_{1}^{\prime} \epsilon_{t}^{[2]}$. Similarly $u_{t}^{g[2]}$ is the corresponding component of $\epsilon_{t}^{[2]}$ orthogonal to both the market return and the long-run volatility component, and so on. Since these factors are orthogonalized, they might be quite different from the corresponding base factors. This is especially true for $u_{t}^{\tau}$ and $u_{t}^{g}$ because $f_{t}^{\tau[2]}$ and $f_{t}^{g[2]}$ are faily correlated $(0.55$ in Table 5). However, three orthogonalized factors in (vi) and (vii) as a group do span about the same space as in $(i i)$ and hence all the performance measures are similar; this is a common feature in all orthogonalized factor specifications. In addition to the ${ }^{37} f^{\tau}$ and $f^{g}$ in Panel B are estimated from VAR model with $\mathbf{y}_{t}^{[2]}$. 
orthogonalization, we rescaled the factors to have the same variance as the innovations to the market return $\left(u_{m, t}\right)$ and this resolves the problem of drastically varying magnitudes in estimated prices of risk in $(i)$ and $(i i)$. The model $(v i)$ and $(i i)$ of Table 7 are from the same VAR specification including the same ordering of variables in $\mathbf{y}_{t}^{[2]}$, but the factors in $(v i)$ are orthogonalized while those in $(i i)$ are not. And, this makes a large difference in $t$-stats of estimated prices of risk. Although $f_{t}^{g}$ is significantly priced in $(i i)$, it loses its significance when it is orthogonalized to the market return and long-run volatility component factor. On the contrary, when the order of $\tau_{t}$ and $g_{t}$ is reversed in $\mathbf{y}_{t}^{[2]}$ as in Table 7 (vii), i.e. common shocks to $\tau_{t}$ and $g_{t}$ have been elminated from $f_{t}^{\tau}$ but not from $f_{t}^{g}$, the long-run volatility component factor loses some of its explanatory power in cross-sectional variation of mean asset returns but still fairly priced unlike $f_{t}^{g}$ in Table 7 (vi). This is consistent with our VAR predictability results; although $p$-values for both $\tau_{t}$ and $g_{t}$ are far less than 0.01, that for $\tau_{t}$ is smaller than that for $g_{t}$. Being the better predictor, $\tau_{t}$ generates a factor that encompasses the pricing information of $g_{t}$ innovation factor.

To further examine the information content in $f_{t}^{\tau}$, or what pricing information (among SMB, HML, WML, and LIQ) $f_{t}^{\tau}$ captures, we run the Fama-MacBeth regressions with one factor model of $f_{t}^{\tau}$ on each of decile portfolios separately. For comparison, we also run cross-sectional regressions with the market factor and the corresponding traded factors that are directly related to the decile portfolios. Note that these traded factors take a form of a spread between two end portfolios (say, \#10 and \#1), and they are designed to explain the cross-sectional variation of the corresponding decile portfolios. Table 8 shows these results. In terms of $R^{2}$ and RMSPE, one factor model of $f_{t}^{\tau}$ performs close to the two factor model with the corresponding traded factors in case of size- and liquidity-sorted decile portfolios. ${ }^{38}$ For the momentum portfolios, one factor model of

\footnotetext{
${ }^{38}$ When we add market factor to $f_{t}^{\tau}$, they get even closer to the two factor models on the left hand side of the Table 8.
} 
$f_{t}^{\tau}$ achieves $R^{2}=0.80$, but RMSPE is huge when compared with that achieved by the corresponding two factor model. As is pointed out previously, this is due to the large mispricing of \#10 momentum portfolio; if we eliminate \#10 portfolio, and test on remaining 9 portfolios, RMSPE of two traded factor model reduces to 0.0003574 while that of $f_{t}^{\tau}$ model drastically reduces to 0.0004866 from 0.0011503 . These results are also consistent with pricing error decomposition for model $(i)$ and $(i i)$ in Table 7 . All these empirical evidences suggest that our $f_{t}^{\tau}$ factor summarizes pricing information in SMB, WML, and LIQ. In a similar sense, we have to conclude that we cannot link HML to stock market volatility. ${ }^{39}$ These results are largely consistent with our results in the predictability tests shown in Table 2 and 3 ; each of $\left\{\tau_{t}, f_{t}^{S M B}, f_{t}^{W M L}, f_{t}^{L I Q}\right\}$ is shown to predict future stock market volatility. The asset pricing equation (17) implies that these factors should be priced across assets. Moreover, since $\tau_{t}$ is the strongest predictor of future stock market volatility $\left(\tau_{t+1}\right)$, we won't be surprised to find out that $f_{t}^{\tau}$ wins the horse races against these factors. In this context, it is also reasonable to find out $f_{t}^{\tau}$ contains pricing information of these traded factors in the set. What is also interesting in Table 8 is that the prices of risk for single $f_{t}^{\tau}$ factor model estimated over each of decile portfolios are strikingly similar to one another although they are all estimated separately. This explains why one factor model of $f_{t}^{\tau}$ performs well over total test assets of 40 portfolios.

\subsubsection{Trading Strategy Based Factors}

Table 9 shows results of cross-sectional regressions with trading strategy based factors. Panel A of Table 9 present the results with base factors. Note that the base factors of traded factors are by no means modified or corrected; they are in their original

\footnotetext{
${ }^{39}$ The predictability results show that HML does not contain the information about the future market volatility, and the our cross-sectional studies show that the volatility factor does not contain pricing information of HML as well. It is possible that the linkage to HML got lost in the simplification of $V_{i \eta, t}$ in (4). HML might relate to the covariance of consumption growth and market return although this link is not examined in the paper.
} 
form from the data decribed in Section 4.1. Model $(i)$ in Table 9 follows Fama and French (1993) three factor model specification and miserably fails to explain cross-sectional variation of mean asset returns with majority (93\%) of SSPE incurred by momenum and liquidity decile portfolios; note that the momentum and the liquidity factors are missing from the model. Three factor models of the market factor and two of any traded factors (SMB, HML, WML, LIQ) show performance that are not significantly different from ( $i$ ) in Table 9; $\left\{R_{m, t}^{e}, f_{t}^{H M L}, f_{t}^{W M L}\right\}$ performs the best among those with $R^{2}=0.19$ and $\mathrm{RMSPE}=0.001506$. All the configurations of the three factor models share a common feature that most of SSPE incurred by two decile portfolios which are related to the other two missing traded factors.

Carhart (1997) suggests a four factor model as specified in (ii) in Table 9. Table 9 (iii) adopts $f_{t}^{L I Q}$ instead of $f_{t}^{W M L}$. In fact, these two models are the best performers among other possible configurations of four traded factor models and these models perform roughly similar to the one factor model of $f_{t}^{\tau}$. As in three traded factor models, it is interesting to see that most (61\% in (ii) and $80 \%$ in (iii)) of SSPE incurred by the decile portfolios that are related to the missing factor (LIQ in (ii) and WML in (iii)). It is only when all four traded factors in addition to the market factor are added that performance measures jump to a different level; roughly $R^{2}$ doubles and RMSPE halves when compared with any four traded factor models. However, Lewellen, Nagel, and Shanken (2006), with simulated artificial factors, show that the power of the test is extremely small for three or five factors; the sampling distribution of the adjusted $R^{2}$ is almost the same when the true $R^{2}$ is zero and when it is as high as $70 \%$ or $80 \%$. We are also very skeptical about the performance measures for the five factor model in Table 9 (iv). One of the empirical evidence that supports this skepticism is that most of SSPE is incurred by the decile portfolios that are related to the traded factors mising from the specified model. This implies that, in order to correctly price a certain decile portfolios, one needs to include the traded factor that is generated from the spread of that decile 
portfolios; a traded factor seems to correctly price only the decile portfolios, the spread of which generated the factor.

Although we do not report in Table 8, we run cross-sectional regressions of various configurations of two traded factor model, a market factor and one of traded factors, on one of four decile portfolios. These results shed light on the characteristics of the traded factors. What is surprising is that these two factor models perform quite well even on the decile portfolios which are irrelevant to the added traded factor. However, the problem is that the estimated price of risk varies drastically depending on the choice of test decile portfolios. For an example, when we run cross-sectional regressions of two factor model, $\left\{R_{m, t}^{e}, f_{t}^{W M L}\right\}$, on size-, BM-, and liquidity-sorted decile portfolios separately, the estimated prices of WML risk are 0.0008 (0.11), -0.0199 (-1.93), 0.0150 (2.05) with very high $R^{2}$ 's regardless of a choice of decile portfolios. ${ }^{40}$ This is a common feature in most of the two factor models investigated in the same way. This implies that the loadings on any traded factor, say $f_{t}^{W M L}$, can potentially fit the cross-sectional variation of mean returns in all four decile portfolios. However, a two traded factor model, say $\left\{R_{m, t}^{e}, f_{t}^{W M L}\right\}$, cannot fit mean returns of all four decile portfolios together because the prices of the factor risk (WML in this case) that will fit each of decile portfolios differ so much. When we include all four traded factors in addition to the market factor as in Table $9(i v)$, loadings of a traded factor $\left(e . g f_{t}^{W M L}\right)$ for the corresponding decile portoflios (e.g. momentum portfolios) are far larger than loadings of the same factor for other decile portfolios. This is quite reasonable since a traded factor and the decile portfolios that generated this factor should be highly correlated and Table 10 confirms this idea. ${ }^{41}$ Table 10 presents factor loadings for five factor model of Table $9(i v)$ averaged

\footnotetext{
${ }^{40}$ The numbers in the parenthesis are the $t$-stats computed with Jagannathan and Wang (1998) corrected standard errors. The price of WML risk is 0.0088 for momentum decile portfolios (See Table $8)$.

${ }^{41}$ In Table 10, the average loadings of $f_{t}^{W M L}$ on momentum portfolios show a different bahavior when compared with loadings on other factors for their corresponding decile portfolios. This is partly because the loadings of $f_{t}^{W M L}$ on momentum portfolios switch sign from (-) to (+) and partly because it seems
} 
over each decile portfolios. This allows the model to fit the mean returns of a decile portfolio fitted by the corresponding traded factor; essentially, a traded factor needs to price only the corresponding decile portfolio. For an example, the mean returns of size-sorted decile portfolios are dominantly determined by the SMB since factor loadings of $f_{t}^{S M B}$ are far larger than those of other traded factors and at the same time the prices of risks shown in Table $9(i v)$ are in comparable magnitude. Hence, we suggest that the performance measures of the five factor model in Table $9(i v)$ should be interpreted with caution and are not as impressive as they appear.

Panel B of Table 9 presents the results for the same set of model specifications in Panel A, but with orthogonalized factors. The VAR variables for construction of orthogonalized factors in Table 9 are ordered as $\mathbf{y}_{t}^{[1]}$ in Section 3.2. Hence, although $f_{t}^{\tau}$ and $f_{t}^{g}$ are not included in the examined factor specifications in Panel B of Table 9, all the orthogonalized traded factors such as $u_{t}^{S M B}$ are orthogonal to $f_{t}^{\tau}$ and $f_{t}^{g}$ as well as $r_{m, t}$. However, orthogonalizing the traded factors with respect to $f_{t}^{\tau}$ and $f_{t}^{g}$ will not drive the traded factors far away from their base factor form since Table 5 shows that all the traded factors have very low correlations with $f_{t}^{\tau}$ and $f_{t}^{g}$. On the other hand, Table 5 shows the traded factors are fairly correlated with one another and market factor and these correlation structure will take much effect in the factor orthogonalization. As was observed in Table 7, the performance measures in Panel A and Panel B are very close for the matching specifications. An interesting observation is that there are only a few significantly priced traded factors in Panel A while HML, WML, and LIQ are consistently priced in Panel B. Also, in consistence with many articles reporting that the size effect is not significant from early 1980's, the $t$-stats for the price of size risk are near zero even in the orthogonalized factor specifications.

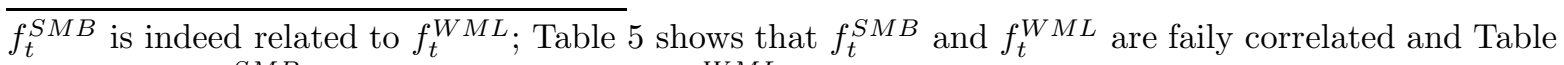
3 shows that $f_{t}^{S M B}$ strongly predicts future $f_{t}^{W M L}$. 


\subsubsection{Macroeconomic Factors}

Chen, Roll, and Ross (1986) suggest a linear factor model of macroeconomic variables. Unlike the trading strategy based factors, the macroeconomic factors represent very intuitive macroeconomic risks. This is why many have tried to link less intuitive trading strategy based factors to macroeconomic factors to offer risk-based explanations for the strong explanatory power of the traded factors in cross-sectional variation of mean asset returns. However, Shanken and Weinstein (2006) re-examine Chen, Roll, and Ross (1986) model and find it is surprisingly sensitive to reasonable alternative procedures for generating size portfolio returns and estimating betas. In Table 11, we also test macroeconomic factor models on our 40 test assets. ${ }^{42}$

Unlike Chen, Roll, and Ross (1986) where they treat macroeconomic variables themselves as innovations, we explicitly model innovations to these macroeconomic variables using a VAR model as specified in Section 3.2 and use these innovations as our base factors. The factors of our interest are $f_{t}^{M P}, f_{t}^{P P I}$, and $f_{t}^{U T S}$. Table 2 shows $\mathrm{MP}_{t}$ and $\mathrm{PPI}_{t}$ strongly predict future long-run volatility component. Table 3 also confirms this finding although in much weaker degee. It also shows that $\mathrm{UTS}_{t}$ stongly predict future market return although $R^{2}$ of market return equation stays at $5 \%$. We are interested to see how innovations to these macroeconomic variables are priced across our test assets.

Table $11(i)$ shows the results for our full specification model of macroeconomic factors. The overall performance measures of $R^{2}$ and RMSPE of the five macroeconomic

\footnotetext{
${ }^{42}$ Although we do not report in the table, we examined various specifications of macroeconomic factor model starting from the original Chen, Roll, and Ross (1986) specification of $\mathrm{MP}_{t}, \mathrm{DEI}_{t}, \mathrm{UI}_{t}, \mathrm{UTS}_{t}$, and $\mathrm{UPR}_{t}$ where the macroeconomic variables themselves are taken as innovation factors. We tested them on Fama-French 25 portfolios and various combinations of decile portfolios and our results show that the estimated prices of risk lack robustness (switch signs although significant) and sensitive to the choice of variables in the model and test assets. Our VAR innovation factor model of macroeconomic variables as in Table $11(i)$ is far more robust and it is consistent with Shanken and Weinstein (2006) in the sense that value-weighted market index and industrial production growth factor turn out to be significantly priced.
} 
factor model tell us that it shows performance similar to four traded factor models in (ii) and (iii) of Table 9 and one factor model of $f_{t}^{\tau}$ in $(i v)$ of Table 7 . It turns out that

only $f_{t}^{P P I}$, among our factors of interest, is significantly priced. When $f_{t}^{P P I}$ is left out of the model as in Table $11(i i), f_{t}^{M P}$ becomes a significantly priced factor. Although RMSPE increases as $f_{t}^{P P I}$ is eliminated, pricing error decomposition shows that the SSPE portion due to momentum portfolios halves implying that $f_{t}^{M P}$ might have good explanatory power in cross-sectional variations of mean returns of momentum portfolios. This relates to Liu and Zhang (2008) in which they argue that $\mathrm{MP}_{t}$ risk is the underlying risk of momentum profits. Liu and Zhang (2008) show that the combined effect of $\mathrm{MP}_{t}$ loadings and risk premiums accounts for more than half of momentum profits. However, it seems that $f_{t}^{M P}$ is not a good factor overall since the overall performance measures for specification without $f_{t}^{M P}$ in Table 11 ( $\left.i i i\right)$ hardly get worse when compared with Table $11(i)$. Panel B of Table 11 shows the results for the same set of specifications as in Panel A but with the orthogonalized factors.

\subsubsection{Volatility Factor versus Other Factors}

The predictability tests we examined in Section 4.3 and 4.4 indicate that $\left\{\tau_{t}, g_{t}\right.$, $\left.\mathrm{SMB}_{t}, \mathrm{WML}_{t}, \mathrm{LIQ}_{t}, \mathrm{MP}_{t}, \mathrm{PPI}_{t}\right\}$ predict future market volatility and $\left\{\mathrm{SMB}_{t}, \mathrm{UTS}_{t}\right\}$ predict future market return. Moreover, among these variables, $\tau_{t}$ and $\mathrm{UTS}_{t}$ are the strongest predictors of future stock market volatility and future market return, respectively. However, there is a large gap between the prediction power of these two predictors; in VAR analysis, $R^{2}$ 's of $\tau_{t}$ equation and $r_{m, t}$ equation are $99 \%$ and $12 \%$.

The asset pricing equation (17) implies that innovations to the variables that predict either future market return or future market volatility should be priced across assets. In this sense, our predictablity analyses indicate that innovations to $\left\{\tau_{t}, g_{t}, \mathrm{SMB}_{t}\right.$, $\left.\mathrm{WML}_{t}, \mathrm{LIQ}_{t}, \mathrm{MP}_{t}, \mathrm{PPI}_{t}, \mathrm{UTS}_{t}\right\}$ should be priced. Moreover, since $\tau_{t}$ and $\mathrm{UTS}_{t}$ are the 
strongest predictors, we expect $f_{t}^{\tau}$ and $f_{t}^{U T S}$ to be the strongest factors of all. Being the innovations to the strongest predictor of future market volatility, $f_{t}^{\tau}$ is also expected to contain pricing information of other factors that are the innovations to the variables that also forecast market volatility; $\left\{f_{t}^{g}, f_{t}^{S M B}, f_{t}^{W M L}, f_{t}^{L I Q}, f_{t}^{M P}, f_{t}^{P P I}\right\}$.

Our cross-sectional studies with each of factor groups from Section 5.1.1 to 5.1.3 confirm many of the implications of predictability analyses in Section 4.3-4.4. It turns out that $f_{t}^{\tau}$ is indeed strongly priced. One factor model of $f_{t}^{\tau}$ explains $35 \%$ of crosssectional variation of mean test asset returns. Pricing error decompositions in Table 7 and the results for cross-sectional regressions in Table 8 indicate that $f_{t}^{\tau}$ contains pricing information of $\left\{f_{t}^{S M B}, f_{t}^{W M L}, f_{t}^{L I Q}\right\}$. Also, the results for the cross-sectional regression in Table 9 and 11 suggest that $\left\{f_{t}^{H M L}, f_{t}^{W M L}, f_{t}^{L I Q}, f_{t}^{M P}, f_{t}^{P P I}\right\}$ are significantly priced. To our disappointment, $f_{t}^{U T S}$ is not priced across our test assets.

In the current section, we are going to directly test the information content of $f_{t}^{\tau}$ by running a horse race of $f_{t}^{\tau}$ and other priced factors which are innovations to the variables that are shown to predict future market volatility. Table 12 and 14 show the one to one horse race of $f_{t}^{\tau}$ and one of other factors. Panel A of both tables show the results for base factors whereas Panel $\mathrm{B}$ for the orthogonalized factors. For the results in Panel B, the variable orders in the VAR models are also presented. The orthogonalized factors in Table 12 are generated from $\mathbf{y}_{t}^{[1]}$ with the first three variables ordered as shown in the table and those in Table 14 are generated from $\mathbf{y}_{t}^{[2]}$ with the first three variables also ordered as shown in the table. With only one exception, both $R_{m, t}^{e}$ and $f_{t}^{\tau}$ are strongly priced while the prices of risk for the remaining factor are all insignificant. The exception is Table $14(i v)$ where $t$-stat for $u_{t}^{\tau}$ is 1.93 . Since the specification in Table $14(i v)$ indicates $\mathrm{MP}_{t}$ is the first element of the vector in VAR model, we have $u_{t}^{M P}=f_{t}^{M P}$ while common component of $f_{t}^{\tau}$ and $f_{t}^{M P}$ is eliminated from $f_{t}^{\tau}$ to construct $u_{t}^{\tau}$. The empirical finding that long-run volatility component factor loses some explanatory power when it is orthogonalized to $f_{t}^{M P}$ implies that $f_{t}^{M P}$ 
carries somewhat significant pricing information of $f_{t}^{\tau}$. This seems to have some relation to Adrian and Rosenberg (2008) in which they show close relation between long-run volatility component factor and industrial production growth; Adrian and Rosenberg (2008) show that time series correlation between prices of long-run volatility risk and that of industrial production growth is $-98 \%$. They also show that cross-sectional correlation between loadings of long-run volatility factor and that of industrial production growth is $-94 \%$.

While we run one to one horse races in Table 12 and 14, we investigate in Table 13 information content of $f_{t}^{\tau}$ and test explanatory power of $f_{t}^{\tau}$ by looking at the $t$ stats for the price of long-run volatility component risk as we add traded factors. All the previous results in Table 7-9 suggest that $f_{t}^{\tau}$ contains pricing information of $f_{t}^{S M B}$, $f_{t}^{W M L}$, and $f_{t}^{L I Q}$, but not $f_{t}^{H M L} ; f_{t}^{\tau}$ is unlikely to lose its explanatory power (in terms of $t$-stat) in cross-sectional variations in mean asset returns when any combinations of $f_{t}^{S M B}, f_{t}^{W M L}$, and $f_{t}^{L I Q}$ are added to the model, but might lose the power when $f_{t}^{H M L}$ is added. Although Table $13(i)$ shows the specification where $f_{t}^{W M L}$ and $f_{t}^{L I Q}$ are added to $\left\{R_{m, t}^{e}, f_{t}^{\tau}\right\}$, the results for all the configurations of models to which two of any traded factors are added are the same in the sense that $t$-stats for the added traded factors are insignificant whereas those for $\left\{R_{m, t}^{e}, f_{t}^{\tau}\right\}$ are both significant. Table $13(i i)$ and (iii) show that $t$-stat for price of $f_{t}^{\tau}$-risk gets insignificant when $f_{t}^{H M L}$ is also added in addition to $f_{t}^{W M L}$ and $f_{t}^{L I Q}$ possibly because a set of four factors, $\left\{R_{m, t}^{e}, f_{t}^{H M L}, f_{t}^{W M L}, f_{t}^{L I Q}\right\}$, spans a larger space than $f_{t}^{\tau}$ and better explains cross-sectional variations in mean asset returns. This is consistent with the empirical finding that $f_{t}^{\tau}$ does not contain pricing information of $f_{t}^{H M L}$.

It becomes more clear when you look at the results with the orthogonalized factors. The orthogonalized factors in Panel B of Table 13 are constructed from the VAR model with variables as in $\mathbf{y}_{t}^{[1]}$ of Section 3.2 and the order of the variables are as they are in $\mathbf{y}_{t}^{[1]}$. Since all the orthogonalized factors in $(i v)-(v i)$ are from exactly the same $\mathbf{y}_{t}^{[1]}$ and 
the orthogonalized factors are orthogonal to one another, the loadings of a factor are identical across the specifications in Table $13(i v)-(v i)$. For the same reason, loadings of a factor in Table $13(i v)-(v i)$ are identical to the loadings of the factor in Table 9 $(v)$-(viii). This feature allows us to compare the explanatory power of various factors more intuitively because regressors (loadings or $\beta$ 's) in cross-sectional regressions do not change as the factor specifications change. For an example, $\beta_{W M L}$ 's estimated from time-series regressions and used as regressors in cross-sectional regressions in models specified in Table $9(v i)$ and (viii) and Table $13(i v)-(v i)$ are all identical. When we run the Fama-MacBeth regressions with the base factors, loadings of a factor change in general depending on the covariance structure of that factor and other factors included in the model specification. Since loadings of a factor changes (i.e. the regressors in the cross-sectional regression changes) when another factor is added, it's not easy to interpret the results of the horse races of the base factors. The results in Panel B confirm the results shown in Panel A. $\tau_{t}$ innovation factor stands strong in Table $13(i v)$ $(v)$ while added traded factors are all insignificant. The long-run volatility component factor becomes insignificant in (vi) while all the traded factors including HML suddenly become significant. These results are consistent with the previous empirical finding that the long-run volatility component factor does not contain pricing information of HML.

Another advantage we expect from utilizing the orthogonalized factors is that the prices of risk estimated using the orthogonalized factors should be more close to theoretical values implied by the asset pricing equation (17) than those estimated with the base factors. ${ }^{43}$ This is because the beta's in the equation (17) is defined as univariate betas as was discussed in Jagannathan and Wang (1998). However, there is also a downside. The space spanned by a set of base factors and the space spanned by the set of the corresponding orthogonalized factors can differ very much. For an example,

\footnotetext{
${ }^{43}$ This advantage is not exploited in our paper since we don't compare the prices of risk implied by the time-series studies and those estimated from the cross-sectional studies.
} 
in the model specification of Table $13(i v), u_{t}^{W M L}$ is not only orthogonal to $r_{m, t}$ and $f_{t}^{\tau}$

but also to $\left\{f_{t}^{S M B}, f_{t}^{H M L}\right\}$, and $u_{t}^{S M B}$ and $u_{t}^{H M L}$ are not included in the factor model specification of $\left\{u_{m, t}, u_{t}^{\tau}, u_{t}^{W M L}, u_{t}^{L I Q}\right\}$. Hence, the space spanned by $\left\{R_{m, t}^{e}, f_{t}^{\tau}, f_{t}^{W M L}\right.$, $\left.f_{t}^{L I Q}\right\}$ is not the same as $\left\{u_{m, t}, u_{t}^{\tau}, u_{t}^{W M L}, u_{t}^{L I Q}\right\}$. This can be easily verified by the big differences in overall performance measures in Panel A and Panel B.

\subsection{Explaining Profits of Trading Strategy Based Factors}

In an effort to reveal underlying macroeconomic risk of momentum profits, Griffin, $\mathrm{Ji}$, and Martin (2003) examine how much of the momentum profits can be explained by the macroeconomic variable model of Chen, Roll, and Ross (1986) and conclude that macroeonomic risk variables can not explain the momentum effect. On the other hand, using a similar empirical framework, Liu and Zhang (2008) show that their basic inferences can be overturned with two changes in the test design. First, Liu and Zhang (2008) use 30 portfolios based on one-way sorts on size, book-to-market, and momentum to replace Griffin, Ji, and Martin's (2003) 25 two-way sorted size and book-to-market portfolios as testing assets in estimating risk premiums. Second, Liu and Zhang (2008) robustify their results by using various ways to estimate loadings of factors; rollingwindow, extending-window, and full-sample regressions in the first stage of risk premium estimation.

We use 40 test portfolios one-way sorted by size, book-to-market, momentum, and liquidity. For the estimation of betas, we use full-sample regressions as in Section 5.1. We extend the framework used in Griffin, Ji, and Martin (2003) and Liu and Zhang (2008) in two ways. First, since $\mathrm{SMB}_{t}, \mathrm{HML}_{t}$, and $\mathrm{LIQ}_{t}$ are all traded factors, we can apply the methodology to these factors as well. Second, since our primary purpose is not to link traded factors to macroeconomic variables, we can apply all our three basic factor models (volatility, trading-strategy based, and macroeconomic factor model) and 
the variants to price each traded factors and see how much of profits generated by various trading strategies these models or a certain factor can explain.

Our basic test design follows Griffin, Ji, and Martin (2003) and Liu and Zhang (2008). We regress one of the traded factors, $\mathcal{F}=\left\{\mathrm{SMB}_{t}, \mathrm{HML}_{t}, \mathrm{WML}_{t}, \mathrm{LIQ}_{t}\right\}$, on our choice of factors as in time-series regression (20): ${ }^{44}$

$$
\mathcal{F}_{t}^{\bullet}=a^{\bullet}+\sum_{s=1}^{S} \beta_{s}^{\bullet} F_{t}^{s}+e_{t}^{\bullet}
$$

Then, the expected profits, $E\left[\mathcal{F}^{\bullet}\right]$, are estimated as:

$$
E\left[\mathcal{F}^{\bullet}\right]=\sum_{s=1}^{S} \hat{\Lambda}_{s} \hat{\beta}_{s}^{\bullet}
$$

where $\hat{\beta}_{s}^{\bullet}$ is estimated from the full-sample time-series regressions in (22) and the prices of risk, $\hat{\Lambda}_{s}$, are estimated from two-stage Fama and MacBeth (1973) regressions using the 40 test assets. In fact, we already have the prices of risk estimates from results in Section 5.1 (Table 7, 9, and 11).

Table $15(i)$ shows the observed mean profits from various trading strategies. How much of these profits our choice of factor models can explain will be explored in Table (15) (ii)-(vii). A couple of things should be noted before we interpret the results in the table. For each model specifications in Table 15 (ii)-(vii), the table and the specification that show the corresponding prices of risk are noted in the top left corner of each table. Also, the numbers shown in each column of factors are the risk premium as measured by $\left(\hat{\Lambda}_{s} \cdot \hat{\beta}_{s}^{\bullet}\right)$. The far right column of each table shows ratio of expected over observed profits, i.e $E\left[\mathcal{F}^{\bullet}\right] / E_{T}\left[\mathcal{F}^{\bullet}\right]$ where $E\left[\mathcal{F}^{\bullet}\right]$ is as defined in equation (23) and $E_{T}$ represents the sample average operator.

The results shown in Table 15 confirm many of empirical findings from the previous

\footnotetext{
${ }^{44}$ Note that these traded factors are not included in 40 test assets.
} 
cross-sectional regressions especially with regard to the pricing error decomposition. We start with Table $15(i v)-(v)$, which present the results with traded factor models. For these traded factor models, the prices of risk should be, in theory, equal to expected return of the traded factors themselves. However, we do not impose these restrictions in either cross-sectional regressions in (21) and (23). If we run a time-series regression as in $(22)$ of $\mathcal{F}_{t}^{\bullet}$ on $\{F\}_{s=1}^{s=S}$ where $\mathcal{F}_{t}^{\bullet} \in\{F\}_{s=1}^{s=S}$, the beta of the corresponding factor (i.e. $\left.F_{t}^{s}=\mathcal{F}_{t}^{\bullet}\right)$ would be one and other betas zeros. Hence, the expected profits of a traded factor $\left(\mathcal{F}_{t}^{\bullet}\right)$ in Table $15(i v)-(v)$ are if $\mathcal{F}_{t}^{\bullet}$ itself is included in the factor set, identical to the prices of risk for that traded factor estimated from the cross-sectional regression referred in the top left corner in each table. Table $15(v)$ shows that the prices of risk for four traded factors and the market factor come very close to the mean returns of the corresponding factors as predicted by the theory. This success seems to be due to good match between test assets and the factor specification as was already carefully discussed in Section 5.1. Consistent with the cross-sectional regression results in Table $9(i)$, the Fama-French three factor model in Table 15 ( $i v)$ fails miserably by predicting negative mean returns for $\mathrm{WML}_{t}$ and $\mathrm{LIQ}_{t}$, and barely explaining $\mathrm{HML}_{t}$ profits $(17 \%)$ yet $\mathrm{HML}_{t}$ is included in the factor set. ${ }^{45}$ On the other hand, a single factor model with the longrun volatility component factor shows impressive results; one factor of $f_{t}^{\tau}$ explains $73 \%$, $65 \%$, and $46 \%$ of size, liquidity, and momentum trading strategy profits but only $12 \%$ of value profits. These results are also largely consistent with the cross-sectional regression results in the sense that $f_{t}^{\tau}$ contains pricing information of $\mathrm{SMB}_{t}, \mathrm{WML}_{t}$, and $\mathrm{LIQ}_{t}$, but not $\mathrm{HML}_{t}$. Addition of the market factor in Table 15 (iii) doesn't help increasing the explanatory power for all the trading strategy based profits except for $\mathrm{SMB}_{t}$.

Lastly, Table 15 (vi)-(vii) show the results with macroeconomic factors allowing us to examine the relations between macroeconomic factors and traded factors; this was

\footnotetext{
${ }^{45}$ The expected profits for $\mathrm{SMB}_{t}$ and $\mathrm{HML}_{t}$ are equal to the prices of risk of these factors in Table 9 (i).
} 
the major interests of Griffin, Ji, and Martin (2003) and Liu and Zhang (2008). Our approach differs from these papers in that our macroeconomic factors are taken from the corresponding innovations of the VAR with macroeconomic variables as defined in Chen, Roll, and Ross (1986) while these macroeconomic variables themselves are taken as factors in Griffin, Ji, and Martin (2003) and Liu and Zhang (2008). Also, we adopt $\mathrm{PPI}_{t}$ as a macrovariable of our interest while both of Griffin, Ji, and Martin (2003) and Liu and Zhang (2008) take $\mathrm{DEI}_{t}$ and $\mathrm{UI}_{t}$ instead. The results with two specifications in Table $15(v i)$ and (vii) suggest that macroeconomic factors can be related to $\mathrm{WML}_{t}$ and $\mathrm{SMB}_{t}$. Although the specification in Table $15(v i)$ explains far less of the crosssectional variations in mean returns than (vii), macroeconomic factor specification with innovations to industrial production growth better explains size profits yet not value or liquidity profits. Similar to robust findings of Liu and Zhang (2008), macroeconomic factor model explains roughly half of momentum profits. Our empirical results seem to support Liu and Zhang (2008) in the sense that large portion of expected momentum trading profits are due to $f_{t}^{M P}$ although $\hat{\Lambda}_{M P} \hat{\beta}_{M P} / E_{T}\left[\mathcal{F}^{W M L}\right]$ ratio is less than what is typically shown in Liu and Zhang (2008). When $f_{t}^{M P}$ is absent, $f_{t}^{U P R}$ takes the role and explains about the same portfion of the momentum profits.

Industrial production growth seems to be quite robustly priced. The original work of Chen, Roll, and Ross (1986) and follow-up work of Shanken and Weinstein (2006) both report $\mathrm{MP}_{t}$ is strongly priced across 20 size portfolios. In fact, in Shanken and Weinstein (2006) where 5 years of post-ranking returns are used to estimate betas, only the market factor and $\mathrm{MP}_{t}$ turn out to be significantly priced. ${ }^{46}$ Our results are consistent with these studies in the sense that our macroeconomic factor specification in Table 15 ( vi) explains size profits quite well. Also, the corresponding cross-sectional regression results in Table 11 (ii) show that innovations to industrial production growth are significantly priced. However, the results in Table $11(i)-(i i i)$ cast doubts in the robustness of industrial

\footnotetext{
${ }^{46}$ Chen, Roll, and Ross (1986) use 5 years of pre-ranking returns to estimate betas.
} 
production growth factor when producer price index inflation rate is also included in the model. With regard to the linkages of industrial production growth to other factors, Liu and Zhang (2008) suggest $\mathrm{MP}_{t}$ represents the underlying macroeconomic risk of the momentum factor. Adrian and Rosenberg (2008) show that time series correlation between prices of long-run volatility risk and that of industrial production growth is $-98 \%$. They also show that cross-sectional correlation between loadings of long-run volatility factor and that of industrial production growth is $-94 \%$. Our predictability analyses in Section 4.3-4.4 indicate that these variables (long-run volatility component, $\mathrm{MP}_{t}$, and momentum factor) share common information about the future stock market volatility. Furthermore, innovations to the long-run stock market volatility component, a strongest predictor of future stock market volatilty, works great in summarizing pricing information of $\mathrm{MP}_{t}$ innovation factor and the momentum factor as was discussed in detail in Section 5.1. Our view and empirical findings on the relations among these variables might shed new light on the empirical findings of Adrian and Rosenberg (2008) and Liu and Zhang (2008).

\subsection{Discussion}

Due to the empirical sucess of trading strategy based factors in explaining the crosssectional variation of mean asset returns, it has been interests of many researchers to find out what sort of risk these traded factors represent. Because of their intuitive nature concerning state of an economy, macroeconomic factors are potentially very appealing candidates to which the traded factors is supposed to link. For this reason, many have

tried to explain trading strategy based profits with macroeconomic variables. SMB and HML are related to innovations in economic growth expectations (e.g. Liew and Vassalou 2000, Vassalou 2003, Kelly 2003), default risk (e.g. He and Ng 1994, Vassalou and Xing 2004, Hahn and Lee 2006, Petkova 2006), term spread (e.g. Hahn and 
Lee 2006, Petkova 2006), and inflation (e.g. Kelly 2003). As for WML, although Griffin, Ji, and Martin (2003) report that unconditional model based on the Chen, Roll, and Ross (1986) factors cannot explain momentum profits, Liu and Zhang (2008) show quite extensively that $\mathrm{MP}_{t}$ explains more than half of momentum profits. Also, Chordia and Shivakumar (2002) show that momentum profits can be explained by macroeconomic variables that are related to the business cycle (e.g. dividend yield, default spread, yield on three-month T-bills, and term spread). Pástor and Stambaugh (2003) report that their liquidity risk factor accounts for half of the momentum profits. To the best of our knowledge, the links between liquidity factor and macroeconomic variables has not been investigated yet.

It looks like there are much evidence that various trading strategy profits are compensations for bearing specific macroeconomic risks. However, as was already pointed out by Shanken and Weinstein (2006), the pricing of macroeconomic risks lack robustness. Moreover, macroeconomic factors, although they represent more intuitive risks regarding the state of an economy than traded factors, are not free from "fishing license" critique of Fama (1991) unless one can show how the macroeconomic variables can be linked to a pricing kernel both theoretically and empirically. Cochrane (2001) also emphasizes that the ICAPM really is not quite such an expansive license and it gives tighter restrictions on state variables than are commonly checked: State variables should forecast something. Campbell (1993) suggests that investment opportunity set state variables should forecast the market returns. However, the problem is that the market return is very hard to predict especially over a short horizon like a month and the $R^{2}$ is very low even when the well-known predictors of the market return are added.

On the other hand, Liew and Vassalou (2000) show that SMB and HML contain significant information about the future GDP growth. The follow-up work of Vassalou (2003) suggests that SMB and HML appear to contain mainly news related to future GDP growth by showing that SMB and HML lose much of their ability to explain the 
cross-section when news related to future GDP growth is present. No one will argue that GDP growth news is not included in the investors' information set. No one will argue that GDP growth is not an important piece of information in asset pricing. However, we do not know how GDP growth news is going to affect the pricing kernel or the MRS of investors. We are not even sure that GDP growth news is linearly related to MRS. For an another exmaple, Petkova (2006) chooses short-term T-bill, term spread, aggregate dividend yield, and default spread as state variables to model two aspects of the investment opportunity set, the yield curve and the conditional distribution of asset returns. Petkova (2006) argue that her results can avoid "fishing license" critique by choosing these variables since they have forecasting power for future investment opportunities. However, Petkova (2006) is vague about exactly what the variables of her choice forecast, and how these variables are related to MRS, and does not explicitly show the prediction ability of these variables.

This paper differs from the previous studies in that $(i)$ we explicitly present the pricing kernel that our empirical work is based on and hence we explicitly show how the state variables and the corresponding factors are related to the pricing kernel, $(i i)$ we clearly show the predictability analyses on stock market return and stock market volatility. Within this context, Chen (2003) comes close to our paper. Although Chen (2003) derives an asset pricing equation which shows that an asset may command risk premia because it forecasts future volatilities, VAR-MGARCH approach doesn't allow Chen (2003) to examine the predictability relations between stock market volatility and variables in the VAR model as those between the market return and variables in the VAR model. Moreover, Chen (2003) focuses only on the book-to-market effect. We examine this missing link between the stock market volatility and other well-established factors. We find strong link between stock market volatility and the priced factors. The empirical work of Ang, Hodrick, Xing, and Zhang (2006) and Adrian and Rosenberg (2008) can also be understood in this framework. 
Schwert (1989) investigates macroeconomic sources of stock market volatility. Although he obtains mixed results, Schwert (1989) reports a close relation between NBER recession indicator and stock market volatility; stock market volatility is higher during recessions. Quite possibly this might be the reason why many have found that trading strategy based factors are linked to business cycle related macroeconomic variables. Also, there have been research that hinted this link between the stock market volatility and the factors investigated in this paper. Engle, Ghysels, and Sohn (2008) report that PPI and MP contain significant information about the future market volatility and especially over long-horizon. Guo (2006) and Guo and Savickas (2006) show that the momentum strategy is closely related to the dynamics of stock market volatility. Chordia, Roll, and Subrahmanyam (2001) and Chordia, Sarkar, and Subrahmanyam (2005) create various liquidity series and investigate their short-run dynamics. The former finds that the daily variation in liquidity is influenced by factors such as market returns, volatility, order flow, and interest rates. The latter finds that order flow, volatility, mutual fund flow are important drivers of liquidity. After all, we've been watching the evidence of the link between the stock market volatility and the priced factors piled up. 


\section{Conclusion}

We allow heteroskedasticity of asset returns in Campbell (1993) and investigate its implications on linear factor pricing models. The extended model implies that the variables that forecast either stock market return or stock market volatility should show

up as valid factors. Within this context, we examine the relationship between stock market volatility and the empirically-well-established factors. First, we examine the predictablity relations between stock market volatility and the priced factors. Our results show that the momentum factor as well as short- and long-run volatility component strongly predict future market volatility. Also, SMB, LIQ, MP, and PPI contain fair amount of information about the furue market volatility. In addition to the time-series studies, we examine the information content of $\tau_{t}$ innovation factor by using the FamaMacBeth cross-sectional regressions. Being the strongest predictor of stock market volatility, the long-run volatility component should generate a factor that encompasses other factors generated from the variables that also predict future market volatility. Consistent with the time-series results, the long-run volatility component factor contain pricing information of SMB, WML, LIQ, MP, and PPI. 


\section{Table 1: Summary Table for VAR Variables}

Summary statistics for the variables (January, 1966 - December, 1999) included in VAR factor models of (13) are presented. $r_{m, t}$ is monthly market $\log$ return. $\tau_{t}$ and $g_{t}$ are monthly volatility components timeaggregated from the daily components estimated from the GARCH-MIDAS model with rolling window RV as specified in (7)-(11). The factors shown in Panel B are size, value, momentum, and liquidity factors. The Panel C presents the summary statistics for industrial production growth, producer price index inflation rate, term spread, and default premium. $\rho_{n}$ is the autocorrelation with $n$-th lag. The autocorrelations marked with $*$ are beyond the two standard deviations from zero.

\begin{tabular}{|c|c|c|c|c|c|c|c|c|c|}
\hline & mean & std & skewness & kurtosis & $\rho_{1}$ & $\rho_{2}$ & $\rho_{3}$ & $\rho_{6}$ & $\rho_{12}$ \\
\hline \multicolumn{10}{|c|}{ Panel A: Market Return and Monthly Aggregated Volatility Component } \\
\hline$r_{m, t}$ & 0.0056 & 0.0453 & -0.50 & 5.30 & 0.05 & -0.04 & -0.03 & -0.04 & 0.03 \\
\hline$\tau_{t}$ & 0.0014 & 0.0010 & 5.15 & 37.95 & $0.90^{*}$ & $0.72^{*}$ & $0.53^{*}$ & $0.17^{*}$ & 0.05 \\
\hline$g_{t}$ & 21.3558 & 16.8644 & 12.56 & 205.79 & $0.30^{*}$ & 0.01 & -0.04 & 0.03 & -0.01 \\
\hline \multicolumn{10}{|c|}{ Panel B: Trading Strategy Based Factors } \\
\hline $\mathrm{SMB}_{t}$ & 0.0015 & 0.0297 & 0.21 & 3.85 & $0.16^{*}$ & 0.03 & -0.04 & $0.12^{*}$ & $0.19^{*}$ \\
\hline $\mathrm{HML}_{t}$ & 0.0031 & 0.0272 & -0.11 & 3.85 & $0.20^{*}$ & 0.07 & 0.02 & 0.06 & $0.12^{*}$ \\
\hline $\mathrm{WML}_{t}$ & 0.0084 & 0.0443 & -1.53 & 10.06 & -0.04 & -0.06 & -0.03 & 0.03 & $0.29 *$ \\
\hline $\mathrm{LIQ}_{t}$ & 0.0033 & 0.0448 & 0.02 & 3.70 & 0.05 & 0.01 & -0.04 & 0.01 & 0.07 \\
\hline \multicolumn{10}{|c|}{ Panel C: Macroeconomic Factors } \\
\hline $\mathrm{MP}_{t}$ & 0.0024 & 0.0075 & -0.86 & 6.54 & $0.36^{*}$ & $0.26^{*}$ & $0.24^{*}$ & 0.06 & -0.02 \\
\hline $\mathrm{PPI}_{t}$ & 0.0033 & 0.0071 & 1.88 & 13.23 & $0.32^{*}$ & $0.27^{*}$ & $0.28^{*}$ & $0.25^{*}$ & $0.31^{*}$ \\
\hline $\mathrm{UTS}_{t}$ & 0.0095 & 0.0139 & -0.35 & 2.99 & $0.95^{*}$ & $0.89^{*}$ & $0.84^{*}$ & $0.71^{*}$ & $0.57^{*}$ \\
\hline $\mathrm{UPR}_{t}$ & 0.0107 & 0.0044 & 1.27 & 4.26 & $0.96^{*}$ & $0.92^{*}$ & $0.88^{*}$ & $0.79^{*}$ & $0.62^{*}$ \\
\hline
\end{tabular}




\section{Table 2: GARCH-MIDAS Model Estimates}

The GARCH-MIDAS models with various regressors are fitted over daily market returns from Jan. 3, 1966 to Dec. 31, 1999 by QMLE. The GARCH-MIDAS model with rolling window RV is specified as in (7)-(11) with $\omega_{2}$ fixed at 1 for monotonicaly decreasing weighting function. $J=125$ and $N^{\prime}=22$ are chosen. The rest of the GARCH-MIDAS specifications follow (7)-(8) and (11)-(12) with $J^{\prime}=36$. Due to the limited availability of $\mathrm{LIQ}_{t}$ data, the GARCH-MIDAS(LIQ $)$ are fitted over daily market returns from Jan. 2, 1969 to Dec. 31, 1999 and it explains the noticeably small log-likelihood fundtion value (LLF) when compared with others. BIC is Bayesian Information Criterion and the numbers shown in the parenthesis are robust $t$-stats computed with HAC standard errors. Variance ratio is calculated as $\operatorname{Var}\left(\log \left[\tau_{\delta / t}(\bullet)\right]\right) / \operatorname{Var}\left(\log \left[\tau_{\delta / t}(\bullet) g_{\delta / t}\right]\right)$ where $\bullet$ refers to a specific regressor.

\begin{tabular}{lcccccccc}
\hline \hline & & & & & & & \\
& $\alpha$ & $\beta$ & $\theta$ & $\omega_{1}$ & $\omega_{2}$ & $m$ & LLF $/$ BIC & var ratio \\
& & & & & & & & \\
\hline & & & & & & & & \\
Rolling RV & 0.10412 & 0.81748 & 0.16403 & 1.85513 & & 0.00514 & 29742.22 & 0.43 \\
& $(8.71)$ & $(37.72)$ & $(15.13)$ & $(3.42)$ & & $(11.67)$ & -6.9420 & \\
$\mathrm{SMB}_{t}$ & 0.08277 & 0.89267 & -0.32821 & 1.94741 & 1.23420 & -9.54066 & 29741.79 & 0.17 \\
& $(8.32)$ & $(65.17)$ & $(-2.89)$ & $(1.35)$ & $(2.13)$ & $(-75.37)$ & -6.9408 & \\
$\mathrm{HML}_{t}$ & 0.08053 & 0.90099 & -0.12908 & 22.41781 & 3.42036 & -9.51647 & 29735.59 & 0.06 \\
& $(8.25)$ & $(49.15)$ & $(-1.44)$ & $(0.82)$ & $(1.13)$ & $(-60.90)$ & -6.9394 & \\
$\mathrm{WML}_{t}$ & 0.08305 & 0.88381 & 0.56600 & 1.24584 & 1.13119 & -10.10900 & 29760.64 & 0.31 \\
& $(9.49)$ & $(44.50)$ & $(6.37)$ & $(6.25)$ & $(5.75)$ & $(-92.04)$ & -6.9452 & \\
$\mathrm{LIQ}_{t}$ & 0.07863 & 0.89681 & 0.32150 & 1.41969 & 1.52295 & -9.64859 & 27029.87 & 0.22 \\
& $(8.19)$ & $(41.39)$ & $(3.62)$ & $(2.05)$ & $(0.92)$ & $(-70.17)$ & -6.8944 & \\
$\mathrm{MP}_{t}$ & 0.08440 & 0.89293 & -0.82063 & 3.66275 & 1.00000 & -9.39545 & 29742.20 & 0.15 \\
& $(10.43)$ & $(37.12)$ & $(-3.95)$ & $(0.31)$ & $(0.29)$ & $(-65.92)$ & -6.9409 & \\
$\mathrm{PPI}_{t}$ & 0.08351 & 0.89453 & 0.62253 & 8.87842 & 6.52780 & -9.78843 & 29738.59 & 0.15 \\
& $(8.18)$ & $(43.20)$ & $(3.48)$ & $(1.41)$ & $(0.84)$ & $(-64.30)$ & -6.9401 & \\
$\mathrm{UTS}_{t}$ & 0.08179 & 0.89707 & -0.11676 & 6.50885 & 1.00000 & -9.46958 & 29736.17 & 0.06 \\
& $(8.03)$ & $(36.71)$ & $(-0.66)$ & $(0.03)$ & $(0.02)$ & $(-50.46)$ & -6.9395 & \\
$\mathrm{UPR}_{t}$ & 0.08485 & 0.89122 & 0.86386 & 17.98284 & 1.00000 & -10.15661 & 29741.46 & 0.15 \\
& $(7.77)$ & $(12.64)$ & $(0.10)$ & $(0.05)$ & $(0.06)$ & $(-28.54)$ & -6.9407 & \\
& & & & & & & & \\
\hline \hline
\end{tabular}




\section{Table 3: VAR Predictability Tests (F-test): $p$-values}

This table presents the Granger causality tests of the VAR model with two chosen sets of variables. The VAR order chosen for Panel A is 3 and that for Panel B is 4 . The numbers in the table are $p$-values for the F-tests. The F-tests reflect the incremental ability of the column variable to predict the respective row variables, given the other variables in the VAR system. The definitions of variables involved follows the ones explained in Table 1.

\begin{tabular}{|c|c|c|c|c|c|c|c|c|}
\hline \multirow{2}{*}{$\begin{array}{l}\text { Dependent } \\
\text { Variable }\end{array}$} & \multicolumn{7}{|c|}{ Panel A: VAR with Trading Strategy Based Factors } & \multirow[b]{2}{*}{$R^{2}$} \\
\hline & $r_{m, t}$ & $\tau_{t}$ & $g_{t}$ & $f_{t}^{S M B}$ & $f_{t}^{H M L}$ & $f_{t}^{W M L}$ & $f_{t}^{L I Q}$ & \\
\hline$r_{m, t}$ & 0.69 & 0.64 & 0.79 & 0.07 & 0.66 & 0.84 & 0.94 & 0.05 \\
\hline$\tau_{t}$ & 0.38 & 0.00 & 0.00 & 0.55 & 0.77 & 0.01 & 0.11 & 0.99 \\
\hline$g_{t}$ & 0.01 & 0.98 & 0.00 & 0.56 & 0.91 & 0.51 & 0.99 & 0.15 \\
\hline$f_{t}^{S M B}$ & 0.00 & 0.29 & 0.05 & 0.51 & 0.88 & 0.49 & 0.32 & 0.14 \\
\hline$f_{t}^{H M L}$ & 0.78 & 0.21 & 0.44 & 0.61 & 0.01 & 0.75 & 0.48 & 0.08 \\
\hline$f_{t}^{W M L}$ & 0.47 & 0.19 & 0.47 & 0.01 & 0.50 & 0.13 & 0.11 & 0.10 \\
\hline$f_{t}^{L I Q}$ & 0.30 & 0.19 & 0.58 & 0.55 & 0.93 & 0.81 & 0.86 & 0.04 \\
\hline \multicolumn{9}{|c|}{ Panel B: VAR with Macroeconomic Factors } \\
\hline Variable & $r_{m, t}$ & $\tau_{t}$ & $g_{t}$ & $\mathrm{MP}_{t}$ & $\mathrm{PPI}_{t}$ & $\mathrm{UTS}_{t}$ & $\mathrm{UPR}_{t}$ & $R^{2}$ \\
\hline$r_{m, t}$ & 0.95 & 0.98 & 0.53 & 0.48 & 0.32 & 0.00 & 0.25 & 0.12 \\
\hline$\tau_{t}$ & 0.01 & 0.00 & 0.00 & 0.09 & 0.06 & 0.51 & 0.98 & 0.99 \\
\hline$g_{t}$ & 0.00 & 0.94 & 0.00 & 0.54 & 0.61 & 0.58 & 0.74 & 0.16 \\
\hline $\mathrm{MP}_{t}$ & 0.14 & 0.77 & 0.74 & 0.00 & 0.24 & 0.03 & 0.38 & 0.27 \\
\hline $\mathrm{PPI}_{t}$ & 0.57 & 0.55 & 0.90 & 0.05 & 0.00 & 0.01 & 0.79 & 0.22 \\
\hline $\mathrm{UTS}_{t}$ & 0.01 & 0.70 & 0.73 & 0.00 & 0.00 & 0.00 & 0.68 & 0.92 \\
\hline $\mathrm{UPR}_{t}$ & 0.01 & 0.43 & 0.22 & 0.01 & 0.33 & 0.00 & 0.00 & 0.95 \\
\hline
\end{tabular}




\section{Table 4: VAR Estimates for $\tau_{t}$ Equation}

The VAR parameter estimates for $\tau_{t}$ equation in two VAR specifications are shown. The order for the VAR model with the traded factors (Panel A) is 3 and that for the VAR model with the macroeconomic variables (Panel $\mathrm{B})$ is 4 . The numbers in the parenthesis are $t$-stats.

\begin{tabular}{|c|c|c|c|c|c|c|c|}
\hline & \multicolumn{7}{|c|}{ Panel A: VAR with Trading Strategy Based Factors } \\
\hline & $r_{m, t}$ & $\tau_{t}$ & $g_{t}$ & $\mathrm{SMB}_{t}$ & $\mathrm{HML}_{t}$ & $\mathrm{WML}_{t}$ & $\mathrm{LIQ}_{t}$ \\
\hline Lag 1 & $\begin{array}{l}0.0000 \\
(-0.23)\end{array}$ & $\begin{array}{l}1.3054 \\
(22.92)\end{array}$ & $\begin{array}{l}0.0000 \\
(57.38)\end{array}$ & $\begin{array}{c}-0.0003 \\
(-1.42)\end{array}$ & $\begin{array}{c}0.0001 \\
(0.48)\end{array}$ & $\begin{array}{c}-0.0001 \\
(-1.32)\end{array}$ & $\begin{array}{c}0.0002 \\
(1.16)\end{array}$ \\
\hline Lag 2 & $\begin{array}{c}0.0002 \\
(1.70)\end{array}$ & $\begin{array}{c}-0.5196 \\
(-6.06)\end{array}$ & $\begin{array}{l}0.0000 \\
(-5.25)\end{array}$ & $\begin{array}{l}0.0001 \\
(0.31)\end{array}$ & $\begin{array}{c}-0.0002 \\
(-0.93)\end{array}$ & $\begin{array}{l}0.0003 \\
(3.00)\end{array}$ & $\begin{array}{c}-0.0003 \\
(-2.04)\end{array}$ \\
\hline Lag 3 & $\begin{array}{l}0.0000 \\
(-0.05)\end{array}$ & $\begin{array}{l}0.0601 \\
(1.45)\end{array}$ & $\begin{array}{l}0.0000 \\
(3.58)\end{array}$ & $\begin{array}{l}0.0001 \\
(0.26)\end{array}$ & $\begin{array}{l}0.0001 \\
(0.51)\end{array}$ & $\begin{array}{l}0.0001 \\
(1.28)\end{array}$ & $\begin{array}{l}0.0000 \\
(-0.32)\end{array}$ \\
\hline & \multicolumn{7}{|c|}{ Panel B: VAR with Macroeconomic Factors } \\
\hline & $r_{m, t}$ & $\tau_{t}$ & $g_{t}$ & $\mathrm{MP}_{t}$ & $\mathrm{PPI}_{t}$ & $\mathrm{UTS}_{t}$ & $\mathrm{UPR}_{t}$ \\
\hline Lag 1 & $\begin{array}{c}-0.0002 \\
(-1.61)\end{array}$ & $\begin{array}{l}1.1453 \\
(20.13)\end{array}$ & $\begin{array}{c}0.0000 \\
(60.43)\end{array}$ & $\begin{array}{c}-0.0008 \\
(-1.20)\end{array}$ & $\begin{array}{c}-0.0003 \\
(-0.47)\end{array}$ & $\begin{array}{c}0.0006 \\
(0.48)\end{array}$ & $\begin{array}{c}0.0023 \\
(0.49)\end{array}$ \\
\hline Lag 2 & $\begin{array}{c}0.0003 \\
(3.08)\end{array}$ & $\begin{array}{c}-0.2960 \\
(-3.27)\end{array}$ & $\begin{array}{l}0.0000 \\
(-2.62)\end{array}$ & $\begin{array}{c}0.0006 \\
(0.90)\end{array}$ & $\begin{array}{c}0.0004 \\
(0.59)\end{array}$ & $\begin{array}{c}0.0005 \\
(0.33)\end{array}$ & $\begin{array}{c}-0.0014 \\
(-0.21)\end{array}$ \\
\hline Lag 3 & $\begin{array}{c}0.0002 \\
(1.36)\end{array}$ & $\begin{array}{l}-0.2086 \\
(-2.44)\end{array}$ & $\begin{array}{c}0.0000 \\
(2.16)\end{array}$ & $\begin{array}{c}-0.0003 \\
(-0.37)\end{array}$ & $\begin{array}{c}0.0014 \\
(2.02)\end{array}$ & $\begin{array}{c}0.0003 \\
(0.18)\end{array}$ & $\begin{array}{c}0.0005 \\
(0.08)\end{array}$ \\
\hline Lag 4 & $\begin{array}{c}0.0001 \\
(1.13)\end{array}$ & $\begin{array}{c}0.1458 \\
(3.68)\end{array}$ & $\begin{array}{c}0.0000 \\
(5.84)\end{array}$ & $\begin{array}{c}-0.0015 \\
(-2.21)\end{array}$ & $\begin{array}{c}0.0011 \\
(1.51)\end{array}$ & $\begin{array}{c}-0.0009 \\
(-0.77)\end{array}$ & $\begin{array}{c}-0.0016 \\
(-0.37)\end{array}$ \\
\hline
\end{tabular}




\section{Table 5: Base Factor Correlations}

This table presents the correlation structure of the base factors as defined in Section 3.2. $f_{t}^{\tau[\bullet]}$ and $f_{t}^{g[\bullet]}$ with $\bullet=\{1,2\}$ are the innovations to $\tau_{t}$ and $g_{t}$ in the VAR model with the traded factors and the VAR model with the macroeconomic variables, respectively. As we explained in Section 3.2 , the trading strategy based factors themselves are taken as base factors, and hence $\left\{f_{t}^{S M B}, f_{t}^{H M L}, f_{t}^{W M L}, f_{t}^{L I Q}\right\}$ are size, value, momentum, and liquidity factors. On the other hand, $\left\{f_{t}^{M P}, f_{t}^{P P I}, f_{t}^{U T S}, f_{t}^{U P R}\right\}$ are innovations to industrial production growth, producer price index inflation rate, term spread, and default premium, respectively, in the VAR model as specified with $\mathbf{y}_{t}^{[2]}$ in Section 3.2 .

\begin{tabular}{|c|c|c|c|c|c|c|c|c|c|c|c|c|c|}
\hline & $R_{m, t}^{e}$ & $f_{t}^{\tau[1]}$ & $f_{t}^{\tau[2]}$ & $f_{t}^{g[1]}$ & $f_{t}^{g[2]}$ & $f_{t}^{S M B}$ & $f_{t}^{H M L}$ & $f_{t}^{W M L}$ & $f_{t}^{L I Q}$ & $f_{t}^{M P}$ & $f_{t}^{P P I}$ & $f_{t}^{U T S}$ & $f_{t}^{U P R}$ \\
\hline$R_{m, t}^{e}$ & 1 & -0.12 & -0.15 & -0.33 & -0.32 & 0.32 & -0.41 & 0.00 & -0.34 & 0.00 & -0.12 & 0.02 & 0.08 \\
\hline$f_{t}^{\tau[1]}$ & -0.12 & 1 & 0.90 & 0.52 & 0.51 & -0.03 & -0.01 & -0.07 & -0.04 & -0.04 & 0.02 & 0.08 & 0.05 \\
\hline$f_{t}^{\tau[2]}$ & -0.15 & 0.90 & 1 & 0.54 & 0.55 & -0.06 & 0.03 & -0.08 & -0.02 & -0.08 & 0.01 & 0.08 & 0.08 \\
\hline$f_{t}^{g[1]}$ & -0.33 & 0.52 & 0.54 & 1 & 0.98 & -0.19 & 0.08 & -0.04 & 0.14 & -0.02 & 0.03 & 0.06 & 0.01 \\
\hline$f_{t}^{g[2]}$ & -0.32 & 0.51 & 0.55 & 0.98 & 1 & -0.19 & 0.08 & -0.06 & 0.12 & -0.03 & 0.03 & 0.06 & 0.03 \\
\hline$f_{t}^{S M B}$ & 0.32 & -0.03 & -0.06 & -0.19 & -0.19 & 1 & -0.17 & -0.24 & -0.55 & 0.02 & 0.00 & 0.12 & -0.02 \\
\hline$f_{t}^{H M L}$ & -0.41 & -0.01 & 0.03 & 0.08 & 0.08 & -0.17 & 1 & -0.21 & -0.09 & 0.03 & 0.06 & 0.18 & 0.04 \\
\hline$f_{t}^{W M L}$ & 0.00 & -0.07 & -0.08 & -0.04 & -0.06 & -0.24 & -0.21 & 1 & 0.27 & 0.06 & 0.02 & -0.14 & 0.03 \\
\hline$f_{t}^{L I Q}$ & -0.34 & -0.04 & -0.02 & 0.14 & 0.12 & -0.55 & -0.09 & 0.27 & 1 & 0.00 & 0.08 & -0.18 & -0.08 \\
\hline$f_{t}^{M P}$ & 0.00 & -0.04 & -0.08 & -0.02 & -0.03 & 0.02 & 0.03 & 0.06 & 0.00 & 1 & 0.07 & -0.11 & -0.27 \\
\hline$f_{t}^{P P I}$ & -0.12 & 0.02 & 0.01 & 0.03 & 0.03 & 0.00 & 0.06 & 0.02 & 0.08 & 0.07 & 1 & -0.08 & -0.14 \\
\hline$f_{t}^{U T S}$ & 0.02 & 0.08 & 0.08 & 0.06 & 0.06 & 0.12 & 0.18 & -0.14 & -0.18 & -0.11 & 0 & 1 & 0.23 \\
\hline$f_{t}^{U P R}$ & 0.08 & 0.05 & 0.08 & 0.01 & 0.03 & -0.02 & 0.04 & 0.03 & -0.08 & -0.27 & -0.14 & 0.23 & 1 \\
\hline
\end{tabular}




\section{Table 6: Test Portfolios and Estimated Betas}

Our test assets for the cross-sectional studies are 40 test portfolios consist of four different decile portfolios sorted on size, book-to-market ratio, momentum, and liquidity. The size and BM portfolios are from Prof. Kenneth French's website. The momentum portfolios are the ones used in Liu and Zhang (2008) and the liquidity portfolios are from Pástor and Stambaugh (2003). The average monthly returns of these portfolios covering January 1966 - December 1999 are shown in the table. The betas are from time-series regressions, as specified in (20), of monthly test portfolio returns on a factor set of $\left\{R_{m, t}^{e}, f_{t}^{\tau}, f_{t}^{g}\right\}$ which is the same as Table $7(i i)$. The numbers in the parenthesis are $t$-stats.

\begin{tabular}{|c|c|c|c|c|c|c|c|c|c|c|}
\hline \multirow{5}{*}{$\begin{array}{l}\text { portfolio \# } \\
\text { mean } \\
\beta_{\tau}\end{array}$} & \multicolumn{10}{|c|}{ Size-Sorted Decile Portfolios } \\
\hline & 9 & 10 & 8 & 1 & 6 & 2 & 7 & 4 & 3 & 5 \\
\hline & 0.01089 & 0.01090 & 0.01143 & 0.01157 & 0.01161 & 0.01206 & 0.01215 & 0.01233 & 0.01243 & 0.01295 \\
\hline & 2.82 & -7.70 & 6.19 & 27.52 & 7.25 & 19.43 & 11.53 & 5.29 & 14.52 & 12.15 \\
\hline & $(0.38)$ & $(-1.05)$ & $(0.66)$ & $(0.97)$ & $(0.53)$ & $(0.87)$ & $(1.06)$ & $(0.29)$ & $(0.74)$ & $(0.79)$ \\
\hline \multirow[t]{3}{*}{$\beta_{g}$} & 0.00000 & 0.00008 & -0.00002 & -0.00029 & -0.00007 & -0.00023 & -0.00009 & -0.00017 & -0.00017 & -0.00017 \\
\hline & $(-0.05)$ & $(2.02)$ & $(-0.39)$ & $(-1.82)$ & $(-0.94)$ & $(-1.82)$ & $(-1.45)$ & $(-1.72)$ & $(-1.56)$ & $(-2.00)$ \\
\hline & \multicolumn{10}{|c|}{ BM-Sorted Decile Portfolios } \\
\hline \multirow{4}{*}{$\begin{array}{l}\text { portfolio \# } \\
\text { mean } \\
\beta_{\tau}\end{array}$} & 1 & 5 & 4 & 2 & 3 & 6 & 8 & 7 & 9 & 10 \\
\hline & 0.01032 & 0.01034 & 0.01086 & 0.01105 & 0.01131 & 0.01157 & 0.01218 & 0.01223 & 0.01355 & 0.01459 \\
\hline & -5.67 & 6.97 & -2.86 & 16.06 & -0.60 & 5.69 & 2.42 & -11.72 & -21.68 & 28.03 \\
\hline & $(-0.38)$ & $(0.58)$ & $(-0.24)$ & $(1.66)$ & $(-0.06)$ & $(0.46)$ & $(0.17)$ & $(-0.84)$ & $(-1.32)$ & $(1.26)$ \\
\hline \multirow[t]{2}{*}{$\beta_{g}$} & 0.00014 & -0.00014 & -0.00003 & -0.00007 & -0.00008 & -0.00009 & -0.00002 & 0.00017 & 0.00008 & -0.00016 \\
\hline & $(1.67)$ & $(-2.13)$ & $(-0.50)$ & $(-1.27)$ & $(-1.46)$ & $(-1.36)$ & $(-0.19)$ & $(2.12)$ & $(0.85)$ & $(-1.25)$ \\
\hline
\end{tabular}

Table continued on next page ... 


\section{Table 6 continued}

\begin{tabular}{|c|c|c|c|c|c|c|c|c|c|c|}
\hline \multirow{3}{*}{$\begin{array}{l}\text { portfolio \# } \\
\text { mean }\end{array}$} & \multicolumn{10}{|c|}{ Momentum-Sorted Decile Portfolios } \\
\hline & 1 & 2 & 3 & 4 & 5 & 6 & 7 & 8 & 9 & 10 \\
\hline & 0.00889 & 0.00927 & 0.01083 & 0.01166 & 0.01207 & 0.01297 & 0.01345 & 0.01442 & 0.01575 & 0.01724 \\
\hline \multirow[t]{2}{*}{$\beta_{\tau}$} & 61.22 & 52.30 & 39.87 & 33.84 & 30.40 & 21.30 & 11.47 & 6.32 & 8.93 & 27.81 \\
\hline & $(1.41)$ & $(1.77)$ & $(1.65)$ & $(1.63)$ & $(1.62)$ & $(1.22)$ & $(0.65)$ & $(0.35)$ & $(0.43)$ & $(0.97)$ \\
\hline \multirow[t]{2}{*}{$\beta_{g}$} & -0.00018 & -0.00019 & -0.00016 & -0.00021 & -0.00025 & -0.00027 & -0.00026 & -0.00027 & -0.00025 & -0.00026 \\
\hline & $(-0.74)$ & $(-1.18)$ & $(-1.22)$ & $(-1.77)$ & $(-2.38)$ & $(-2.80)$ & $(-2.61)$ & $(-2.67)$ & $(-2.14)$ & $(-1.61)$ \\
\hline
\end{tabular}

\section{Liquidity-Sorted Decile Portfolios}

\begin{tabular}{lcccccccccc} 
portfolio $\#$ & 1 & 5 & 2 & 3 & 4 & 10 & 7 & 6 & 8 & 9 \\
\cline { 2 - 10 } mean & 0.00851 & 0.00975 & 0.01056 & 0.01059 & 0.01087 & 0.01177 & 0.01179 & 0.01192 & 0.01206 & 0.01211 \\
$\beta_{\tau}$ & 55.31 & 3.15 & 33.85 & 7.11 & 3.26 & -8.36 & 10.77 & -11.63 & -0.38 & -12.56 \\
& $(2.29)$ & $(0.31)$ & $(1.83)$ & $(0.49)$ & $(0.28)$ & $(-0.58)$ & $(1.09)$ & $(-1.22)$ & $(-0.04)$ & $(-1.17)$ \\
$\beta_{g}$ & -0.00011 & -0.00006 & -0.00009 & 0.00002 & -0.00004 & 0.00013 & -0.00004 & 0.00002 & -0.00003 & 0.00002 \\
& $(-0.79)$ & $(-1.00)$ & $(-0.87)$ & $(0.23)$ & $(-0.68)$ & $(1.64)$ & $(-0.71)$ & $(0.46)$ & $(-0.62)$ & $(0.40)$
\end{tabular}

$\overline{=}$ 


\section{Table 7: Cross-Sectional Regression with Volatility Factors}

This table presents the estimated prices of risk, presented as percentage per month, and the corresponding $t$-stats, shown in the parenthesis, computed with Jagannathan and Wang (1998) corrected standard errors. These are estimated following Fama and MacBeth (1973) procedure on 40 test portfolios consist of four different decile portfolios sorted on size, BM, momentum, and liquidity; the full-sample time series regressions as in (20) and cross-sectional regressions as in (21) for the sample from July 1966 to December 1999. For each factor specifications, three overall performance measures are provided; intuitive $R^{2}$, root mean squared pricing error (RMSPE), and the pricing error decomposition. The $R^{2}$ is identical to the one in the cross-sectional OLS regression with average returns as dependent variables. The pricing error decomposition shows the portion of sum of squared pricing errors (SSPE) that belongs to each decile portfolios. The orthogonalized factors in Panel $\mathrm{C}$ are constructed following Campbell (1996), and the VAR variable orders are also shown in the table since they do matter in the orthogonalized factors. See Section 3.2 for more details.

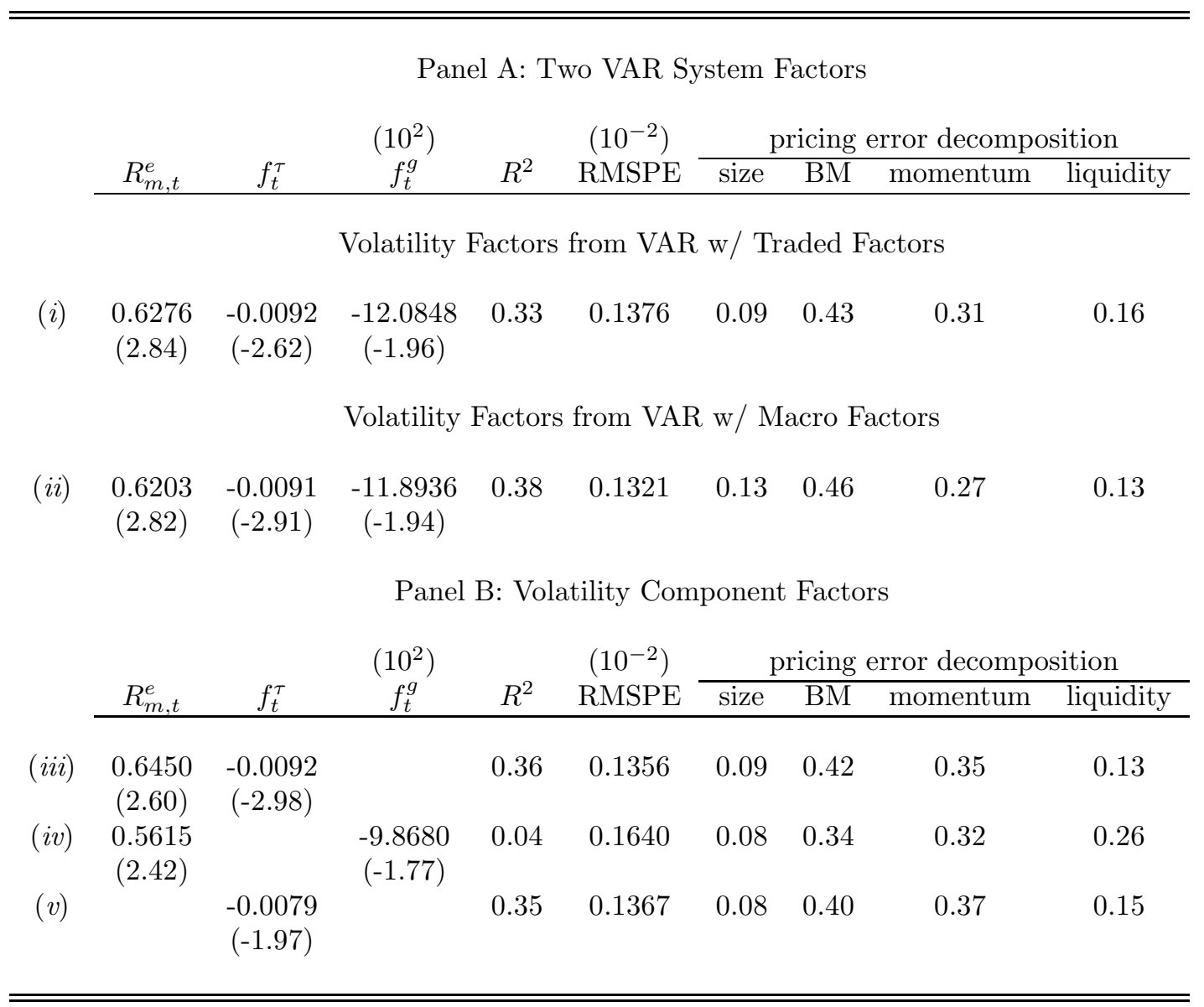




\section{Table 7 continued}

\begin{tabular}{|c|c|c|c|c|c|c|c|c|c|}
\hline & \multicolumn{9}{|c|}{ Panel C: Orthogonalized Factors } \\
\hline & & & & & $\left(10^{-2}\right)$ & \multicolumn{4}{|c|}{ pricing error decomposition } \\
\hline \multirow{4}{*}{$(v i)$} & \multicolumn{3}{|c|}{ variable order } & \multirow[t]{2}{*}{$R^{2}$} & \multirow[t]{2}{*}{ RMSPE } & size & $\mathrm{BM}$ & momentum & liquidity \\
\hline & $u_{m, t}$ & $u_{t}^{\tau}$ & $u_{t}^{g}$ & & & & & & \\
\hline & 0.6607 & -4.7443 & -1.2207 & 0.38 & 0.1320 & 0.13 & 0.45 & 0.29 & 0.13 \\
\hline & $(2.51)$ & $(-2.93)$ & $(-0.51)$ & & & & & & \\
\hline \multirow[t]{3}{*}{ (vii) } & $u_{m, t}$ & $u_{t}^{g}$ & $u_{t}^{\tau}$ & & & & & & \\
\hline & 0.6607 & -3.4288 & -3.4992 & 0.38 & 0.1320 & 0.13 & 0.45 & 0.29 & 0.13 \\
\hline & $(2.51)$ & $(-1.73)$ & $(-1.65)$ & & & & & & \\
\hline
\end{tabular}




\section{Table 8: Separate Cross-Sectional Regressions on Each Decile Portfolios}

This table presents the estimated prices of risk, presented as percentage per month, and the corresponding $t$-stats, shown in the parenthesis, computed with Jagannathan and Wang (1998) corrected standard errors. These are estimated following Fama and MacBeth (1973) procedure separately on each of four decile portfolios; size-, BM-, momentum- and liquidity-sorted decile portfolios. First, we run the full-sample time series regressions as in (20) to estimate loadings on factors, and then cross-sectional regressions as in (21) for the sample from July 1966 to December 1999. For each of four decile portfolios, one factor model of $\tau_{t}$ innovation and two factor model of excess market return and the relevant traded factor are examined. For each factor specifications, two overall performance measures are provided; intuitive $R^{2}$ and root mean squared pricing error (RMSPE). The $R^{2}$ is identical to the one in the cross-sectional OLS regression with average returns as dependent variables.

\begin{tabular}{|c|c|c|c|c|c|c|c|c|}
\hline \multirow{3}{*}{ (i) } & \multicolumn{8}{|c|}{ Test on size-sorted decile portfolios } \\
\hline & $R_{m, t}^{e}$ & $f_{t}^{S M B}$ & $R^{2}$ & $\operatorname{RMSPE}\left(10^{-2}\right)$ & $(i i)$ & $f_{t}^{\tau}$ & $R^{2}$ & $\operatorname{RMSPE}\left(10^{-2}\right)$ \\
\hline & $\begin{array}{c}0.5926 \\
(2.70)\end{array}$ & $\begin{array}{c}0.1208 \\
(0.64)\end{array}$ & 0.67 & 0.0365 & & $\begin{array}{c}-0.0099 \\
(-1.86)\end{array}$ & 0.46 & 0.0467 \\
\hline \multirow{3}{*}{$(i i i)$} & \multicolumn{8}{|c|}{ Test on BM-sorted decile portfolios } \\
\hline & $R_{m, t}^{e}$ & $f_{t}^{H M L}$ & $R^{2}$ & $\operatorname{RMSPE}\left(10^{-2}\right)$ & $(i v)$ & $f_{t}^{\tau}$ & $R^{2}$ & $\operatorname{RMSPE}\left(10^{-2}\right)$ \\
\hline & $\begin{array}{c}0.5848 \\
(2.60)\end{array}$ & $\begin{array}{c}0.1812 \\
(1.08)\end{array}$ & 0.80 & 0.0594 & & $\begin{array}{c}-0.0105 \\
(-1.14)\end{array}$ & -1.02 & 0.1868 \\
\hline \multirow{3}{*}{$(v)$} & \multicolumn{8}{|c|}{ Test on momentum-sorted decile portfolios } \\
\hline & $R_{m, t}^{e}$ & $f_{t}^{W M L}$ & $R^{2}$ & $\operatorname{RMSPE}\left(10^{-2}\right)$ & $(v i)$ & $f_{t}^{\tau}$ & $R^{2}$ & $\operatorname{RMSPE}\left(10^{-2}\right)$ \\
\hline & $\begin{array}{c}0.9665 \\
(3.42)\end{array}$ & $\begin{array}{c}0.8776 \\
(4.64)\end{array}$ & 0.98 & 0.0347 & & $\begin{array}{c}-0.0133 \\
(-1.76)\end{array}$ & 0.80 & 0.1150 \\
\hline \multirow{3}{*}{ (vii) } & \multicolumn{8}{|c|}{ Test on liquidity-sorted decile portfolios } \\
\hline & $R_{m, t}^{e}$ & $f_{t}^{L I Q}$ & $R^{2}$ & $\operatorname{RMSPE}\left(10^{-2}\right)$ & (viii) & $f_{t}^{\tau}$ & $R^{2}$ & $\operatorname{RMSPE}\left(10^{-2}\right)$ \\
\hline & $\begin{array}{c}0.6023 \\
(2.76)\end{array}$ & $\begin{array}{c}0.3983 \\
(1.68)\end{array}$ & 0.51 & 0.0785 & & $\begin{array}{c}-0.0098 \\
(-1.95)\end{array}$ & 0.34 & 0.0912 \\
\hline
\end{tabular}




\section{Table 9: Cross-Sectional Regression with Trading-Strategy Based Factors}

This table presents the estimated prices of risk, presented as percentage per month, and the corresponding $t$-stats, shown in the parenthesis, computed with Jagannathan and Wang (1998) corrected standard errors. These are estimated following Fama and MacBeth (1973) procedure on 40 test portfolios consist of four different decile portfolios sorted on size, BM, momentum, and liquidity; the full-sample time series regressions as in (20) and cross-sectional regressions as in (21) for the sample from July 1966 to December 1999. For each factor specifications, three overall performance measures are provided; intuitive $R^{2}$, root mean squared pricing error (RMSPE), and the pricing error decomposition. The $R^{2}$ is identical to the one in the cross-sectional OLS regression with average returns as dependent variables. The pricing error decomposition shows the portion of sum of squared pricing errors (SSPE) that belongs to each decile portfolios. The orthogonalized factors in Panel B are constructed following Campbell (1996), and the VAR variable orders are also shown in the table since they do matter in the orthogonalized factors. See Section 3.2 for more details.

\begin{tabular}{|c|c|c|c|c|c|c|c|c|c|c|c|}
\hline & \multirow[b]{3}{*}{$R_{m, t}^{e}$} & \multirow[b]{3}{*}{$f_{t}^{S M B}$} & \multirow[b]{3}{*}{$f_{t}^{H M L}$} & \multirow[b]{3}{*}{$f_{t}^{W M L}$} & \multicolumn{3}{|c|}{ Panel A: Base Factors } & \multirow{2}{*}{\multicolumn{4}{|c|}{ pricing error decomposition }} \\
\hline & & & & & & & $\left(10^{-2}\right)$ & & & & \\
\hline & & & & & $f_{t}^{L I Q}$ & $R^{2}$ & RMSPE & size & $\mathrm{BM}$ & momentum & liquidity \\
\hline (i) & $\begin{array}{c}0.5963 \\
(2.69)\end{array}$ & $\begin{array}{c}0.0864 \\
(0.46)\end{array}$ & $\begin{array}{c}0.0523 \\
(0.35)\end{array}$ & & & -0.14 & 0.1787 & 0.01 & 0.06 & 0.62 & 0.31 \\
\hline (ii) & $\begin{array}{c}0.5715 \\
(2.56)\end{array}$ & $\begin{array}{c}0.2092 \\
(1.13)\end{array}$ & $\begin{array}{c}0.1495 \\
(0.96)\end{array}$ & $\begin{array}{c}0.7255 \\
(3.92)\end{array}$ & & 0.44 & 0.1254 & 0.11 & 0.06 & 0.21 & 0.61 \\
\hline (iii) & $\begin{array}{c}0.6272 \\
(2.85)\end{array}$ & $\begin{array}{c}0.0888 \\
(0.47)\end{array}$ & $\begin{array}{c}0.1792 \\
(1.17)\end{array}$ & & $\begin{array}{c}0.5717 \\
(2.57)\end{array}$ & 0.36 & 0.1344 & 0.05 & 0.07 & 0.80 & 0.08 \\
\hline$(i v)$ & $\begin{array}{c}0.6010 \\
(2.70)\end{array}$ & $\begin{array}{c}0.1976 \\
(1.05)\end{array}$ & $\begin{array}{c}0.2486 \\
(1.57)\end{array}$ & $\begin{array}{c}0.7111 \\
(3.91)\end{array}$ & $\begin{array}{c}0.4224 \\
(1.89)\end{array}$ & 0.80 & 0.0743 & 0.32 & 0.20 & 0.29 & 0.19 \\
\hline
\end{tabular}

Table continued on next page ... 


\section{Table 9 continued}

\begin{tabular}{|c|c|c|c|c|c|c|c|c|c|c|c|}
\hline & \multicolumn{11}{|c|}{ Panel B: Orthogonalized Factors } \\
\hline & \multirow[b]{2}{*}{$u_{m, t}$} & \multirow[b]{2}{*}{$u_{t}^{S M B}$} & \multirow[b]{2}{*}{$u_{t}^{H M L}$} & \multirow[b]{2}{*}{$u_{t}^{W M L}$} & \multirow[b]{2}{*}{$u_{t}^{L I Q}$} & \multirow[b]{2}{*}{$R^{2}$} & \multirow{2}{*}{$\begin{array}{c}\left(10^{-2}\right) \\
\text { RMSPE }\end{array}$} & \multicolumn{4}{|c|}{ pricing error decomposition } \\
\hline & & & & & & & & size & $\mathrm{BM}$ & momentum & liquidity \\
\hline \multirow[t]{2}{*}{$(v)$} & 0.6116 & -0.0761 & 0.3854 & & & -0.11 & 0.1770 & 0.02 & 0.06 & 0.62 & 0.31 \\
\hline & $(2.71)$ & $(-0.24)$ & $(1.47)$ & & & & & & & & \\
\hline \multirow[t]{2}{*}{$(v i)$} & 0.5872 & 0.1328 & 0.5432 & 0.9566 & & 0.44 & 0.1259 & 0.10 & 0.06 & 0.23 & 0.62 \\
\hline & $(2.58)$ & $(0.43)$ & $(1.99)$ & $(4.28)$ & & & & & & & \\
\hline \multirow[t]{2}{*}{$(v i i)$} & 0.6355 & -0.0864 & 0.5824 & & 1.0224 & 0.24 & 0.1461 & 0.04 & 0.06 & 0.85 & 0.05 \\
\hline & $(2.82)$ & $(-0.27)$ & $(2.19)$ & & $(4.40)$ & & & & & & \\
\hline \multirow[t]{2}{*}{ (viii) } & 0.6112 & 0.1234 & 0.7423 & 0.9693 & 1.0395 & 0.80 & 0.0756 & 0.31 & 0.19 & 0.30 & 0.20 \\
\hline & $(2.68)$ & $(0.39)$ & $(2.70)$ & $(4.42)$ & $(4.44)$ & & & & & & \\
\hline
\end{tabular}




\section{Table 10: Average Factor Loadings for Each Decile Portfolios}

The characteristics of betas of the five factor model as in Table 9 (iv) are explored. First, we run full-sample time series regressions of 40 test portfolios on market return, size, value, momentum, and liquidity factors as in (20) for the sample covering July 1966 - December 1999. Then, the loadings for each factor are averaged over each decile portfolios. For an example, the first element of the table, 1.0039 , is the average of market factor betas for 10 size-sorted portfolios.

\begin{tabular}{lccccc}
\hline \hline & & & & & \\
Decile Portfolio & $R_{m, t}^{e}$ & $f_{t}^{S M B}$ & $f_{t}^{H M L}$ & $f_{t}^{W M L}$ & $f_{t}^{L I Q}$ \\
\hline Size & & & & & \\
BM & 1.0039 & 0.5279 & 0.0883 & 0.0014 & -0.0387 \\
Momentum & 1.0076 & 0.0195 & 0.2411 & -0.0001 & -0.0463 \\
Liquidity & 0.9347 & 0.9056 & 0.2240 & -0.1678 & 0.0000 \\
& 1.0227 & -0.0156 & 0.0292 & -0.0144 & -0.1048 \\
\hline \hline
\end{tabular}




\section{Table 11: Cross-Sectional Regression with Macroeconomic Factors}

This table presents the estimated prices of risk, presented as percentage per month, and the corresponding $t$-stats, shown in the parenthesis, computed with Jagannathan and Wang (1998) corrected standard errors. These are estimated following Fama and MacBeth (1973) procedure on 40 test portfolios consist of four different decile portfolios sorted on size, BM, momentum, and liquidity; the full-sample time series regressions as in (20) and cross-sectional regressions as in (21) for the sample from July 1966 to December 1999. For each factor specifications, three overall performance measures are provided; intuitive $R^{2}$, root mean squared pricing error (RMSPE), and the pricing error decomposition. The $R^{2}$ is identical to the one in the cross-sectional OLS regression with average returns as dependent variables. The pricing error decomposition shows the portion of sum of squared pricing errors (SSPE) that belongs to each decile portfolios. The orthogonalized factors in Panel B are constructed following Campbell (1996), and the VAR variable orders are also shown in the table since they do matter in the orthogonalized factors. See Section 3.2 for more details.

\begin{tabular}{|c|c|c|c|c|c|c|c|c|c|c|c|}
\hline \multirow[b]{4}{*}{$(i)$} & \multirow[b]{3}{*}{$R_{m, t}^{e}$} & \multirow[b]{3}{*}{$f_{t}^{M P}$} & \multirow[b]{3}{*}{$f_{t}^{P P I}$} & \multirow[b]{3}{*}{$f_{t}^{U T S}$} & \multicolumn{3}{|c|}{ Panel A: Base Factors } & \multirow{2}{*}{\multicolumn{4}{|c|}{ pricing error decomposition }} \\
\hline & & & & & & & $\left(10^{-2}\right)$ & & & & \\
\hline & & & & & $f_{t}^{U P R}$ & $R^{2}$ & RMSPE & size & $\mathrm{BM}$ & momentum & liquidity \\
\hline & $\begin{array}{c}0.5993 \\
(2.13)\end{array}$ & $\begin{array}{c}-0.0649 \\
(-0.21)\end{array}$ & $\begin{array}{c}0.6638 \\
(2.32)\end{array}$ & $\begin{array}{c}-0.0359 \\
(-0.30)\end{array}$ & $\begin{array}{c}0.0952 \\
(1.36)\end{array}$ & 0.41 & 0.1292 & 0.05 & 0.24 & 0.46 & 0.25 \\
\hline (ii) & $\begin{array}{c}0.6159 \\
(2.60)\end{array}$ & $\begin{array}{c}0.6397 \\
(2.37)\end{array}$ & & $\begin{array}{c}-0.0351 \\
(-0.35)\end{array}$ & $\begin{array}{c}0.0218 \\
(0.40)\end{array}$ & 0.13 & 0.1560 & 0.03 & 0.23 & 0.24 & 0.51 \\
\hline \multirow[t]{4}{*}{$(i i i)$} & $\begin{array}{c}0.5988 \\
(2.09)\end{array}$ & & $\begin{array}{c}0.6974 \\
(2.66)\end{array}$ & $\begin{array}{c}-0.0340 \\
(-0.27)\end{array}$ & $\begin{array}{c}0.0987 \\
(1.48)\end{array}$ & 0.40 & 0.1293 & 0.06 & 0.23 & 0.48 & 0.23 \\
\hline & \multicolumn{11}{|c|}{ Panel B: Orthogonalized Factors } \\
\hline & & & & & & & $\left(10^{-2}\right)$ & & icing & rror decomp & sition \\
\hline & $u_{m, t}$ & $u_{t}^{M P}$ & $u_{t}^{P P I}$ & $u_{t}^{U T S}$ & $u_{t}^{U P R}$ & $R^{2}$ & RMSPE & size & $\mathrm{BM}$ & momentum & liquidity \\
\hline$(i v)$ & $\begin{array}{c}0.6322 \\
(2.05)\end{array}$ & $\begin{array}{c}-1.2403 \\
(-0.50)\end{array}$ & $\begin{array}{c}5.3412 \\
(2.29)\end{array}$ & $\begin{array}{c}-0.0822 \\
(-0.05)\end{array}$ & $\begin{array}{c}5.2986 \\
(1.63)\end{array}$ & 0.44 & 0.1259 & 0.06 & 0.24 & 0.49 & 0.22 \\
\hline$(v)$ & $\begin{array}{c}0.6465 \\
(2.57)\end{array}$ & $\begin{array}{c}3.9512 \\
(2.17)\end{array}$ & & $\begin{array}{c}0.1816 \\
(0.15)\end{array}$ & $\begin{array}{c}2.8454 \\
(1.08)\end{array}$ & 0.13 & 0.1561 & 0.02 & 0.19 & 0.25 & 0.53 \\
\hline$(v i)$ & $\begin{array}{c}0.6345 \\
(2.15)\end{array}$ & & $\begin{array}{c}4.6999 \\
(2.50)\end{array}$ & $\begin{array}{c}-0.1025 \\
(-0.07)\end{array}$ & $\begin{array}{l}5.0908 \\
(1.83)\end{array}$ & 0.43 & 0.1268 & 0.05 & 0.24 & 0.44 & 0.27 \\
\hline
\end{tabular}




\section{Table 12: Cross-Sectional Regression: Volatility Factors vs. Trading-Strategy Based Factors (I)}

This table presents the estimated prices of risk, presented as percentage per month, and the corresponding $t$-stats, shown in the parenthesis, computed with Jagannathan and Wang (1998) corrected standard errors. These are estimated following Fama and MacBeth (1973) procedure on 40 test portfolios consist of four different decile portfolios sorted on size, BM, momentum, and liquidity; the full-sample time series regressions as in (20) and cross-sectional regressions as in (21) for the sample from July 1966 to December 1999. For each factor specifications, three overall performance measures are provided; intuitive $R^{2}$, root mean squared pricing error (RMSPE), and the pricing error decomposition. The $R^{2}$ is identical to the one in the cross-sectional OLS regression with average returns as dependent variables. The pricing error decomposition shows the portion of sum of squared pricing errors (SSPE) that belongs to each decile portfolios. The orthogonalized factors in Panel B are constructed following Campbell (1996), and the VAR variable orders are also shown in the table since they do matter in the orthogonalized factors. See Section 3.2 for more details.

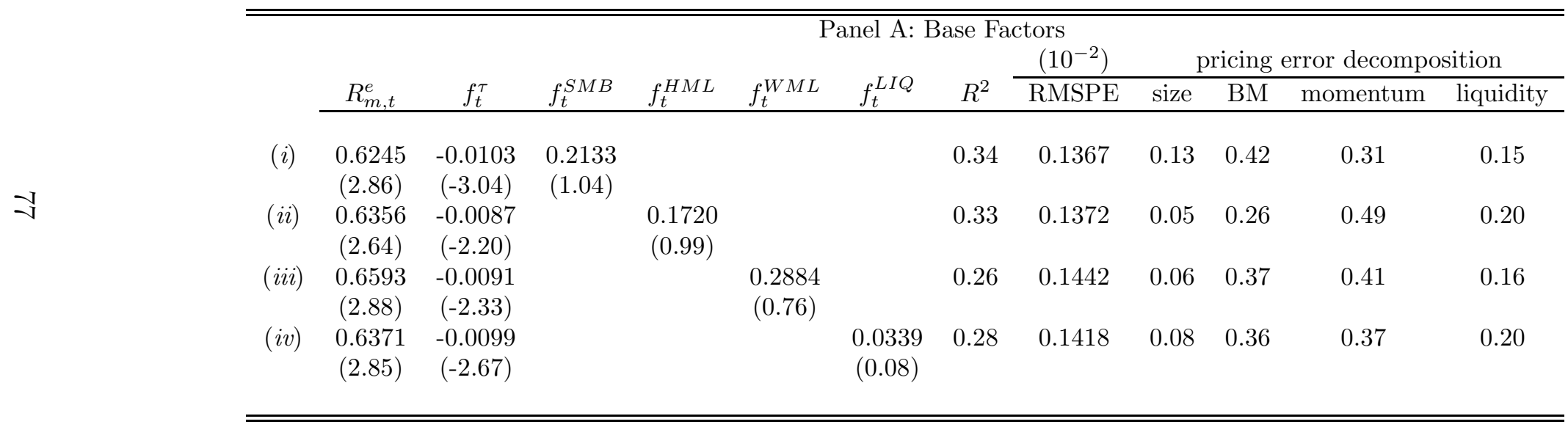

Table continued on next page ... 


\section{Table 12 continued}

\begin{tabular}{|c|c|c|c|c|c|c|c|c|c|c|c|c|}
\hline & \multicolumn{12}{|c|}{ Panel B: Orthogonalized Factors } \\
\hline & \multirow{2}{*}{\multicolumn{3}{|c|}{ Variable Order A }} & \multirow{2}{*}{\multicolumn{3}{|c|}{ Variable Order B }} & \multirow[b]{2}{*}{$R^{2}$} & \multirow{2}{*}{$\begin{array}{c}\left(10^{-2}\right) \\
\text { RMSPE }\end{array}$} & \multicolumn{4}{|c|}{ pricing error decomposition } \\
\hline & & & & & & & & & size & $\mathrm{BM}$ & momentum & liquidity \\
\hline \multirow[t]{3}{*}{$(v)$} & $u_{t}^{\tau}$ & $u_{t}^{S M B}$ & $u_{m, t}$ & $u_{t}^{S M B}$ & $u_{t}^{\tau}$ & $u_{m, t}$ & & & & & & \\
\hline & -5.2961 & 0.1090 & -0.1586 & 0.3304 & -5.2860 & -0.1385 & 0.33 & 0.1370 & 0.13 & 0.41 & 0.31 & 0.15 \\
\hline & $(-2.98)$ & $(0.26)$ & $(-0.38)$ & $(0.77)$ & $(-2.97)$ & $(-0.34)$ & & & & & & \\
\hline \multirow[t]{3}{*}{$(v i)$} & $u_{t}^{\tau}$ & $u_{t}^{H M L}$ & $u_{m, t}$ & $u_{t}^{H M L}$ & $u_{t}^{\tau}$ & $u_{m, t}$ & & & & & & \\
\hline & -4.4428 & 0.3453 & 0.1683 & 0.3141 & -4.4460 & 0.1731 & 0.34 & 0.1366 & 0.05 & 0.25 & 0.49 & 0.21 \\
\hline & $(-2.14)$ & $(1.15)$ & $(0.32)$ & $(1.06)$ & $(-2.15)$ & $(0.33)$ & & & & & & \\
\hline \multirow[t]{3}{*}{ (vii) } & $u_{t}^{\tau}$ & $u_{t}^{W M L}$ & $u_{m, t}$ & $u_{t}^{W M L}$ & $u_{t}^{\tau}$ & $u_{m, t}$ & & & & & & \\
\hline & -4.5793 & -0.1685 & 0.0297 & 0.3499 & -4.5713 & 0.0302 & 0.26 & 0.1444 & 0.06 & 0.37 & 0.41 & 0.16 \\
\hline & $(-2.28)$ & $(-0.29)$ & $(0.07)$ & $(0.72)$ & $(-2.24)$ & $(0.08)$ & & & & & & \\
\hline \multirow[t]{3}{*}{ (viii) } & $u_{t}^{\tau}$ & $u_{t}^{L I Q}$ & $u_{m, t}$ & $u_{t}^{L I Q}$ & $u_{t}^{\tau}$ & $u_{m, t}$ & & & & & & \\
\hline & -5.1092 & -0.0685 & -0.1062 & 0.0632 & -5.1098 & -0.1171 & 0.28 & 0.1420 & 0.08 & 0.35 & 0.37 & 0.20 \\
\hline & $(-2.63)$ & $(-0.14)$ & $(-0.23)$ & $(0.13)$ & $(-2.62)$ & $(-0.25)$ & & & & & & \\
\hline
\end{tabular}




\section{Table 13: Cross-Sectional Regression: Volatility Factors vs. Trading-Strategy Based Factors (II)}

This table presents the estimated prices of risk, presented as percentage per month, and the corresponding $t$-stats, shown in the parenthesis, computed with Jagannathan and Wang (1998) corrected standard errors. These are estimated following Fama and MacBeth (1973) procedure on 40 test portfolios consist of four different decile portfolios sorted on size, BM, momentum, and liquidity; the full-sample time series regressions as in (20) and cross-sectional regressions as in (21) for the sample from July 1966 to December 1999. For each factor specifications, three overall performance measures are provided; intuitive $R^{2}$, root mean squared pricing error (RMSPE), and the pricing error decomposition. The $R^{2}$ is identical to the one in the cross-sectional OLS regression with average returns as dependent variables. The pricing error decomposition shows the portion of sum of squared pricing errors (SSPE) that belongs to each decile portfolios. The orthogonalized factors in Panel B are constructed following Campbell (1996), and the VAR variable orders are also shown in the table since they do matter in the orthogonalized factors. See Section 3.2 for more details.

\begin{tabular}{|c|c|c|c|c|c|c|c|c|c|c|c|c|}
\hline & \multirow[b]{3}{*}{$R_{m, t}^{e}$} & \multirow[b]{3}{*}{$f_{t}^{\tau}$} & \multirow[b]{3}{*}{$f_{t}^{S M B}$} & \multicolumn{5}{|c|}{ Panel A: Base Factors } & \multirow{2}{*}{\multicolumn{4}{|c|}{ pricing error decomposition }} \\
\hline & & & & & & & & RMSPE & & & & \\
\hline & & & & $f_{t}^{H M L}$ & $f_{t}^{W M L}$ & $f_{t}^{L I Q}$ & $R^{2}$ & $\left(10^{-2}\right)$ & size & $\mathrm{BM}$ & momentum & liquidity \\
\hline (i) & $\begin{array}{c}0.6352 \\
(2.82)\end{array}$ & $\begin{array}{c}-0.0093 \\
(-2.27)\end{array}$ & & & $\begin{array}{c}0.3863 \\
(1.49)\end{array}$ & $\begin{array}{c}-0.0305 \\
(-0.10)\end{array}$ & 0.29 & 0.1409 & 0.08 & 0.34 & 0.34 & 0.24 \\
\hline (ii) & $\begin{array}{c}0.6280 \\
(2.82)\end{array}$ & $\begin{array}{c}-0.0086 \\
(-2.15)\end{array}$ & $\begin{array}{c}0.2445 \\
(1.28)\end{array}$ & & $\begin{array}{l}0.5087 \\
(2.62)\end{array}$ & $\begin{array}{c}0.1404 \\
(0.58)\end{array}$ & 0.38 & 0.1320 & 0.17 & 0.48 & 0.20 & 0.15 \\
\hline (iii) & $\begin{array}{c}0.6320 \\
(2.79)\end{array}$ & $\begin{array}{c}-0.0073 \\
(-1.81)\end{array}$ & & $\begin{array}{c}0.1732 \\
(1.03)\end{array}$ & $\begin{array}{c}0.3711 \\
(1.57)\end{array}$ & $\begin{array}{c}-0.0561 \\
(-0.19)\end{array}$ & 0.36 & 0.1344 & 0.05 & 0.21 & 0.45 & 0.28 \\
\hline
\end{tabular}

Table continued on next page ... 


\section{Table 13 continued}

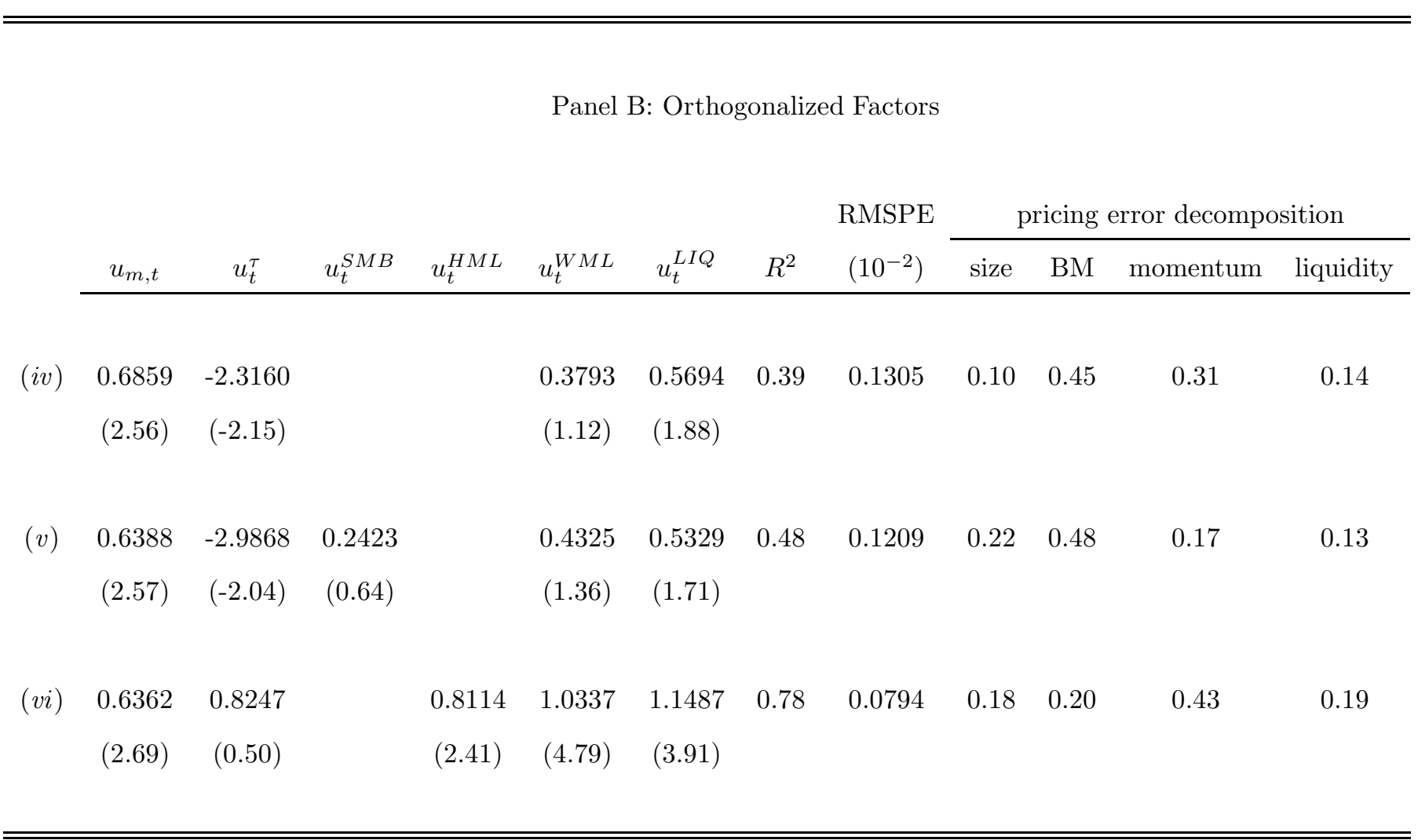




\section{Table 14: Cross-Sectional Regression: Volatility Factors vs. Macroeconomic Factors}

This table presents the estimated prices of risk, presented as percentage per month, and the corresponding $t$-stats, shown in the parenthesis, computed with Jagannathan and Wang (1998) corrected standard errors. These are estimated following Fama and MacBeth (1973) procedure on 40 test portfolios consist of four different decile portfolios sorted on size, BM, momentum, and liquidity; the full-sample time series regressions as in (20) and cross-sectional regressions as in (21) for the sample from July 1966 to December 1999. For each factor specifications, three overall performance measures are provided; intuitive $R^{2}$, root mean squared pricing error (RMSPE), and the pricing error decomposition. The $R^{2}$ is identical to the one in the cross-sectional OLS regression with average returns as dependent variables. The pricing error decomposition shows the portion of sum of squared pricing errors (SSPE) that belongs to each decile portfolios. The orthogonalized factors in Panel B are constructed following Campbell (1996), and the VAR variable orders are also shown in the table since they do matter in the orthogonalized factors. See Section 3.2 for more details.

\begin{tabular}{|c|c|c|c|c|c|c|c|c|c|c|}
\hline & \multicolumn{10}{|c|}{ Panel A: Base Factors } \\
\hline & \multirow[b]{2}{*}{$R_{m, t}^{e}$} & \multirow[b]{2}{*}{$f_{t}^{\tau}$} & \multirow[b]{2}{*}{$f_{t}^{M P}$} & \multirow[b]{2}{*}{$f_{t}^{P P I}$} & \multirow[b]{2}{*}{$R^{2}$} & \multirow{2}{*}{$\begin{array}{c}\text { RMSPE } \\
\left(10^{-2}\right) \\
\end{array}$} & \multicolumn{4}{|c|}{ pricing error decomposition } \\
\hline & & & & & & & size & $\mathrm{BM}$ & momentum & liquidity \\
\hline$(i)$ & $\begin{array}{c}0.6305 \\
(2.59)\end{array}$ & $\begin{array}{c}-0.0090 \\
(-2.25)\end{array}$ & $\begin{array}{c}0.3891 \\
(0.82)\end{array}$ & & 0.44 & 0.1250 & 0.11 & 0.51 & 0.20 & 0.17 \\
\hline \multirow[t]{4}{*}{$(i i)$} & $\begin{array}{c}0.6159 \\
(2.70)\end{array}$ & $\begin{array}{c}-0.0094 \\
(-2.96)\end{array}$ & & $\begin{array}{c}0.2312 \\
(0.71)\end{array}$ & 0.49 & 0.1195 & 0.18 & 0.48 & 0.25 & 0.08 \\
\hline & \multicolumn{10}{|c|}{ Panel B: Orthogonalized Factors } \\
\hline & \multirow{2}{*}{\multicolumn{3}{|c|}{ Variable Order }} & & & RMSPE & \multicolumn{4}{|c|}{ pricing error decomposition } \\
\hline & & & & & $R^{2}$ & $\left(10^{-2}\right)$ & size & $\mathrm{BM}$ & momentum & liquidity \\
\hline$(i i i)$ & $\begin{array}{c}u_{t}^{\tau} \\
-4.6842 \\
(-2.26)\end{array}$ & $\begin{array}{c}u_{t}^{M P} \\
2.3262 \\
(0.66)\end{array}$ & $\begin{array}{c}u_{m, t} \\
0.0493 \\
(0.09)\end{array}$ & & 0.44 & 0.1250 & 0.11 & 0.51 & 0.20 & 0.17 \\
\hline$(i v)$ & $\begin{array}{c}u_{t}^{M P} \\
2.7582 \\
(0.82)\end{array}$ & $\begin{array}{c}u_{t}^{\tau} \\
-4.4394 \\
(-1.93)\end{array}$ & $\begin{array}{c}u_{m, t} \\
0.0498 \\
(0.09)\end{array}$ & & 0.44 & 0.1250 & 0.11 & 0.51 & 0.20 & 0.17 \\
\hline$(v)$ & $\begin{array}{c}u_{t}^{\tau} \\
-4.8334 \\
(-2.79)\end{array}$ & $\begin{array}{c}u_{t}^{P P I} \\
1.6956 \\
(0.72)\end{array}$ & $\begin{array}{c}u_{m, t} \\
0.1866 \\
(0.29)\end{array}$ & & 0.49 & 0.1195 & 0.18 & 0.48 & 0.25 & 0.08 \\
\hline$(v i)$ & $\begin{array}{c}u_{t}^{P P I} \\
1.6781 \\
(0.71)\end{array}$ & $\begin{array}{c}u_{t}^{\tau} \\
-4.8382 \\
(-2.80)\end{array}$ & $\begin{array}{c}u_{m, t} \\
0.1863 \\
(0.29)\end{array}$ & & 0.49 & 0.1195 & 0.18 & 0.48 & 0.25 & 0.08 \\
\hline
\end{tabular}




\section{Table 15: Expected vs. Observed Profits from Various Trading Strategies}

We extend Griffin, Ji, and Martin (2003) and Liu and Zhang (2008) to other traded factors. We regress one of the traded factors, $\mathcal{F}=\left\{\mathrm{SMB}_{t}, \mathrm{HML}_{t}, \mathrm{WML}_{t}, \mathrm{LIQ}_{t}\right\}$, on our choice of factors as in time-series regression (20): $\mathcal{F}_{t}^{\bullet}=a^{\bullet}+\sum_{s=1}^{S} \beta_{s}^{\bullet} F_{t}^{s}+e_{t}^{\bullet}$. Then, the expected profits, $E\left[\mathcal{F}^{\bullet}\right]$, are estimated as $E\left[\mathcal{F}^{\bullet}\right]=\sum_{s=1}^{S} \hat{\Lambda}_{s} \hat{\beta}_{s}^{\bullet}$ where $\hat{\beta}_{s}^{\bullet}$ is estimated from the full-sample time-series regressions and the prices of risk, $\hat{\Lambda}_{s}$, are estimated from two-stage Fama and MacBeth (1973) regressions using the 40 test assets. In fact, we already have the prices of risk estimates from results in Section 5.1 (Table 7, 9, and 11). The numbers shown in $(i)$ are the observed profits from various trading strategies averaged over a period from July 1966 to December 1999. The numbers shown in (ii)-(vii) are expected profits and the corresponding ratios are computed as expected profits over observed profits.

\begin{tabular}{|c|c|c|c|c|c|c|c|}
\hline \multirow[t]{5}{*}{ (i) } & [Trading Strategy] & Mean Profit & (ii) & [Table $7(\mathrm{v})]$ & $f_{t}^{\tau}$ & Ratio & \\
\hline & SMB & 0.15 & & SMB & 0.11 & $72.77 \%$ & \\
\hline & HML & 0.31 & & HML & 0.04 & $12.09 \%$ & \\
\hline & LIQ & 0.33 & & LIQ & 0.21 & $64.53 \%$ & \\
\hline & WML & 0.84 & & WML & 0.38 & $45.54 \%$ & \\
\hline \multirow[t]{5}{*}{ (iii) } & [Table 7(iii)] & $R_{m, t}^{e}$ & $f_{t}^{\tau}$ & Ratio & & & \\
\hline & SMB & 0.14 & 0.05 & $118.70 \%$ & & & \\
\hline & HML & -0.16 & 0.10 & $-19.59 \%$ & & & \\
\hline & LIQ & -0.23 & 0.37 & $44.45 \%$ & & & \\
\hline & WML & 0.00 & 0.38 & $44.44 \%$ & & & \\
\hline \multirow[t]{5}{*}{$(i v)$} & [Table 9(i)] & $R_{m, t}^{e}$ & $f_{t}^{S M B}$ & $f_{t}^{H M L}$ & Ratio & & \\
\hline & SMB & 0.00 & 0.09 & 0.00 & $56.60 \%$ & & \\
\hline & HML & 0.00 & 0.00 & 0.05 & $17.00 \%$ & & \\
\hline & LIQ & -0.18 & -0.07 & -0.03 & $-83.08 \%$ & & \\
\hline & WML & -0.01 & -0.04 & -0.02 & $-7.95 \%$ & & \\
\hline \multirow[t]{5}{*}{$(v)$} & [Table 9(iv)] & $R_{m, t}^{e}$ & $f_{t}^{S M B}$ & $f_{t}^{H M L}$ & $f_{t}^{W M L}$ & $f_{t}^{L I Q}$ & Ratio \\
\hline & SMB & 0.00 & 0.20 & 0.00 & 0.00 & 0.00 & $129.46 \%$ \\
\hline & HML & 0.00 & 0.00 & 0.25 & 0.00 & 0.00 & $80.88 \%$ \\
\hline & LIQ & 0.00 & 0.00 & 0.00 & 0.00 & 0.42 & $129.53 \%$ \\
\hline & WML & 0.00 & 0.00 & 0.00 & 0.71 & 0.00 & $85.15 \%$ \\
\hline \multirow[t]{5}{*}{$(v i)$} & [Table 11(ii)] & $R_{m, t}^{e}$ & $f_{t}^{M P}$ & $f_{t}^{U T S}$ & $f_{t}^{U P R}$ & Ratio & \\
\hline & SMB & 0.13 & 0.04 & -0.04 & -0.05 & $52.30 \%$ & \\
\hline & HML & -0.17 & 0.16 & -0.04 & 0.03 & $-8.59 \%$ & \\
\hline & LIQ & -0.20 & -0.10 & 0.07 & -0.01 & $-76.64 \%$ & \\
\hline & WML & 0.04 & 0.29 & 0.06 & 0.07 & $55.42 \%$ & \\
\hline \multirow[t]{5}{*}{ (vii) } & [Table 11(iii)] & $R_{m, t}^{e}$ & $f_{t}^{P P I}$ & $f_{t}^{U T S}$ & $f_{t}^{U P R}$ & Ratio & \\
\hline & SMB & 0.13 & 0.14 & -0.04 & -0.22 & $2.20 \%$ & \\
\hline & HML & -0.16 & 0.08 & -0.04 & 0.09 & $-10.96 \%$ & \\
\hline & LIQ & -0.20 & 0.14 & 0.07 & -0.02 & $-4.16 \%$ & \\
\hline & WML & 0.04 & 0.12 & 0.06 & 0.27 & $59.64 \%$ & \\
\hline
\end{tabular}




\section{Figure 1: GARCH-MIDAS with Rolling Window RV}

The GARCH-MIDAS model with rolling window RV $\left(J=125, N^{\prime}=22\right)$ as specified in (7)-(11) is fitted over daily stock returns from January 3, 1966 to December 31, 1999 by QMLE. The first panel shows the estimated conditional volatility and its long run component in standard deviation and annualized scale. In the second panel, these daily-varying conditional volatility and its long run component series are summed over a quarter to show quarterly aggregated conditional volatility and its quarterly aggregated long run component. Quarterly RV's are also shown for comparison. As in the first panel, these are shown in standard deviation and annualized scale.
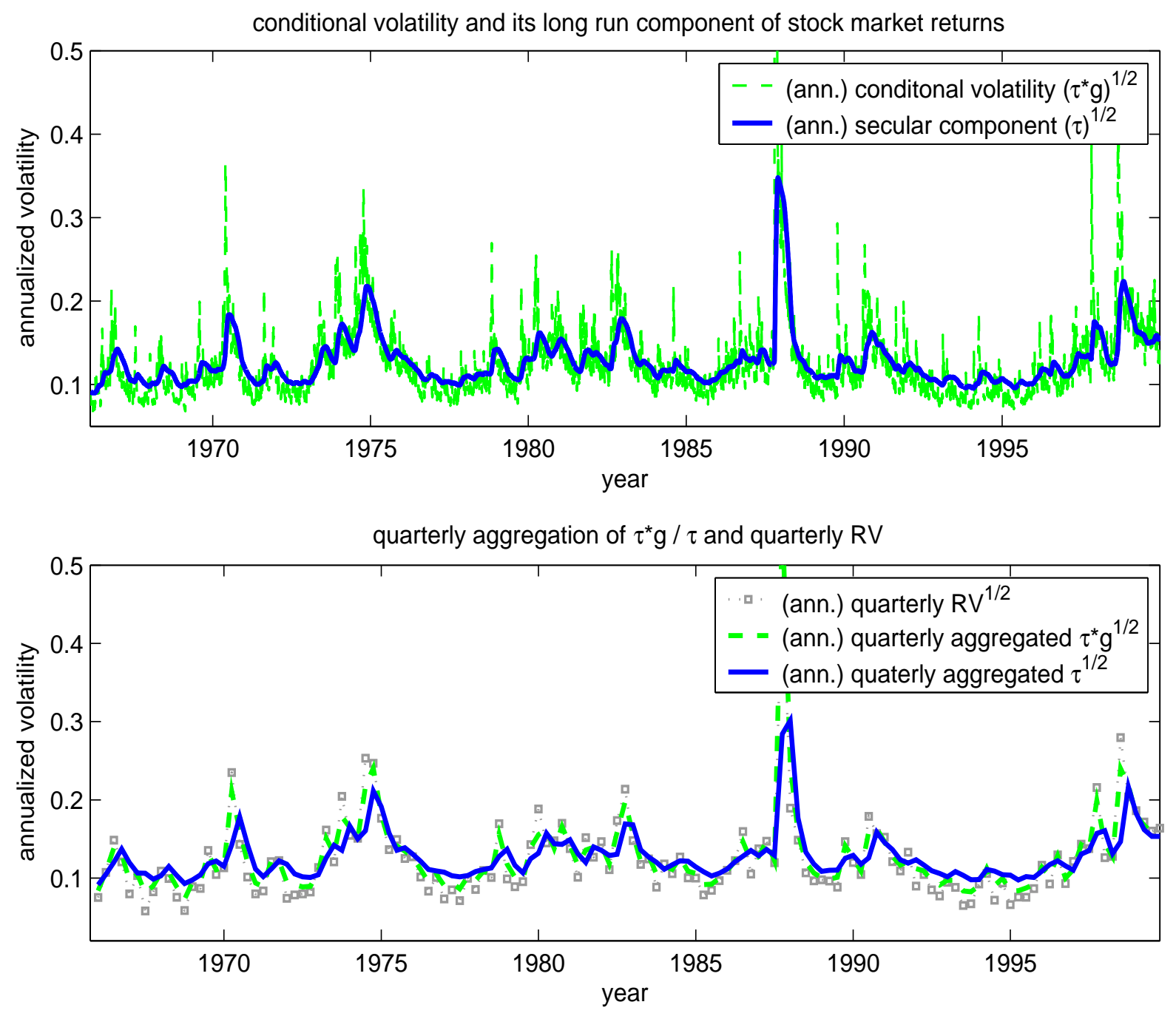


\section{Figure 2: GARCH-MIDAS with Momentum Factor}

The GARCH-MIDAS(momentum factor) model as specified in (7)-(8) and (11)-(12) with $J^{\prime}=36$ is fitted over daily stock returns from January 3, 1966 to December 31, 1999 by QMLE. The figure shows the estimated conditional volatility and its long run component in standard deviation and annualized scale. For comparison, the long-run component from the GARCH-MIDAS model with rolling window RV is also plotted.

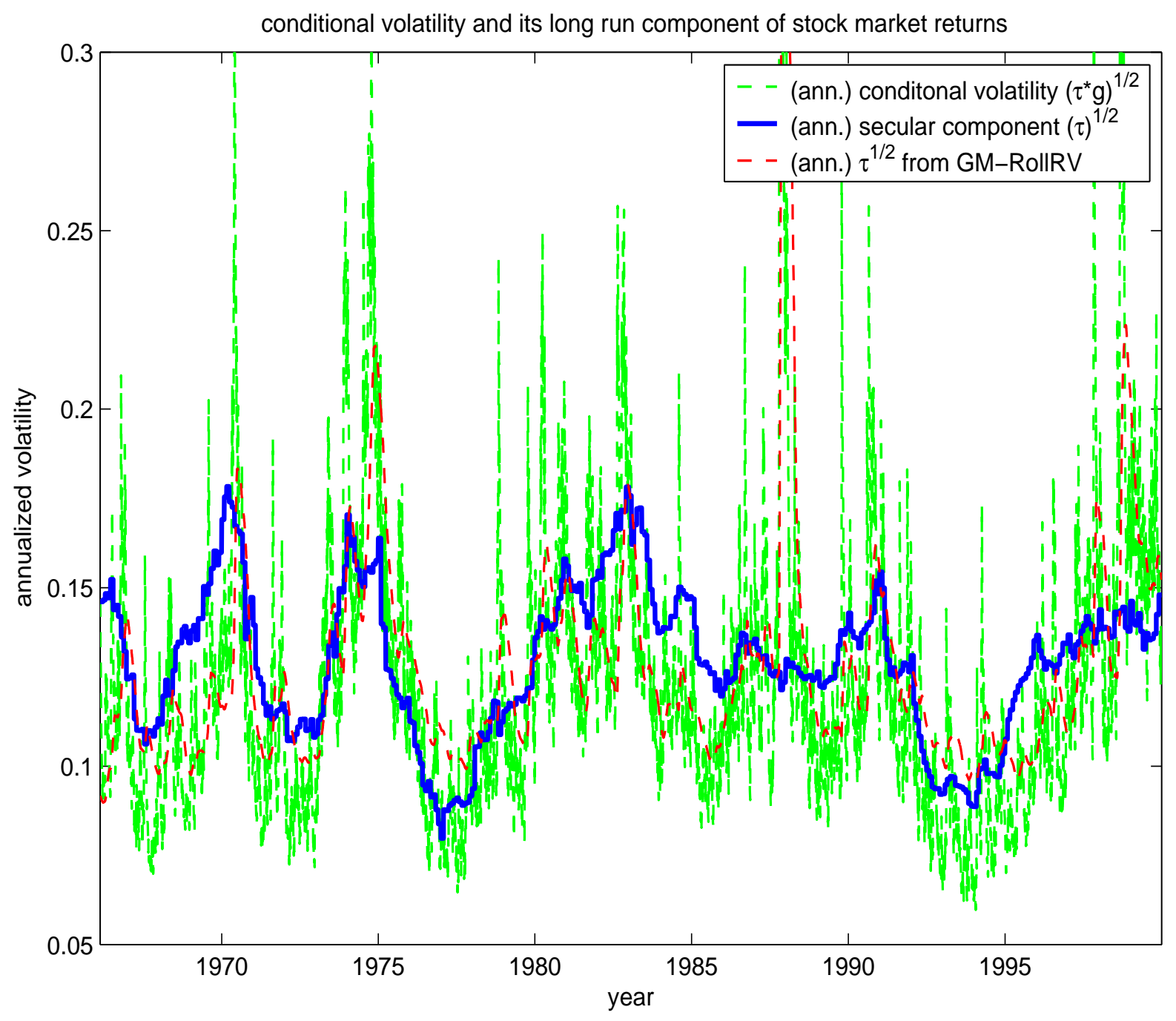




\section{Figure 3: GARCH-MIDAS with Size Factor}

The GARCH-MIDAS(size factor) model as specified in (7)-(8) and (11)-(12) with $J^{\prime}=36$ is fitted over daily stock returns from January 3, 1966 to December 31, 1999 by QMLE. The figure shows the estimated conditional volatility and its long run component in standard deviation and annualized scale. For comparison, the long-run component from the GARCH-MIDAS model with rolling window RV is also plotted.

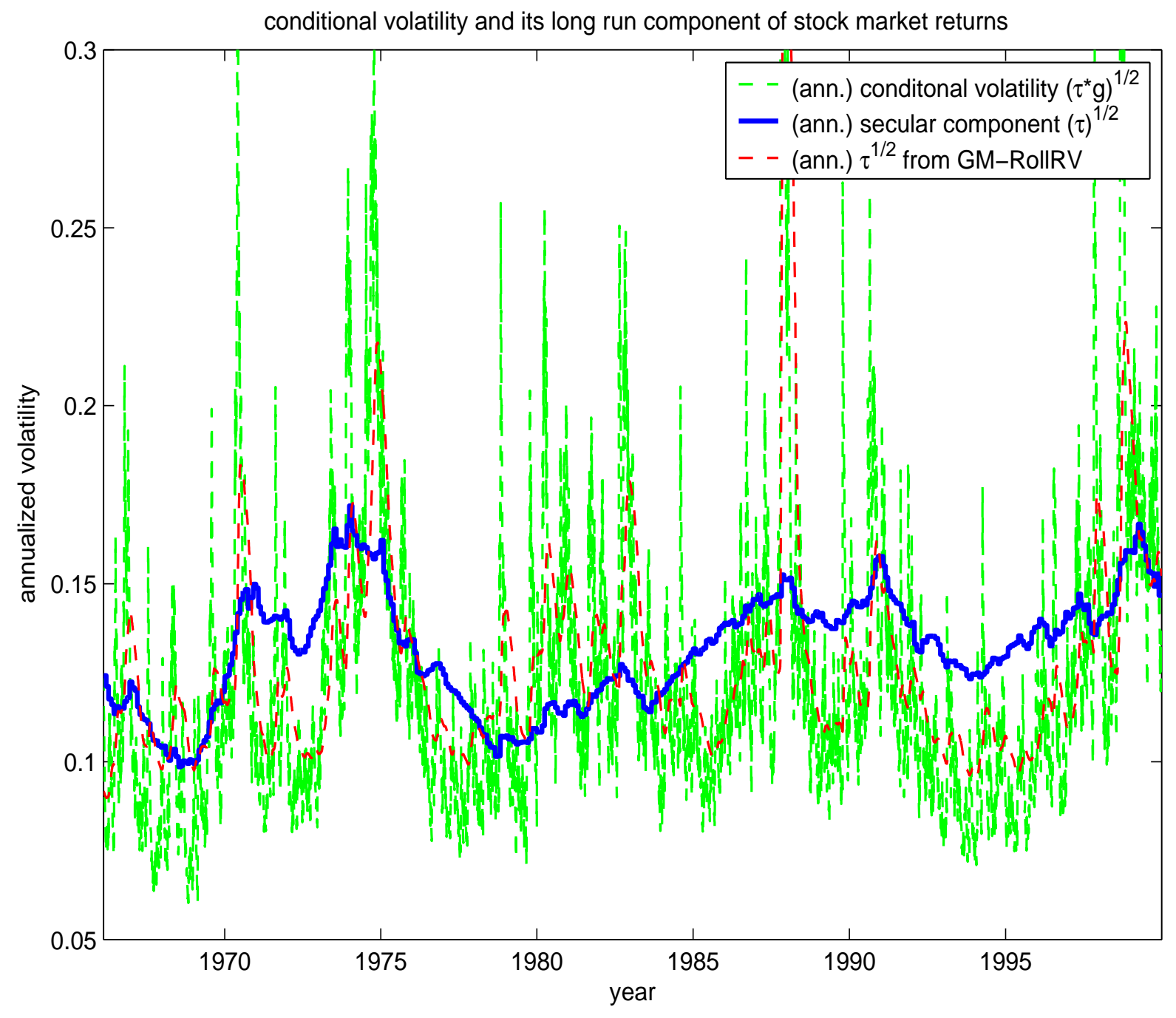




\section{Figure 4: GARCH-MIDAS with Value Factor}

The GARCH-MIDAS(value factor) model as specified in (7)-(8) and (11)-(12) with $J^{\prime}=36$ is fitted over daily stock returns from January 3, 1966 to December 31, 1999 by QMLE. The figure shows the estimated conditional volatility and its long run component in standard deviation and annualized scale. For comparison, the long-run component from the GARCH-MIDAS model with rolling window RV is also plotted.

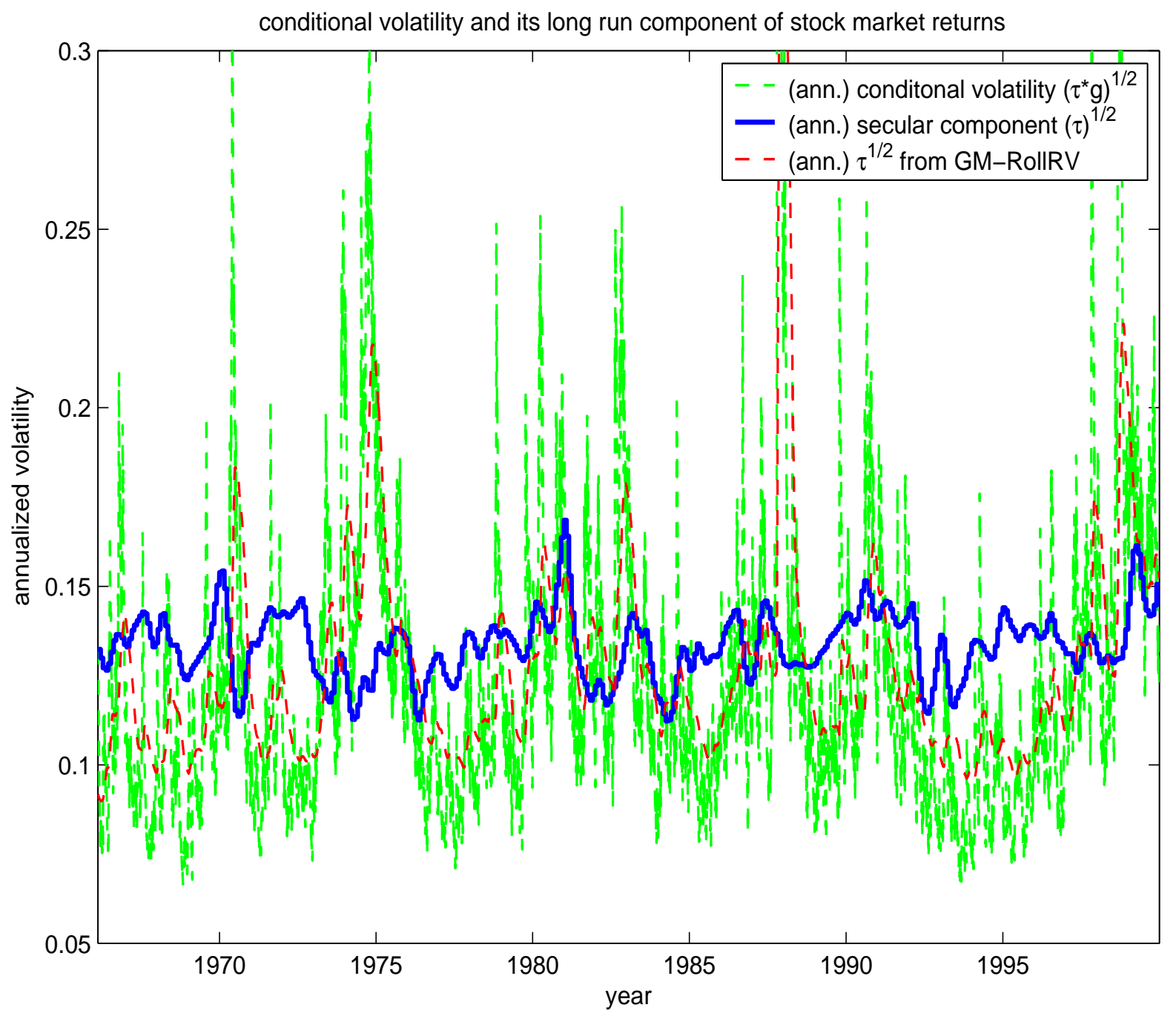




\section{Figure 5: Expected Returns with Volatility Factors}

Realized average returns versus fitted expected returns of our 40 test portfolios consist of four different decile portfolios sorted on size, BM, momentum, and liquidity are shown. The expected returns are estimated by Fama and MacBeth (1973) procedure on our test assets with volatility factors, $\left\{R_{m, t}^{e}, f_{t}^{\tau}, f_{t}^{g}\right\}$, as specified in Table $7(i i)$. Each plot represents one portfolio. The first character denotes the sorting crieteria for the decile portfolios; ' $s$ ' for size, ' $b$ ' for BM, ' $m$ ' for momentum, and ' $l$ ' for liquidty. The number next to the character represents the portfolio number.

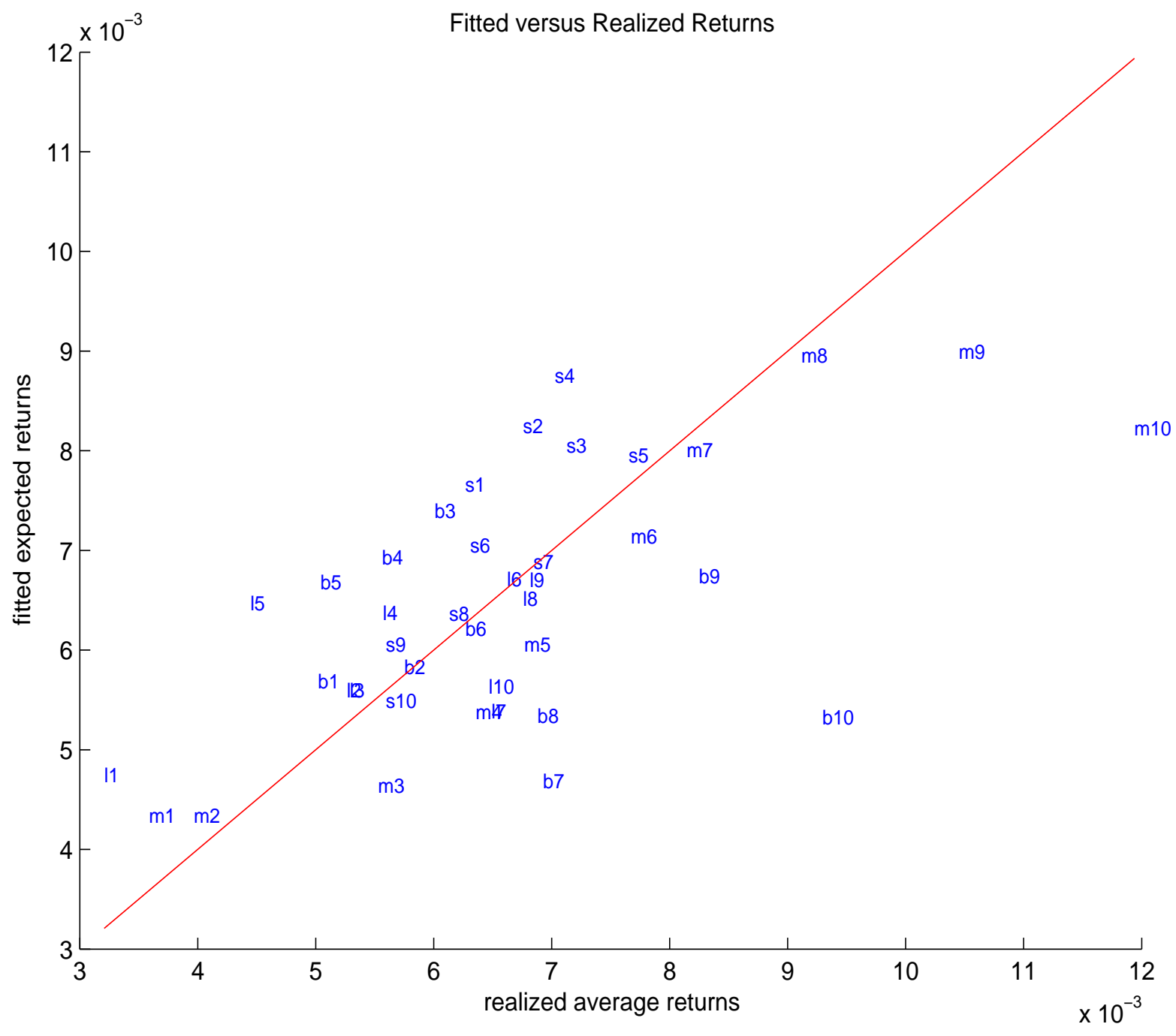




\section{Figure 6: Expected Returns with Volatility Factors: Disaggregative View}

This figure presents the same pricing errors as in Figure 5, but in a different format. The pricing errors that belong to each decile portfolios are separately shown. As in Figure 5 and Table 7 (ii), we follow Fama and MacBeth (1973) procedure to estimate prices of risk of the factor set, $\left\{R_{m, t}^{e}, f_{t}^{\tau}, f_{t}^{g}\right\}$, fitted over our 40 test portfolios. The numbers present the portfolio numbers.
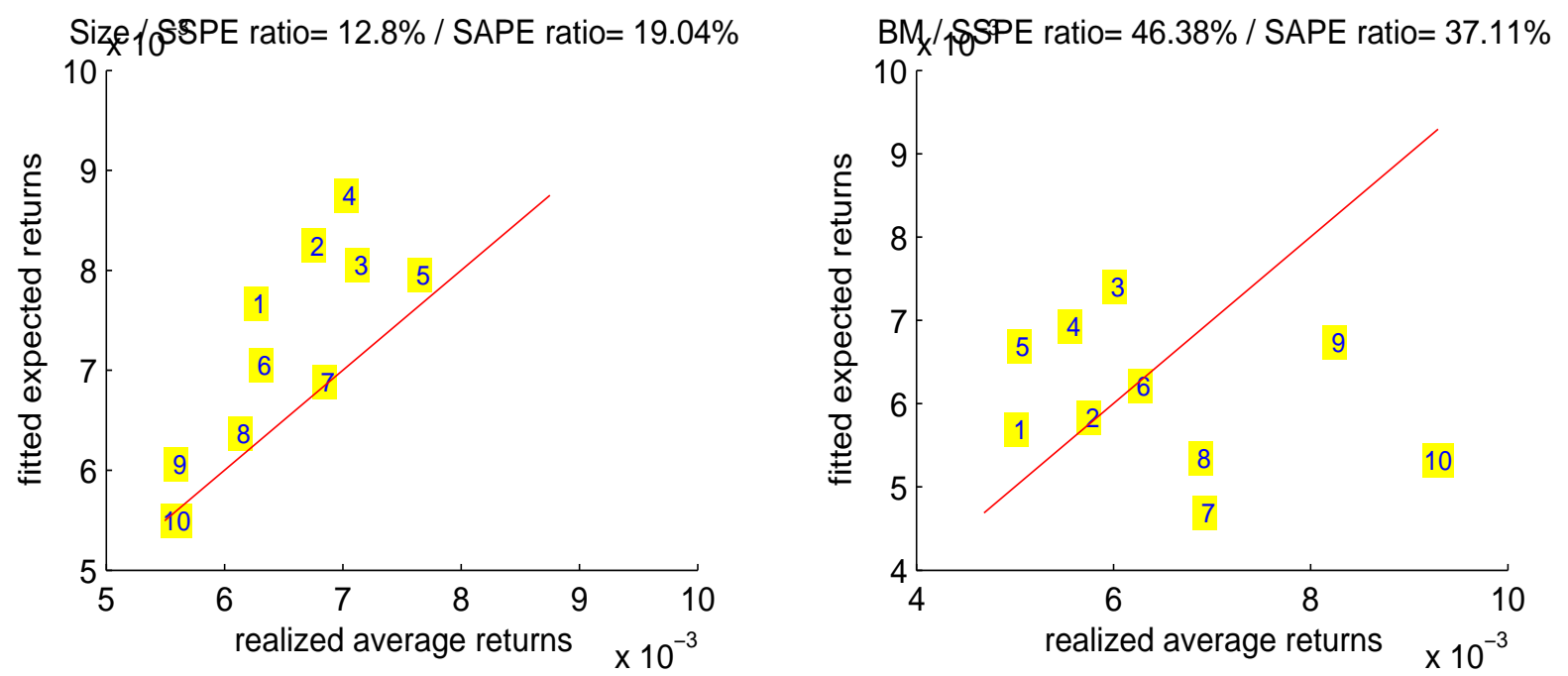

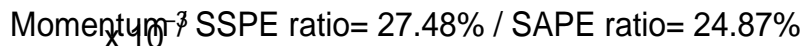
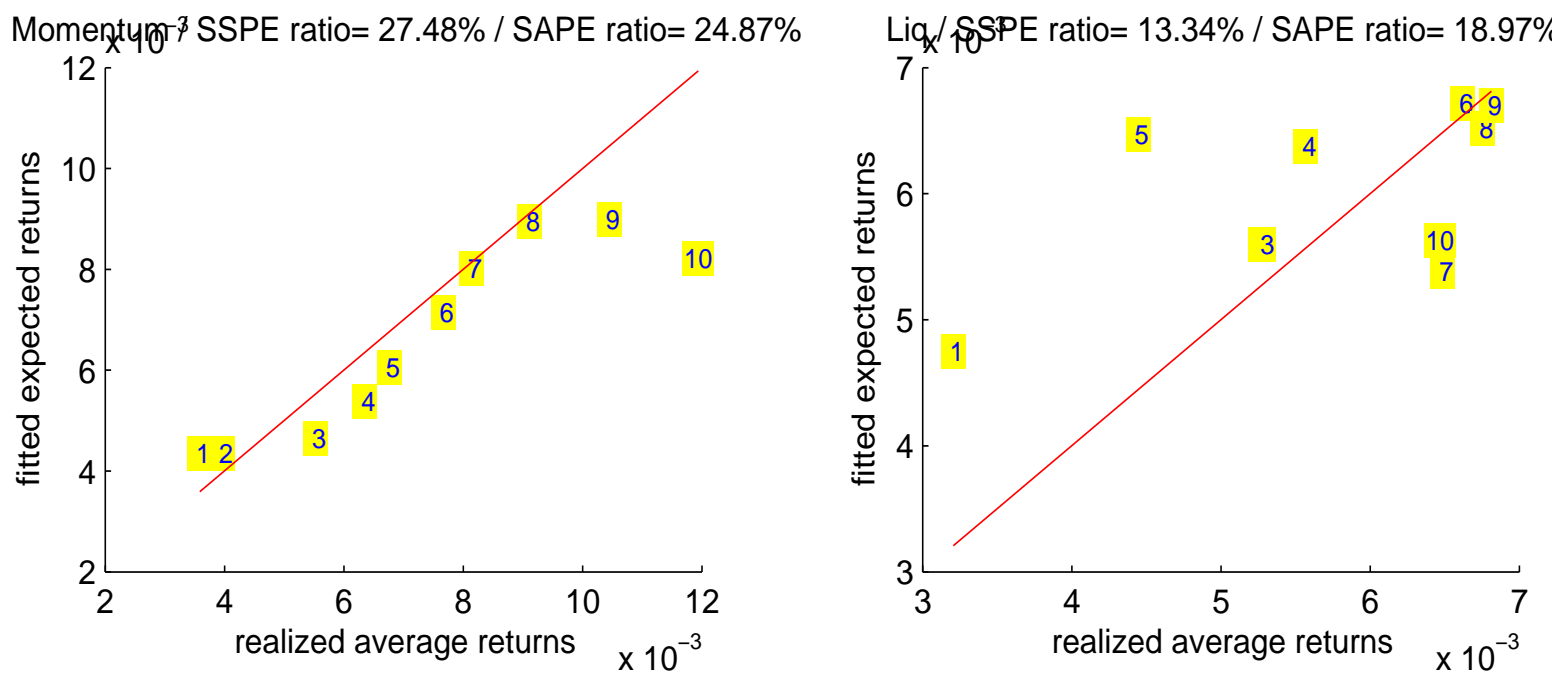
Figure 7: Expected Returns with Single Long-Run Volatility Component Factor: Disaggregative View

This figure shows the pricing errors of one factor model with $\tau_{t}$ innovation as shown in Table $7(v)$. The pricing errors that belong to each decile portfolios are separately shown. We follow Fama and MacBeth (1973) procedure to estimate the price of long-run volatility component risk fitted over our 40 test portfolios. The numbers present the portfolio numbers.
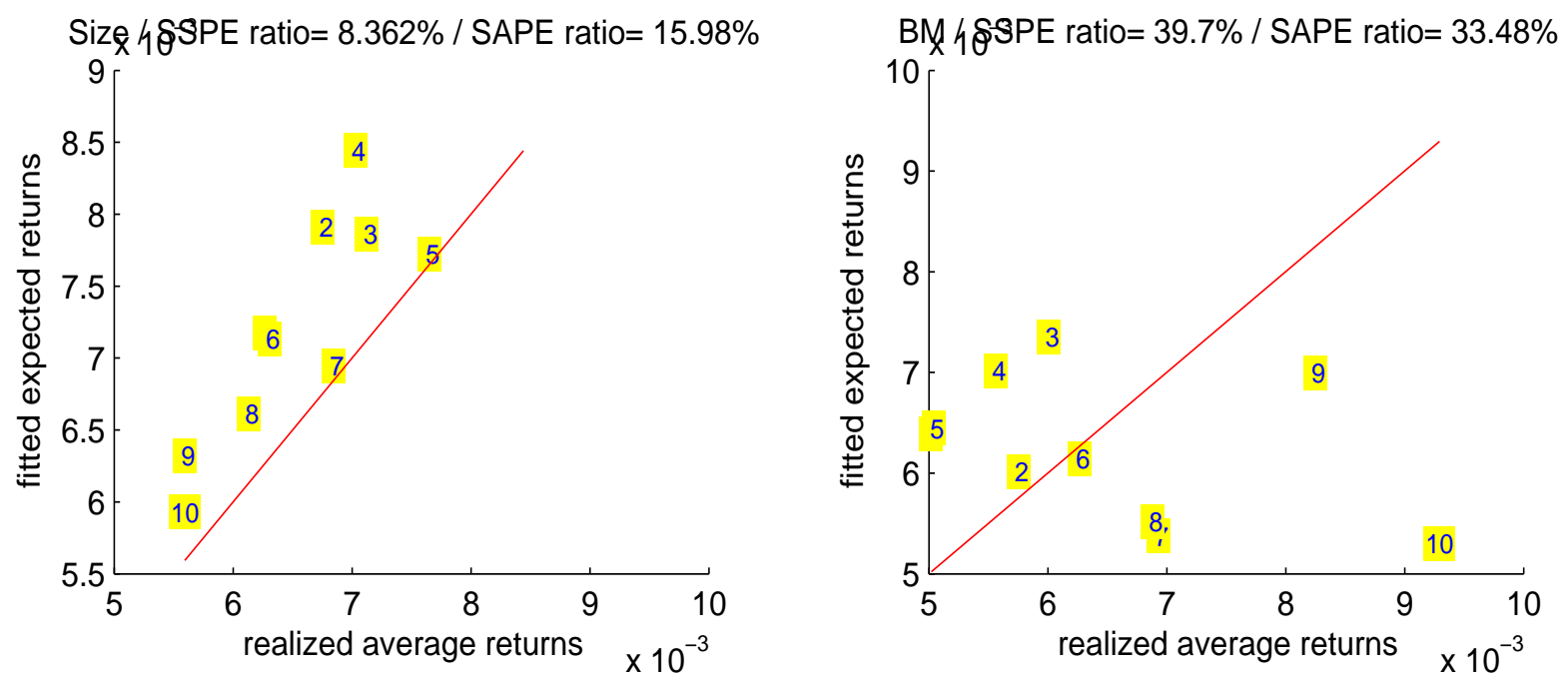

Moment+H ${ }^{3}$ SSPE ratio= $36.63 \% /$ SAPE ratio= $31.5 \%$
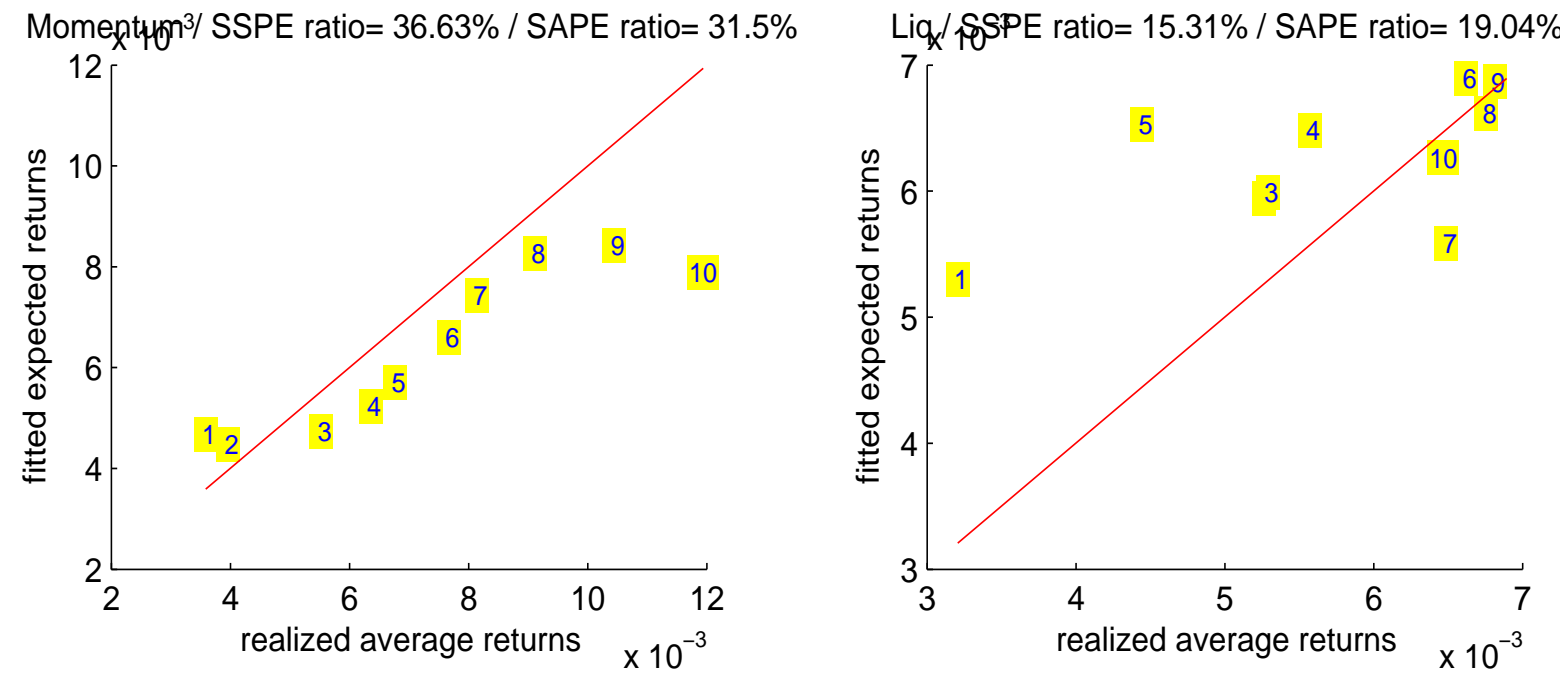


\section{Appendix A}

\section{Simple Extension of Campbell (1993) with Heteroskedasticity}

Campbell (1993) succeeds in substituting out consumption growth from risk premium equation. He achieves this goal by $(i)$ log-linearizing the budget constraint and (ii) assuming asset returns and consumption are jointly conditionally homoskedastic and log-normally distributed. Following Campbell (1993), Epstein and Zin (1991), and many others, we assume stock market is a good proxy for total wealth portfolio. Since we are interested in a case in which heteroskedasticity is allowed, we introduce implications of Campbell (1993) when heteroskedasticity is allowed.

One of major constributions of Campbell (1993) is log-linearization of the budget constraint, which allows us to solve the consumption and portfolio-choice problem in closed form. Using a trivial identity concerning the log total wealth growth and log consumption growth, the resulting budget constraint becomes difference equation of log consumption-wealth ratio:

$$
c_{t+1}-w_{t+1}=\frac{1}{\rho}\left(c_{t}-w_{t}\right)+\Delta c_{t+1}-r_{m, t+1}-k
$$

where $c_{t}, w_{t}$, and $r_{m, t}$ are $\log$ of consumption, total wealth, and market return at time $t$, respectively. $\rho$ and $k$ are constants from the Taylor expansion. Then, by a set of procedures that involve solving it forward and taking conditional expectation of it, he obtains,

$$
c_{t+1}-E_{t}\left[c_{t+1}\right]=\left[E_{t+1}-E_{t}\right] \sum_{j=0}^{\infty} \rho^{j} r_{m, t+1+j}-\left[E_{t+1}-E_{t}\right] \sum_{j=0}^{\infty} \rho^{j} \Delta c_{t+1+j}
$$

So far heteroskedasticity did not get involved in any of the steps, but it does so from the next step. We can explicitly solve Euler equation for the market return when we 
assume market return and consumption growth are jointly conditionally log-normally distributed:

$$
E_{t}\left[\Delta c_{t+1}\right]=\mu_{m, t}+\sigma E_{t}\left[r_{m, t+1}\right]
$$

where

$$
\mu_{m, t}=\sigma \log \beta+\frac{1}{2}\left(\frac{\theta}{\sigma}\right) \operatorname{Var}_{t}\left[\Delta c_{t+1}-\sigma r_{m, t+1}\right]
$$

where $0<\beta<1, \sigma$ is the elasticity of intertemporal substitution, $\theta=(1-\gamma) /[1-(1 / \sigma)]$, and $\gamma$ is the coefficient of relative risk aversion. Note that $\mu_{m, t}$ has a time subscript. When homoskedasticity is assumed it becomes a constant, which enables us to substitute out consumption completely from equation (A-2) by using equation (A-3). This eventually allow us to write risk premium equation solely in terms of market returns. However, we can still substitute out consumption growth in equation (A-2) using equation (A-3). Although it doesn't allow us to substitute out consumption completely, it introduces interesting variables into the consumption (growth) innovation process.

$$
\begin{aligned}
\Delta c_{t+1}-E_{t}\left[\Delta c_{t+1}\right]= & \left(c_{t+1}-c_{t}\right)-E_{t}\left[c_{t+1}-c_{t}\right] \\
= & c_{t+1}-E_{t}\left[c_{t+1}\right] \\
= & r_{m, t+1}-E_{t}\left[r_{m, t+1}\right] \\
& +(1-\sigma)\left[E_{t+1}-E_{t}\right] \sum_{j=1}^{\infty} \rho^{j} r_{m, t+1+j} \\
& -\left[E_{t+1}-E_{t}\right] \sum_{j=1}^{\infty} \rho^{j} \mu_{m, t+j}
\end{aligned}
$$

The following is the equation (18) in Campbell (1993).

$$
E_{t}\left[r_{i, t+1}^{e}\right]+\frac{V_{i i}}{2}=\frac{\theta}{\sigma} V_{i c}+(1-\theta) V_{i m}
$$


where $V_{i i}=\operatorname{Var}\left(r_{i, t}\right), V_{i c}=\operatorname{Cov}\left(r_{i, t}, \Delta c_{t}\right)$, and $V_{i m}=\operatorname{Cov}\left(r_{i, t}, r_{m, t}\right)$. Since Campbell (1993) assume homoskedasticity, the above is written accordingly. However, when heteroskedasticity is allowed for stock return and consumption growth, the above relation still holds if we put time subsripts onto all the second moments. Hence, we can rewrite it as follows; ${ }^{47}$

$$
E_{t}\left[r_{i, t+1}^{e}\right]+\frac{V_{i i, t}}{2}=\frac{\theta}{\sigma} \operatorname{Cov}_{t}\left(\Delta c_{t+1}, r_{i . t+1}^{e}\right)+(1-\theta) \operatorname{Cov}_{t}\left(r_{m, t+1}, r_{i . t+1}^{e}\right)
$$

We can substitute consumption growth for equation (A-5). Finally, we can expand $\mu_{m, t}$ and obtain

$$
\begin{aligned}
E_{t}\left[r_{i, t+1}^{e}\right]+\frac{V_{i i, t}}{2} & \\
= & \frac{\theta}{\sigma} \operatorname{Cov}_{t}\left(\Delta c_{t+1}-E_{t}\left[\Delta c_{t+1}\right], r_{i, t+1}^{e}\right)+(1-\theta) \operatorname{Cov}_{t}\left(r_{m, t+1}, r_{i, t+1}^{e}\right) \\
= & \left(1-\theta+\frac{\theta}{\sigma}\right) \operatorname{Cov}_{t}\left(r_{m, t+1}, r_{i, t+1}^{e}\right) \\
& +\theta \frac{1-\sigma}{\sigma} \operatorname{Cov}_{t}\left(\left[E_{t+1}-E_{t}\right] \sum_{j=1}^{\infty} \rho^{j} r_{m, t+1+j}, r_{i, t+1}^{e}\right) \\
& \quad-\frac{\theta^{2}}{2 \sigma^{2}} \operatorname{Cov}_{t}\left(\left[E_{t+1}-E_{t}\right] \sum_{j=1}^{\infty} \rho^{j} \operatorname{Var}_{t+j}\left[\Delta c_{t+j+1}-\sigma r_{m, t+j+1}\right], r_{i, t+1}^{e}\right)
\end{aligned}
$$

\footnotetext{
${ }^{47}$ Note that risk-free rate for $t+1$ is known at time $t$ and subtracting risk-free rate from a return in conditional covariance term doesn't affect any other terms.
} 


\section{Appendix B}

\section{Conditioning Down the Asset Pricing Equation}

Without any additional assumptions, we follow Campbell and Vuolteenaho (2004) to replace $E_{t}\left[r_{i, t+1}\right]-r_{f, t+1}+V_{i i, t} / 2$ with simple expected returns, $E_{t}\left[R_{i, t+1}-R_{f, t+1}\right]$. In the lognormal model, both expectations are identical, and by using simple returns, we make our results easier to compare with previous empirical studies. Then, we need to condition down equation (16). However, in general, unconditional expectation of conditional covariance and unconditional covariance of two random variables are not the same. Hence, we need a little trick on $V_{i m, t}$. Note that $V_{i m, t}=\operatorname{Cov}_{t}\left(r_{i, t+1}, r_{m, t+1}\right)=$ $\operatorname{Cov}_{t}\left(r_{i, t+1}, \check{r}_{m, t+1}\right)$ where $\check{r}_{m, t+1}=r_{m, t+1}-E_{t}\left[r_{m, t+1}\right]$. Also, note that $\epsilon_{n, t+1}$ 's are already innovations to information set at time $t$. Then, we take unconditional expectations on both sides of equation (16) and obtain

$$
E\left[R_{i, t+1}-R_{f, t+1}\right]=\gamma V_{i \check{m}}+\sum_{n=1}^{N}\left[(\gamma-1) \lambda_{n}-\frac{(\gamma-1)^{2}}{2(\sigma-1)^{2}} \xi_{n}\right] V_{i n}
$$

where $V_{i \check{m}}=\operatorname{Cov}\left(r_{i, t+1}, \check{r}_{m, t+1}\right)$ and $V_{i n}=\operatorname{Cov}\left(r_{i, t+1}, \epsilon_{n, t+1}\right)$. Note that we dropped time subscript $t$ from covariance notation. Furthermore, we can show by first-order Taylor expansion with respect to $R_{i, t+1}=1$ that $r_{i, t+1}=\log R_{i, t+1} \approx R_{i, t+1}-1$. This approximation works well as long as $R_{i, t+1}$ is not far off 1 . We use monthly returns for our cross-sectional studies and average returns of our test assets range from 1.00851 to 1.01724 in terms of simple return and the approximation is expected work well around this range. Hence, equation (B-1) can be rewritten as

$$
\begin{aligned}
E\left[R_{i, t+1}-R_{f, t+1}\right] & =\gamma \sigma_{\check{r}, m}^{2} \beta_{i \check{m}}+\sum_{n=1}^{N}\left[(\gamma-1) \lambda_{n}-\frac{(\gamma-1)^{2}}{2(\sigma-1)^{2}} \xi_{n}\right] \sigma_{\epsilon, n}^{2} \beta_{i n} \\
& =\Lambda_{\check{m}} \beta_{i \check{m}}+\sum_{n=1}^{N} \Lambda_{n} \beta_{i n}
\end{aligned}
$$


where $\beta_{i \check{m}}=\operatorname{Cov}\left(R_{i, t+1}, \check{R}_{m, t+1}\right) / \sigma_{\check{r}, m}^{2}, \beta_{i n}=\operatorname{Cov}\left(R_{i, t+1}, \epsilon_{n, t+1}\right) / \sigma_{\epsilon, n}^{2}, \sigma_{\check{r}, m}^{2}=\operatorname{Var}\left(\check{R}_{m, t+1}\right)$, $\sigma_{\epsilon, n}^{2}=\operatorname{Var}\left(\epsilon_{n, t+1}\right)$, and $\check{R}_{m, t+1}=R_{m, t+1}-E_{t}\left[R_{m, t+1}\right]$. 


\section{Appendix $\mathrm{C}$}

\section{Cross-Sectional Regression with Portfolio Returns in Excess of Risk Free Rate}

Much empirical work in finance is cast in terms of expected return-beta representations of linear factor pricing models of the form

$$
E\left(R^{i}\right)=\gamma+\beta_{a}^{i} \lambda_{a}+\beta_{b}^{i} \lambda_{b}+\cdots
$$

The $\beta$ terms are defined as the coefficients in a multiple regression of returns on factors,

$$
R_{t}^{i}=a^{i}+\beta_{a}^{i} f_{a, t}+\beta_{b}^{i} f_{b, t}+\cdots+\varepsilon_{t}^{i}
$$

The central idea of cross-sectional regression comes from the observation that the drift term in $(\mathrm{C}-1)$ is constant. Exploiting this, we have the following relation:

$$
\begin{aligned}
E\left(R^{i}-R^{j}\right) & =\left(\beta_{a}^{i}-\beta_{a}^{j}\right) \lambda_{a}+\left(\beta_{b}^{i}-\beta_{b}^{j}\right) \lambda_{b}+\cdots \\
\Leftrightarrow E\left(R^{i e}\right) & =\beta_{a}^{i e} \lambda_{a}+\beta_{b}^{i e} \lambda_{b}+\cdots
\end{aligned}
$$

where $R^{i e}$ represents the return of asset $i$ in excess of that of asset $j$. Note two things from here; one is that now drift term is gone and the other is that estimates of $\beta_{a}^{i e}, \beta_{b}^{i e}, \ldots$ can be obtained from time-series regression of

$$
R_{t}^{i e}=a^{i e}+\beta_{a}^{i e} f_{a, t}+\beta_{b}^{i e} f_{b, t}+\cdots+\varepsilon_{t}^{i e}
$$

and these $\beta$ estimates are identical to the differences of $\beta$ 's obtained from separate timeseries regressions of $R_{t}^{i}$ and $R_{t}^{j}$ on the same set of factors. However, a problem arises

when we set $R_{t}^{j}=R_{t}^{f}$. The crucial difference between risk-free rate, $R_{t}^{f}$ and all other 
equity returns is that $R_{t}^{f}$ is pre-determined and that's why it's called risk-free rate. For this reason, $R_{t}^{f}$ must equal to zero-beta rate and it means

$$
\gamma=E\left(R^{f}\right)
$$

(Cochrane (2001) states that $\gamma=R^{f}$, but I think there is no reason that $R_{t}^{f}$ should be constant over time.)

Now, if we set $R_{t}^{i e}=R_{t}^{i}-R_{t}^{f}$ and use (C-5) to estimate $\beta$ 's, these estimates are contaminated by sprurious non-zero $\beta_{a}^{f}$ and $\beta_{b}^{f}$. Recognize that $\beta_{a}^{f}=\beta_{b}^{f}=\ldots=0$ because risk-free rates are predetermined ahead of time. However, if you run time-series regression of

$$
R_{t}^{f}=a^{f}+\beta_{a}^{f} f_{a, t}+\beta_{b}^{f} f_{b, t}+\cdots+\varepsilon_{t}^{i}
$$

you're actually treating that $R_{t}^{f}$ 's are NOT known at the beginning of investment horizon and $\beta$ estimates will not be zero in general. Hence, if we are to set $R_{t}^{j}=R_{t}^{f}$, we should recognize that

$$
\begin{aligned}
E\left(R^{i e}\right) & =\beta_{a}^{i e} \lambda_{a}+\beta_{b}^{i e} \lambda_{b}+\cdots \\
& =\beta_{a}^{i} \lambda_{a}+\beta_{b}^{i} \lambda_{b}+\cdots
\end{aligned}
$$

and, $\beta^{i e}$ 's used in cross-sectional regression should be estimated by $(\mathrm{C}-2)$. 


\section{References}

Adrian, Tobias, and Joshua Rosenberg, 2008, Stock Returns and Volatility: Pricing the Short-Run and Long-Run Components of Market Risk, Journal of Finance, forthcoming.

Alizadeh, Sassan, Michael W. Brandt, and Francis Diebold, 2002, Range-based estimation of stochastic volatility models, Journal of Finance 57, 1047-1091.

Altonji, Joseph G., and Lewis M. Segal, 1996, Small-Sample Bias in GMM Estimation of Covariance Structures, Journal of Business and Economic Statistics 14, 353-366.

Ang, Andrew, Robert J. Hodrick, Yuhang Xing, and Xiaoyan Zhang, 2006, The CrossSection of Volatility and Expected Returns, Journal of Finance 61, 259-299.

Aretz, Kevin, Söhnke M. Bartram, and Peter F. Pope, 2007, Macroeconomic Risks and Characteristic-Based Factor Models, Working Paper, Lancaster University Management School.

Bansal, Ravi, Robert F. Dittmar, and Christian T. Lundblad, 2005, Consumption, Dividends, and the Cross Section of Equity Returns, Journal of Finance 60, 16391672 .

Banz, Rolf W., 1981, The Relationship between Return and Market Value of Common Stocks, Journal of Financial Economics 9, 3-18.

Brennan, Michael J., Ashley W. Wang, and Yihong Xia, 2004, Estimation and Test of a Simple Model of Intertemporal Capital Asset Pricing , Journal of Finance 59, $1743-1775$.

Campbell, John Y., 1991, A Variance Decomposition for Stock Returns, Economic Journal 101, 157-179.

, 1993, Intertemporal Asset Pricing without Consumption Data, "American Economic Review" 83, 487-512.

— , 1996, Understanding Risk and Return, Journal of Political Economy 104, 298345.

- , and N. Gregory Mankiw, 1989, Consumption, Income and Interest Rates: Reinterpreting the Time Series Evidence, NBER Macroeconomics Annual, MIT press.

Campbell, John Y., and Robert J. Shiller, 1988, The Dividend-Price Ratio and Expectations of Future Dividends and Discount Factors, Review of Financial Studies $1,195-228$.

Campbell, John Y., and Tuomo Vuolteenaho, 2004, Bad Beta, Good Beta, American Economic Review 94, 1249-1275. 
Carhart, Mark M., 1997, On Persistence in Mutual Fund Performance, Journal of Finance 52, 57-82.

Chen, Joseph, 2003, Intertemporal CAPM and the Cross-Section of Stock Returns, Working paper, University of Southern California.

Chen, Nai-Fu, Richard Roll, and Stephen A. Ross, 1986, Economic Forces and the Stock Market, Journal of Business 59, 383-403.

Chernov, M., R. Gallant, E. Ghysels, and G. Tauchen, 2003, Alternative models for stock price dynamics, Journal of Econometrics 116, 225-257.

Chordia, Tarun, Richard Roll, and Avanidhar Subrahmanyam, 2001, Market Liquidity and Trading Activity, Journal of Finance 56, 501-530.

Chordia, T., R. Roll, and A. Subrahmanyam, 2002, Order Imbalance, Liquidity, and Market Returns, Journal of Financial Economics 65, 111-130.

Chordia, Tarun, Asani Sarkar, and Avanidhar Subrahmanyam, 2005, An Empirical Analysis of Stock and Bond Market Liquidity, Review of Financial Studies 18, 85-129.

Chordia, Tarun, and Lakshmanan Shivakumar, 2002, Momentum, Business Cycle, and Time-varying Expected Returns, Journal of Finance 57, 985-1019.

Cochrane, John H., 2001, Asset Pricing (Princeton University Press: Princeton, NJ).

Dichev, Ilia D., 1998, Is the Risk of Bankruptcy a Systematic Risk?, Journal of Finance 53, 1131-1147.

Ding, Z., and C. Granger, 1996, Modeling volatility persistence of speculative returns: A new approach, Journal of Econometrics 73, 185-215.

Duffee, Gregory R., 2005, Time Variation in the Covariance between Stock Returns and Consumption Growth, Journal of Finance 60, 1673-1712.

Engle, R., and G. Lee, 1999, A permanent and transitory component model of stock return volatility, $R$. Engle and $H$. White (ed.) Cointegration, Causality, and Forecasting: A Festschrift in Honor of Clive W. J. Granger, Oxford University Press pp. 475-497.

Engle, Robert F., Eric Ghysels, and Bumjean Sohn, 2008, On the Economic Sources of Stock Market Volatility, Working paper, NYU and UNC.

Engle, Robert F., and Jose Gonzalo Rangel, 2008, The Spline GARCH Model for Low Frequency Volatility and Its Global Macroeconomic Causes, Review of Financial Studies 21, 1187-1222.

Epstein, Larry G., and Stanley E. Zin, 1991, Substitution, Risk Aversion, and the Temporal Behavior of Consumption and Asset Returns: An Empirical Analysis, Journal of Political Economy 99, 263-286. 
Fama, Eugene, and Kenneth French, 1993, Common Risk Factors in the return on bonds and stocks, Journal of Financial Economics 33, 3-56.

Fama, Eugene, and MacBeth, 1973, Risk, Return, and Equilibrium: Empirical Tests, Journal of Political Economy 81, 607-636.

Fama, Eugene F., 1991, Efficient Capital Markets II, Journal of Finance 46, 1575-1618.

Gallant, A. Ronald, C.-T. Hsu, and George Tauchen, 1999, Using daily range data to calibrate volatility diffusions and extract the forward integrated variance, Review of Economic Statistics 81, 617-631.

Ghysels, Eric, Pedro Santa-Clara, and Rossen Valkanov, 2002, The MIDAS touch: Mixed data sampling regression models, Working paper, UNC and UCLA.

- 2005, There is a Risk-Return Tradeoff After All, Journal of Financial Economics $76,509-548$.

— 2006, Predicting Volatility: Getting the Most out of Return Data Sampled at Different Frequencies, Journal of Econometrics 131, 59-95.

Ghysels, Eric, Arthur Sinko, and Rossen Valkanov, 2007, MIDAS Regressions: Further Results and New Directions, Econometric Reviews 26, 53-90.

Griffin, John M., Susan Ji, and J. Spencer Martin, 2003, Momentum Investing and Business Cycle Risk: Evidence from Pole to Pole, Journal of Finance 58, 2515-2547.

Guo, Hui, 2006, Time-varying Risk Premia and the Cross Section of Stock Returns, Journal of Banking and Finance 30, 2087-2107.

- and Robert Savickas, 2006, Idiosyncratic Volatility, Stock Market Volatility, and Expected Stock Returns, Journal of Business and Economic Statistics 24, 43-56.

Hahn, Jaehoon, and Hangyong Lee, 2006, Yield Spreads as Alternative Risk Factors for Size and Book-to-Market, Journal of Financial and Quantitative Analysis 41, 245269.

Hall, Robert E., 1988, Intertemporal Substitution in Consumption, Journal of Political Economy 96, 339-357.

Hansen, Lars Peter, 1982, Large Sample Properties of Generalized Method of Moments Estimators, Econometrica 50, 1029-1054.

_ John C. Heaton, and Nan Li, 2008, Consumption Strikes Back? Measuring Long-Run Risk, Journal of Political Economy 116, 260-302.

He, Jia, and Lilian K. Ng, 1994, Economic Forces, Fundamental Variables, and Equity Returns, Journal of Business 67, 599-609. 
Hirshleifer, David, 2001, Investor Psychology and Asset Pricing, Journal of Finance 56, 1533-1597.

Hodrick, Robert J., and Edward C. Prescott, 1997, Postwar U.S. Business Cycles: An Empirical Investigation, Journal of Money, Credit and Banking 29, 1-16.

Horowitz, Joel L., Tim Loughran, and N.E. Savin, 2000, Three Analyses of the Firm Size Premium, Journal of Empirical Finance 7, 143-153.

Hou, Kewei, and Mathijs A. Van Dijk, 2007, Resurrecting the Size Effect: Firm Size, Profitability Shocks, and Expected Stock Returns, Working Paper, Ohio State University and RSM Erasmus University.

Jagannathan, Ravi, and Zhenyu Wang, 1996, The Conditional CAPM and the CrossSection of Expected Returns, Journal of Finance 51, 3-53.

— 1998, An Asymptotic Theory for Estimating Beta-Pricing Models Using CrossSectional Regression, Journal of Finance 53, 1285-1309.

Jegadeesh, Narasimhan, and Sheridan Titman, 1993, Returns to Buying Winners and Selling Losers: Implications for Stock Market Efficiency, Journal of Finance 48, 65-91.

Kelly, Patrick J., 2003, Real and Inflationary Macroeconomic Risk in the Fama and French Size and Book-to-Market Portfolios, Working Paper, University of South Florida.

Lettau, Martin, and Sydney Ludvigson, 2001, Resurrecting the (C)CAPM: A CrossSectional Test When Risk Premia Are Time-Varying, Journal of Political Economy 109, 1238-1287.

Lewellen, Jonathan, Stefan Nagel, and Jay Shanken, 2006, A Skeptical Appraisal of Asset-Pricing Tests, NBER Working Paper No. 12360.

Liew, Jimmy, and Maria Vassalou, 2000, Can Book-to-Market, Size and Momentum Be Risk Factors that Predict Economic Growth?, Journal of Financial Economics 57, $221-245$.

Liu, Laura Xiaolei, and Lu Zhang, 2008, Momentum Profits, Factor Pricing, and Macroeconomic Risk, Review of Financial Studies, forthcoming.

Merton, Robert C., 1973, An Intertemporal Capital Asset Pricing Model, Econometrica $41,867-887$.

Newey, Whitney K., and Kenneth D. West, 1987, A Simple, Positive Semi-Definite, Heteroskedasticity and Autocorrelation Consistent Covariance Matrix, Econometrica 55, 703-708.

Pagan, Adrian, 1984, Econometric Issues in the Analysis of Regressors with Generated Regressors, International Economic Review 25, 221-247. 
Parker, Jonathan A., and Christian Julliard, 2005, Consumption Risk and the Cross Section of Expected Returns, Journal of Political Economy 113, 185-222.

Pástor, Ľuboš, and Robert F. Stambaugh, 2003, Liquidity Risk and Expected Stock Returns, Journal of Political Economy 111, 642-685.

Petkova, Ralitsa, 2006, Do the Fama-French Factors Proxy for Innovations in Predictive Variables, Journal of Finance 61, 581-612.

Roll, Richard, and Stephen A. Ross, 1980, An Empirical Investigation of the Arbitrage Pricing Theory, Journal of Finance 35, 1073-1103.

Schwert, G. W., 1989, Why Does Stock Market Volatility Change Over Time?, Journal of Finance 44, 1207-1239.

Shanken, Jay, 1992, On the Estimation of Beta-Pricing Models, Review of Financial Studies 5, 1-33.

- and Mark I. Weinstein, 2006, Economic Forces and the Stock Market Revisited, Journal of Empirical Finance 13, 129-144.

Sims, Christopher A., 1980, Macroeconomics and Reality, Econometrica 48, 1-48.

Sohn, Bumjean, 2008, On the Cross-Section of Equity Returns: What Does Linear Factor Model from ICAPM with Heteroskedasticity Tell Us?, Work in Progress, UNC.

Van Dijk, Mathijs A., 2006, Is Size Dead? A Review of the Size Effect in Equity Returns, Working Paper, RSM Erasmus University.

Vassalou, Maria, 2003, News Related to Future GDP Growth as a Risk Factor in Equity Returns, Journal of Financial Economics 68, 47-73.

- , and Yuhang Xing, 2004, Default Risk in Equity Returns, Journal of Finance 59, 831-868.

Yogo, Motohiro, 2004, Estimating the Elasticity of Intertemporal Substitution When Instruments Are Weak, Review of Economics and Statistics 86, 797-810. 